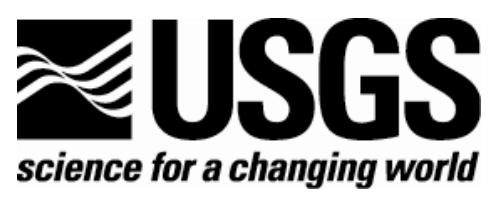

\title{
South San Francisco Bay 2004 Topographic Lidar Survey: Data Overview and Preliminary Quality Assessment
}

By Amy C. Foxgrover and Bruce E. Jaffe

U.S. Geological Survey Pacific Science Center, Santa Cruz, CA

Open-File Report 2005-1284

U.S. Department of the Interior

U.S. Geological Survey 


\section{U.S. Department of the Interior Gale A. Norton, Secretary}

\section{U.S. Geological Survey \\ P. Patrick Leahy, Acting Director}

U.S. Geological Survey, Reston, Virginia 2005

Revised and reprinted: 2005

For product and ordering information:

World Wide Web: http://www.usgs.gov/pubprod

Telephone: 1-888-ASK-USGS

For more information on the USGS - the Federal source for science about the Earth, its natural and living resources, natural hazards, and the environment:

World Wide Web: http://www.usgs.gov

Telephone: 1-888-ASK-USGS

Suggested citation:

Foxgrover, A.C. and Jaffe, B.E., 2005, South San Francisco Bay 2004

Topographic Lidar Survey: Data Overview and Preliminary Quality Assessment: U.S. Geological Survey Open-File Report 2005-1284, 57p.

[URL: http://pubs.usgs.gov/of/2005/1284]

Any use of trade, product, or firm names is for descriptive purposes only and does not imply endorsement by the U.S. Government.

Although this report is in the public domain, permission must be secured from the individual copyright owners to reproduce any copyrighted material contained within this report. 


\section{Table of Contents}

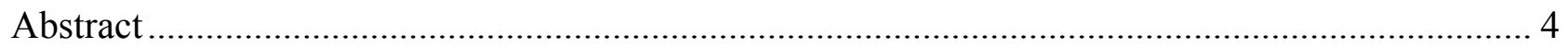

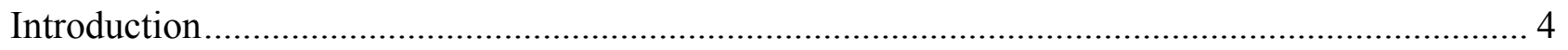

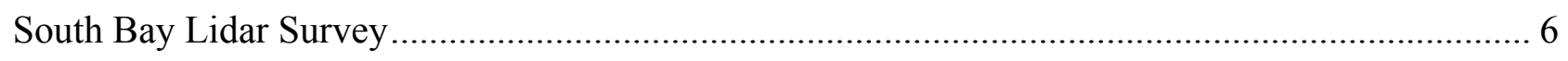

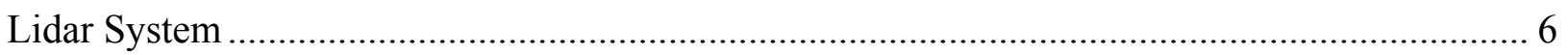

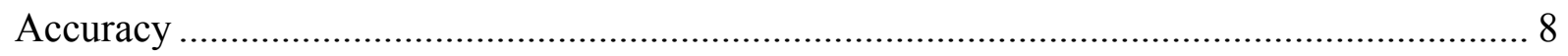

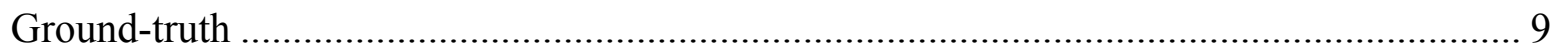

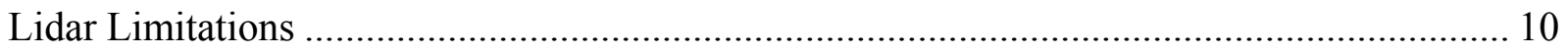

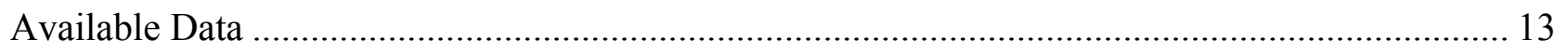

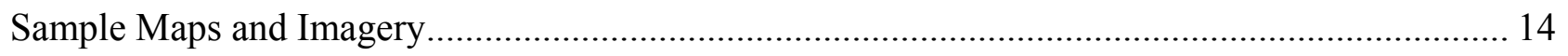

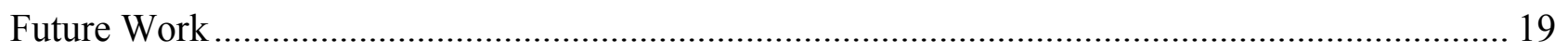

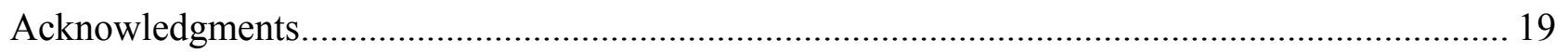

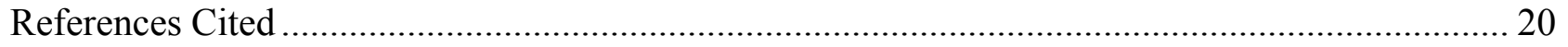

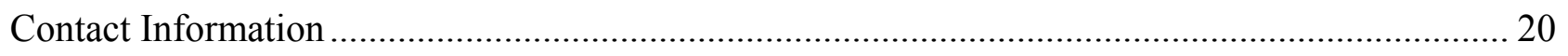

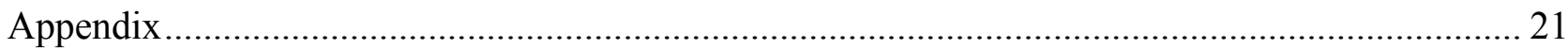




\title{
South San Francisco Bay 2004 Topographic Lidar Survey: Data Overview and Preliminary Quality Assessment
}

\author{
By Amy C. Foxgrover and Bruce E. Jaffe \\ U.S. Geological Survey Pacific Science Center, Santa Cruz, CA
}

\section{Abstract}

Tidal wetlands in South San Francisco Bay (South Bay) have decreased by over $80 \%$ in the past 150 years. The California Coastal Conservancy, in conjunction with other state and federal agencies, is collaboratively managing an effort to restore approximately $61 \mathrm{~km}^{2}(15,100$ acres) of commercial salt evaporation ponds in South Bay to mixed intertidal habitat. In order to best develop restoration strategies, as well as to track morphologic change throughout the restoration process, a topographic lidar survey was conducted in May of 2004. The survey collected more than 250 million elevation points in a $334 \mathrm{~km}^{2}$ area extending from just south of the San Francisco and Oakland airports to the Alviso salt ponds.

This report details the collection of lidar in South Bay, the ground-truthing efforts, preliminary accuracy assessments, and known limitations of the data set. We describe the data generated from the survey and how to obtain it. In addition, we present maps and sample imagery that provides a revealing look into the intricate topographic features of South Bay.

\section{Introduction}

The San Francisco Bay area has changed dramatically since the first settlers arrived in the mid-1700's (Nichols, 1986). From the gold rush of 1849 to the tech boom of Silicon Valley, this urbanized estuary has been dredged, filled, diked, and degraded. Over $80 \%$ of the historic tidal marshes of South San Francisco Bay (South Bay) have been lost due to urbanization, agriculture, and commercial salt production (Foxgrover et al., 2004). Despite numerous anthropogenic alterations, this ecosystem remains a crucial habitat for wildlife and waterfowl as well as a popular recreational destination for the millions of people that live in surrounding communities.

In an effort to enhance this precious estuary, the California State Coastal Conservancy, in conjunction with U.S. Fish and Wildlife Service and the California Department of Fish and Game, has undertaken a monumental project to restore $61 \mathrm{~km}^{2}$ of commercial salt evaporation ponds in South Bay to mixed intertidal habitat (Fig. 1).

A crucial component to planning a successful restoration project is to determine the baseline conditions. To meet this goal, the U.S. Geological Survey (USGS) contracted an airborne topographic lidar survey that was flown in the spring of 2004. The survey covers approximately $334 \mathrm{~km}^{2}$ and extends south of the San Francisco and Oakland airports, covering tidal flats, marsh, levees, and surrounding areas including the 100-year flood plain (Fig. 2). This is the first time that such a highly detailed, comprehensive topographic data set of the South Bay region has been collected. 


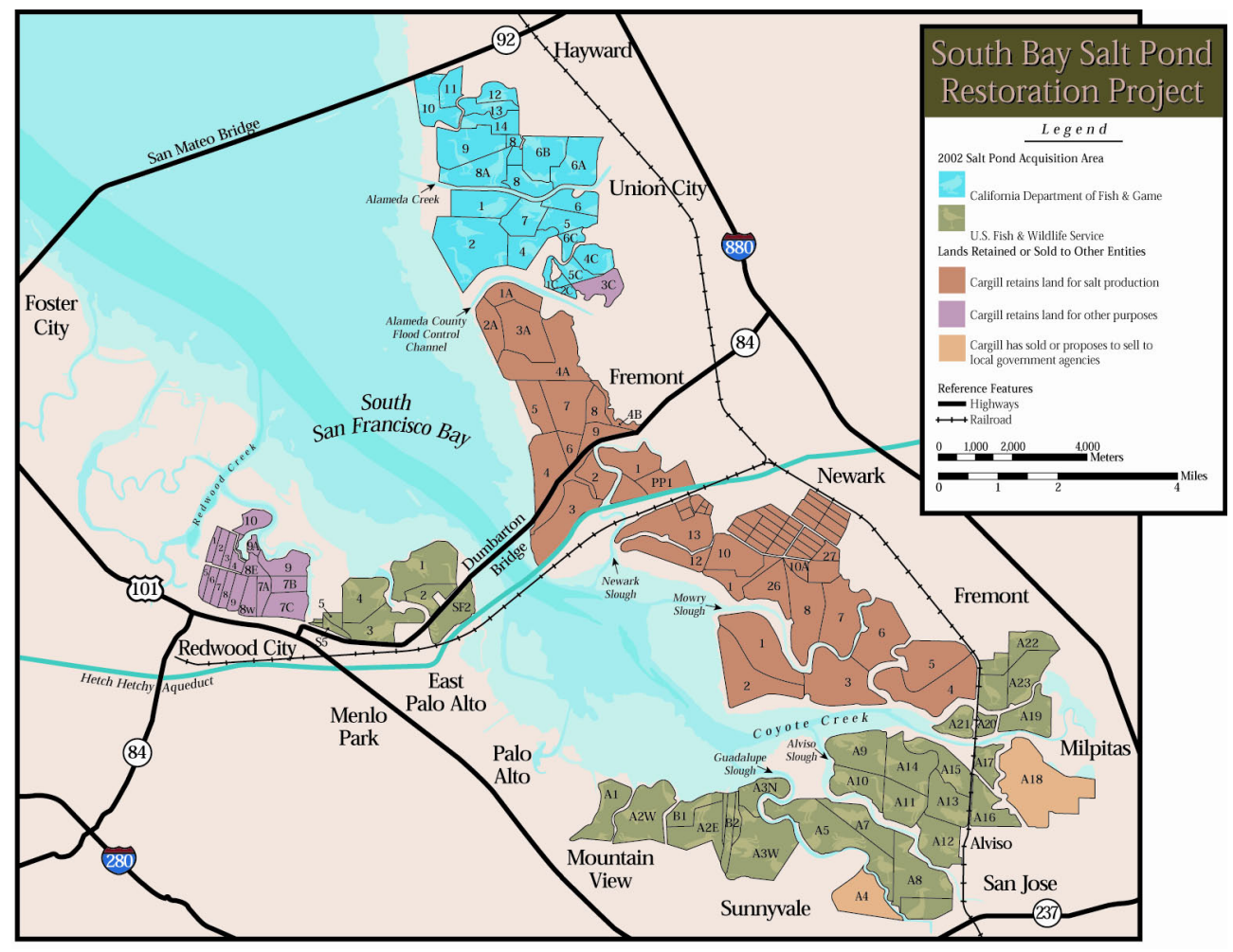

Figure 1. Image of salt pond restoration site. (Image Source: www. southbayrestoration.org.)

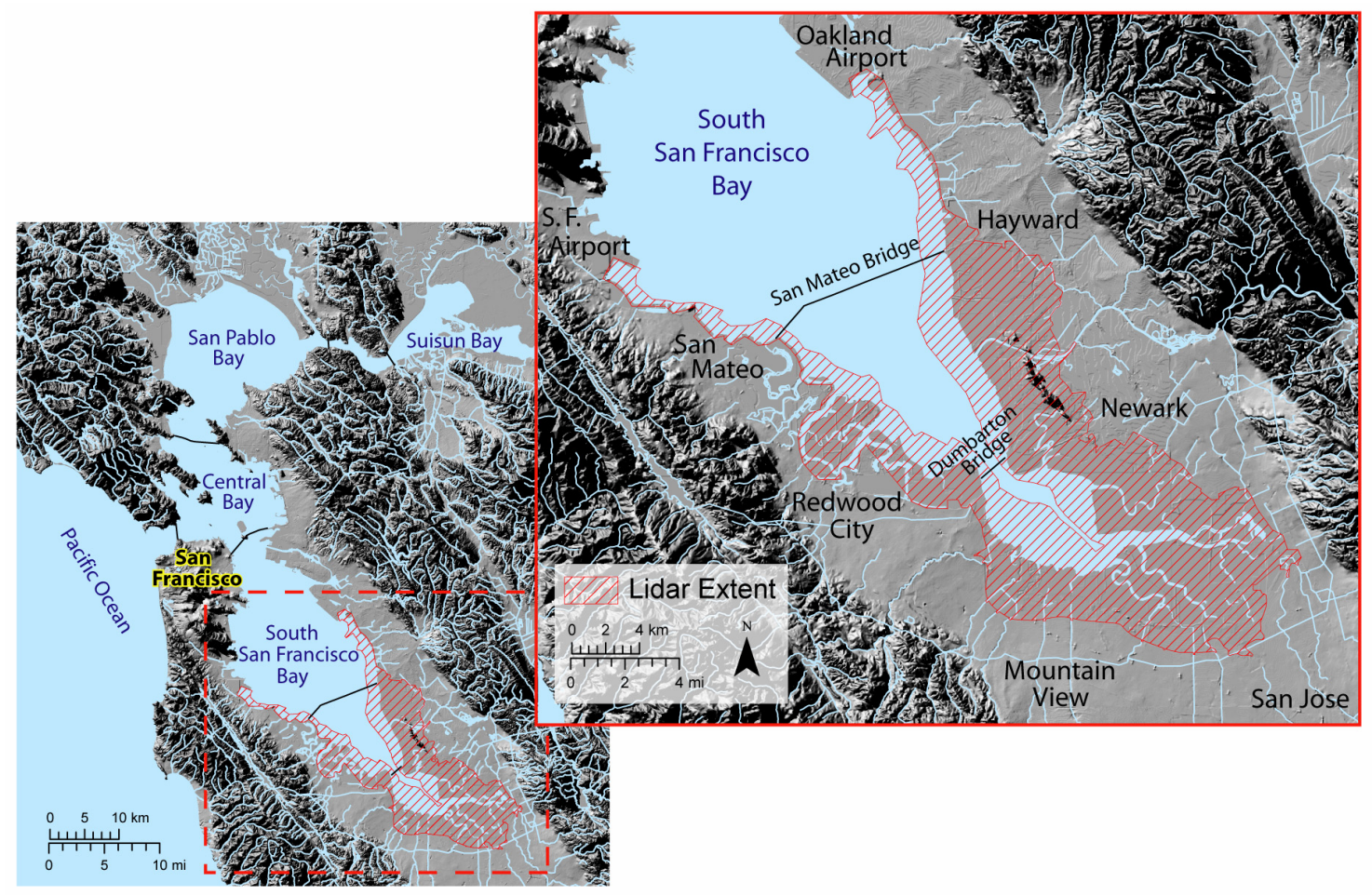

Figure 2. Map of the study area. Hachured area indicates extent of the lidar survey. 


\section{South Bay Lidar Survey}

The South San Francisco Bay lidar survey was conducted by TerraPoint from May $5^{\text {th }}$ to May $21^{\text {st }}, 2004$. The timing of the survey was selected to correspond with extreme low tides during daylight hours so that the tidal flats would be exposed and so video could be collected during data acquisition (Fig. 3). Nominal flight line spacing was 99 meters, providing an overlap of 51\% between adjacent flight lines resulting in the collection of over 250 million returns and a data density greater than one point per square meter.

Local agencies (e.g., Alameda County Public Works Agency, the City of San Jose, Philip Williams \& Associates) have collected elevation data in the past for specific sites of interest within this study area however, traditional surveying methods are not practical given the large area of interest and diversity of terrain. Lidar enables the creation of a very high-resolution digital elevation model (DEM) spanning a variety of terrain while providing an unobtrusive means for collecting elevations in sensitive habitats such as tidal flats and marsh.

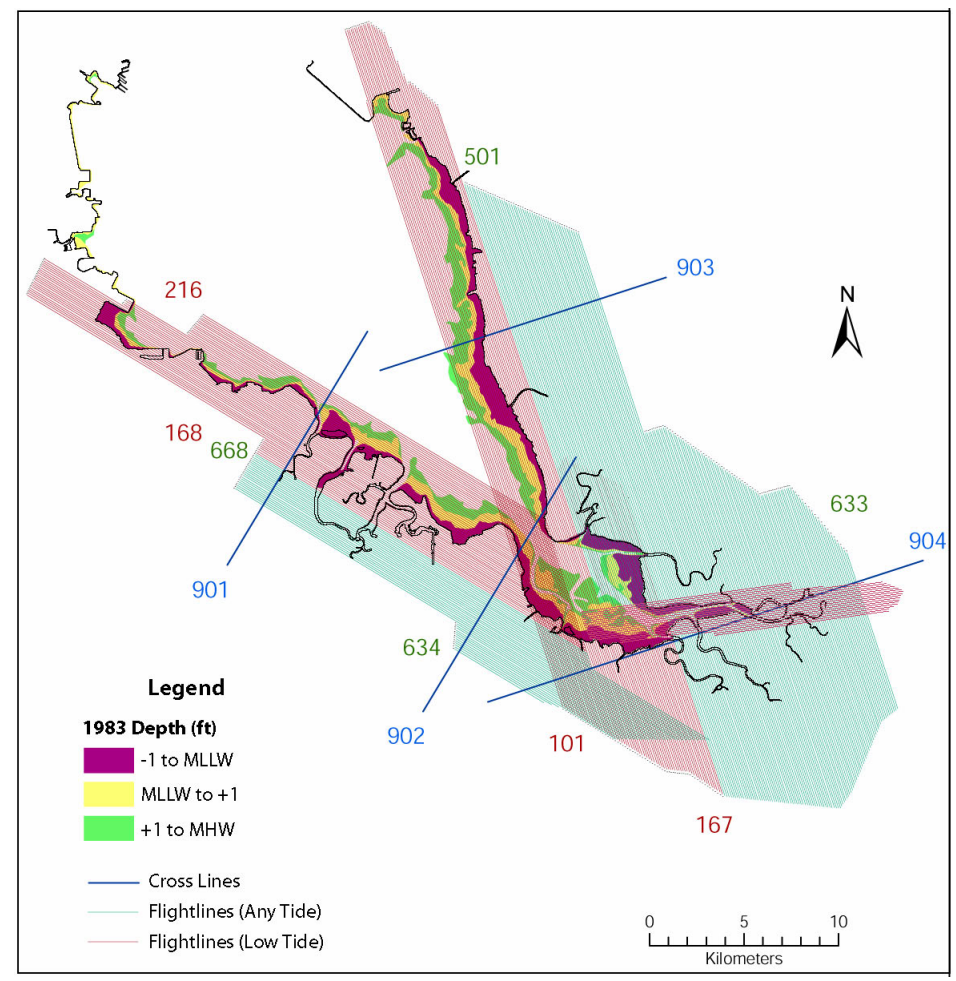

Figure 3. Flight lines for lidar survey. Red colored lines were flown only within specified time windows during daylight hours when the tide was below mean lower low water (MLLW). Teal colored lines were flown during any tide level during daylight hours.

\section{Lidar System}

Lidar (LIght Detection And Ranging) is a remote sensing method where a laser emits and receives thousands of laser pulses per second for the purpose of calculating the distance to an object. The lidar system (in this instance mounted to a fixed wing aircraft) consists of three main components; 1) a scanning laser rangefinder 2) a differential Global Positioning System (GPS), and 3) an Inertial Motion Unit (IMU). Surface elevations are determined using two-way travel time of 
the laser pulse in combination with positioning and orientation information obtained from the onboard GPS and IMU and the GPS base stations on land.

Although hydrographic lidar systems with the ability to penetrate water for bathymetric readings are available, such systems would not work well in the turbid, muddy water of South San Francisco Bay. For this project a topographic lidar system which does not penetrate water was selected. The South Bay survey used TerraPoint's ALMIS (Airborne Laser Mapping Imaging System). The ALMIS consists of a 60-degree full angle Riegel laser with a rotation polygon mirror, a Novatel GPS receiver, and a Honeywell IMU unit. The ALMIS was mounted to a Partenavia P68 twin-engine aircraft flown at an altitude of approximately 245 meters above ground level during the survey. The size of the surface illuminated by the Riegel laser, also referred to as the footprint or spot size, was approximately $0.75 \mathrm{~m}$ in diameter. The lidar was set to pulse at 10 $\mathrm{kHz}$ in an alternating pulse mode that alternates between recording the first and last returns of the signal. The scan pattern produces parallel lines that are perpendicular to the flight line and have a spacing of $1.4 \mathrm{~m}$ in the across-swath direction and $1.1 \mathrm{~m}$ in the along-swath direction. The first/last return system results in a pattern of first returns approximately every 3-meters in the across-swath direction and every meter in the along-swath. This sampling scheme was chosen to facilitate detection and removal of vegetation and structures. The first returns can either be from the top of vegetation (or structures) or bare earth when vegetation or structures are not present. The last returns will be bare earth in instances where either the lidar is able to penetrate vegetation or structures or they are not present. The 51\% side overlap between adjacent swaths ensures that all areas are covered twice (except in areas of water).

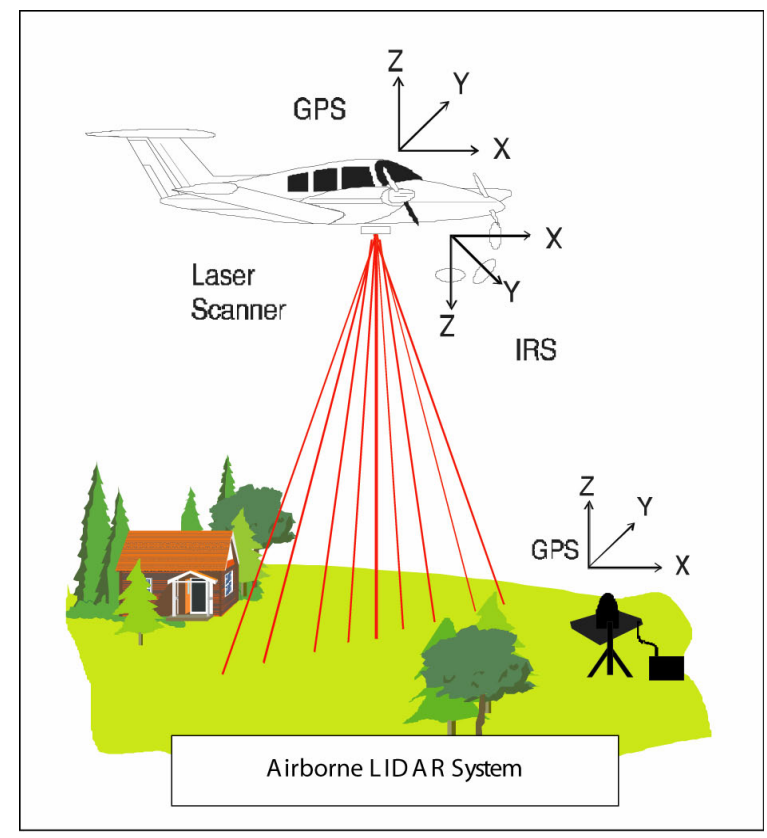

Figure 4. Schematic diagram of lidar collection system. (Image Source: Mosaic Mapping, 2001).

A control network comprised of four GPS base stations was established for differential GPS calculations (Fig. 5). Two base stations were used for each flight to ensure accurate positioning during flight missions. The lidar data is referenced to the UTM coordinate system, horizontal datum NAD83, vertical datum NAVD88. 


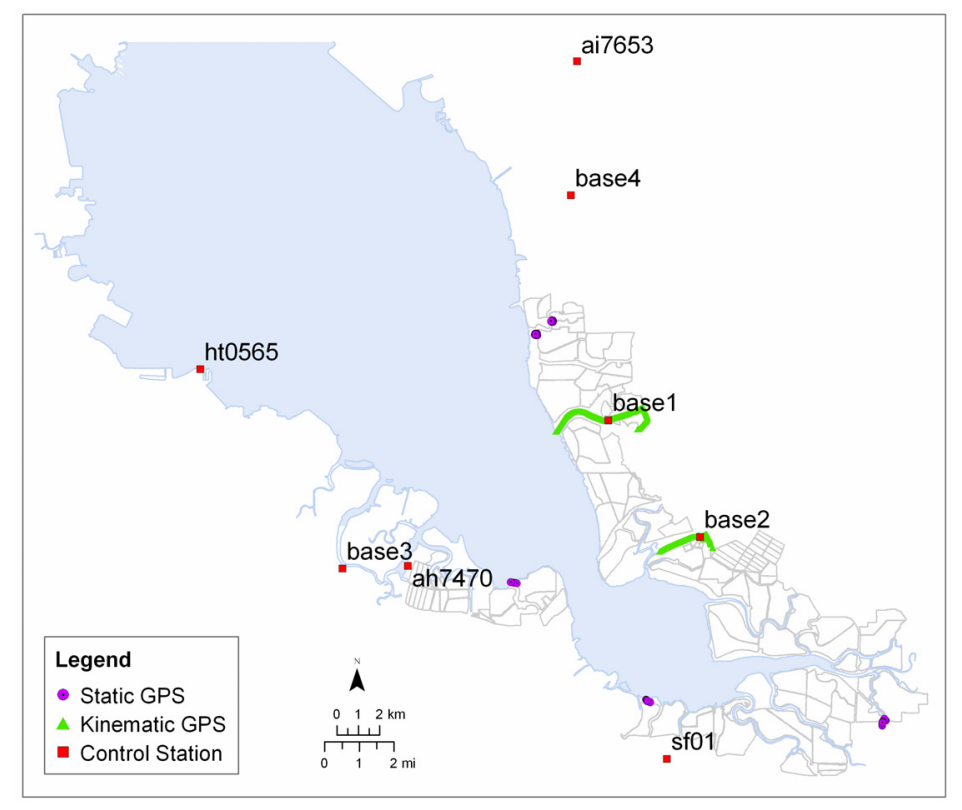

Figure 5. Location map of base stations and ground-truthing locations.

Data from the onboard instruments and GPS base stations were post-processed to determine surface elevations. An additional processing step was required by TerraPoint to correct for a roll error which was introduced as a result of a loose component within the ALMIS. Once the proper boresight correction values were applied to the data, the data met the accuracy criteria in Tables 1 and 2.

\section{Accuracy}

Lidar accuracy is a function of errors in position and orientation of the laser and the characteristics of the surface being illuminated. Uncertainty in the orientation of the laser is the primary factory influencing horizontal accuracy. Errors in differential GPS solutions and uncertainty in elevations of the ground surface on steep terrain also degrade horizontal accuracy. Absolute positional (horizontal) accuracy at the $2 \sigma$ level is 20 to $60 \mathrm{~cm}$ on all but extremely hilly terrain (Table 2).

Uncertainty in orientation of the laser and differences in elevation of the illuminated surface are the primary factors determining vertical accuracy. Ground elevations of steep slopes, such as the sides of levees, are less accurate than elevations on flat surfaces (Table 3). The vertical accuracy of this system on low sloping, hard surfaces is 10 to $15 \mathrm{~cm}$ at the $95 \%(2 \sigma)$ confidence level (Table 1).

Table 1. Absolute vertical accuracy.

\begin{tabular}{|c|c|}
\hline $\begin{array}{c}2 \sigma \text { Error } \\
(\mathrm{cm})\end{array}$ & Terrain Description \\
\hline$+/-10-15$ & Hard Surfaces (roads and buildings) \\
\hline$+/-15-25$ & Soft/Vegetated Surfaces (flat to rolling terrain) \\
\hline$+/-25-40$ & Soft/Vegetated Surfaces (hilly terrain) \\
\hline
\end{tabular}


Table 2. Absolute horizontal accuracy.

\begin{tabular}{|c|c|}
\hline $\begin{array}{c}\text { 20 Error } \\
(\mathbf{c m})\end{array}$ & Terrain Description \\
\hline \multicolumn{2}{|c|}{} \\
\hline$+/-20-60$ & All locations except extremely hilly terrain. \\
\hline
\end{tabular}

\section{Ground-truth}

Over 650 ground-truth measurements were taken in seven areas to evaluate lidar performance (Fig. 5). Ground-truth locations were selected to include the variety of surface types within the study area and included tidal flats, levees, and marshes. Marsh ground-truthing was difficult because our access was restricted to avoid disturbing endangered nesting birds. We were limited in potential marsh sample areas to those that could be reached from overlying PG\&E boardwalks or sites which were known not to be populated by endangered species.

Ground-truthing included static GPS measurements throughout the study area and kinematic GPS surveys on paved roads. Elevations of the static and kinematic GPS ground-truthing points have an accuracy relative to the GPS control network of $2 \mathrm{~cm}$ in three dimensions, at the $95 \%$ confidence interval (see appendix).

A total of 165 static ground-truth points were collected in a variety of terrain to evaluate how well lidar was estimating bare earth elevations in differing vegetations, slopes, and on soft surfaces (tidal flats). Along with each GPS measurement, notes were collected on the description of the terrain, and if present, the type, density, and height of vegetation. The information was analyzed to estimate the lidar error in varying terrain, and to determine if the system was able to penetrate vegetation densities typical of the study area. To do so, a one-meter resolution DEM was generated from the bare earth lidar data points. The ground-truth GPS elevations were then subtracted from the bare earth DEM cell value at that location to determine the difference between the lidar value and the GPS elevations.

For static ground-truth points, the average difference between the lidar and ground-truth elevations was $3.6 \mathrm{~cm}$ and $95 \%(2 \sigma)$ of the lidar elevations were within $28 \mathrm{~cm}$ of ground-truth elevations (see appendix). However, a more detailed look at the accuracy can be taken by separating the statistics into surface types (Table 3). Lidar estimates of the bare earth surface in areas of pickleweed (salicornia virginica) marsh were good with a $2 \sigma$ error of $18 \mathrm{~cm}$ while in the bulrush (Scirpus californicus or Scirpus maritimus), lidar performed poorly with a $2 \sigma$ error of 192 $\mathrm{cm}$. Based upon our limited number of bulrush ground-truth locations, we believe the high error is the result of the very dense vegetation that was impenetrable by the lidar. Gently sloping areas such as those sampled containing pickleweed, tidal flats, or the center of the levees performed relatively well, while the edges of the levees did not. The higher error of measurements at either the top edges of the levees or at the base of the levee banks is a result of the size of the laser footprint and the steep slope of the levees. The laser footprint is approximately $0.75 \mathrm{~m}$ in diameter and with typical levee slopes of 10 to 20 degrees; the lidar is unable to resolve the steep slopes with the same accuracy of gently sloping terrain.

In addition to the 165 static ground-truth points, 593 check points were collected using a kinematic surveying method in which the GPS is mounted to an automobile and set to collect data every second. The kinematic ground-truth points were collected along two separate stretches of paved roads totaling $10 \mathrm{~km}$ in length and compared to the bare earth lidar surface to evaluate absolute accuracy. For the entire set of these points, the average difference between lidar and 
ground-truth elevations was $-1.9 \mathrm{~cm}$ and $95 \%$ of the lidar elevations were within $13.2 \mathrm{~cm}$ of ground-truth elevations (see appendix).

Table 3. Differences between lidar values and ground-truth elevations classified by surface type.

\begin{tabular}{|l|l|l|l|l|l|l|}
\hline \multicolumn{1}{|c|}{ Location } & $\begin{array}{c}\text { Number of } \\
\text { Samples }\end{array}$ & \multicolumn{1}{c|}{ Min } & \multicolumn{1}{c|}{ Mean } & RMSE & $\begin{array}{c}\mathbf{2} \boldsymbol{\sigma} \\
\text { Difference }\end{array}$ \\
\hline \multicolumn{7}{|c|}{} \\
\hline Center of Levee & 19 & -29 & 26 & -6 & 13 & 25 \\
\hline Edges of Levee & 49 & -81 & 114 & 4 & 31 & 61 \\
\hline Pickleweed Marsh & 42 & -7 & 29 & 6 & 9 & 18 \\
\hline Tidal Flat & 14 & -18 & 25 & 2 & 11 & 21 \\
\hline Bulrush Marsh & 3 & 82 & 121 & 96 & 98 & 192 \\
\hline
\end{tabular}

${ }^{1}$ edges of levee includes both the top outer edges of the levee and base of levee banks

\section{Lidar Limitations}

The 2004 South Bay lidar survey collected elevation data from a variety of surfaces including bare earth, vegetation, structures, and water. The primary limitation to using the data set is the uncertainty in the type of surface the return is from. For example, in tidal flat settings, is the return from the tidal flat or from water? In marsh settings, is the return from the bare earth or from vegetation? These determinations are possible, but time consuming, and not always $100 \%$

accurate. Below we discuss three of the most common difficulties in interpreting this lidar data set; 1) discriminating tidal flats from water returns, 2) discriminating bare earth from vegetation, and 3) discriminating wet salt ponds from dry ponds.

The problem of discriminating tidal flats from water can be addressed using the intensity and spatial pattern of lidar returns. When lidar is collected over water or very dark surfaces, rather than receiving the typical full-swath return, the laser beam is only reflected back to the receiver in a in a very narrow range close to nadir (Puget Sound Lidar Consortium Web Site, C. Vickers, Mosaic Mapping Systems Inc., personal communication). This phenomenon results in a limited swath return approximately 30 to $50 \mathrm{~m}$ wide as opposed to the anticipated full swath return of $245 \mathrm{~m}$ over a solid surface. Without the full swath return, data from adjacent flight lines do not overlap, resulting in striped pattern of narrow bands of data alternating between bands of no data (Fig. 6). These values are not an accurate reflection of water levels and must be removed prior to generating a terrain model (Puget Sound Lidar Consortium Web Site).

Unfortunately, there is not a simple automated way of identifying these over-water returns and manually delineating them can be quite laborious. This data set was collected over a time span of three weeks and due to the complex nature of tides in South Bay, it is impossible to determine a single elevation under which all returns would be classified as over-water returns. Although georeferenced video was collected at the time of the flights, it has proven difficult to distinguish tidally influenced areas of shallow water from the mudflats, which both appear brown in the video. Therefore, independently, the video does not serve as a reliable source for identifying over-water returns.

The technique which proved most reliable in this instance was using a combination of highresolution satellite imagery, exaggerated hill-shaded images of the lidar, and lidar return intensity to manually delineate and remove over-water returns. One-meter resolution IKONOS satellite imagery collected in May of 2004 was available for the majority of the project area. The IKONOS proved useful in determining areas of standing water that remained relatively constant from the 
time the imagery was collected and throughout the collection of the lidar. Areas such as levied ponds could be delineated using the IKONOS but this imagery could not be used to identify continually changing tidal inundation levels such as those in the tidal flats. To determine the bayward extent of the tide or to identify small puddles of water within the tidal flats, lidar intensity in conjunction with exaggerated hill-shades of the full feature return lidar data set was best suited for distinguishing these false returns from valid surface elevation returns. Areas of water tend to give a strong lidar return intensity directly at nadir relative to surrounding tidal flats and marsh (Fig. 6). Polygons delineating areas containing water were manually digitized based upon the interpretation of these three data sets. The preliminary water-mask polygons generated using this technique can be obtained as an ArcInfo shapefile by contacting Eric Zhang (ericz@sfei.org or 510-746-7361). Although this is a somewhat subjective technique, the results appear to be promising.

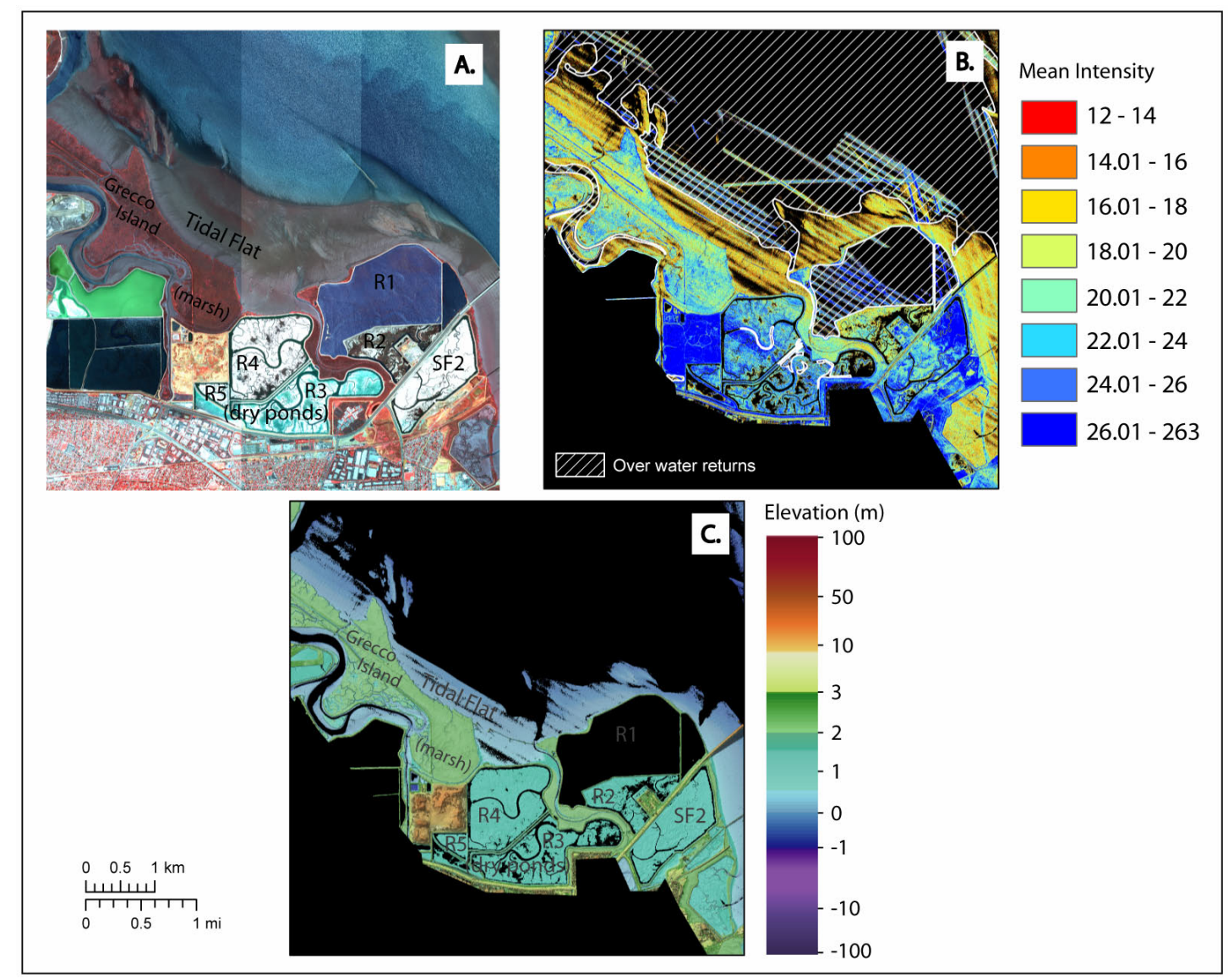

Figure 6. Sample of how IKONS satellite imagery in conjunction with lidar return intensity can be used to mask out over-water returns. (A) IKONOS false color composite satellite imagery ( $1 \mathrm{~m}$ resolution) of the area just northwest of the Dumbarton bridge $(B)$ full feature lidar returns shaded according to average return intensity (averaged over 3x3 m neighborhood) hachured area indicates data that was removed because the returns were over water surfaces $(\mathrm{C})$ resultant DEM with over-water returns eliminated, hill-shaded by elevation.

An additional challenge in generating an accurate bare earth model is determining if the lidar was able to penetrate vegetation. TerraPoint removes vegetation using an automated 
algorithm that iteratively evaluates local slopes (constrained by iteration distance and building size parameters) to determine if the returns meet the criteria of bare earth elevation values (see appendix). This step is followed by a manual quality control process to correct any errors that occurred during the automated process.

We evaluated the vegetation removal process that TerraPoint uses by comparing the lidar elevations with the static ground-truth elevations and vegetation surveys that were collected while the lidar was being flown (Table 3). The lidar was able to penetrate sparse vegetation such a pickleweed to obtain accurate ground measurements. However, in areas of very thick vegetation, such as bulrush, the lidar did not measure ground elevations.

Our field observations of bulrush suggest that the lidar partially penetrates this very dense vegetation and does not measure bare earth elevation. At the three locations where we were able to collect GPS readings and vegetation height measurements, the lidar readings were near the top of the vegetation for the first return values, however, the last return values were from approximately half way down the height of the vegetation, where the bulrush became too dense to penetrate. An additional complication is that the bulrush may grow upon a levee bank adjacent to a channel (as can be found in South Bay). TerraPoint's automated vegetation removal algorithm does not recognize both the first and last returns as vegetation in such circumstances. For instance, on a sloping levee bank, returns reflected from a height mid-way down the stalk of the bulrush (where vegetation becomes too thick to penetrate) could result in an elevation return similar to that of the top of the levee, and could therefore be misinterpreted as a ground return (Fig. 7). In this situation we have been unable to develop a way to identify such returns and encourage the users of this data to be familiar with their particular area of focus and the potential for mis-classifications in areas of extremely dense vegetation.

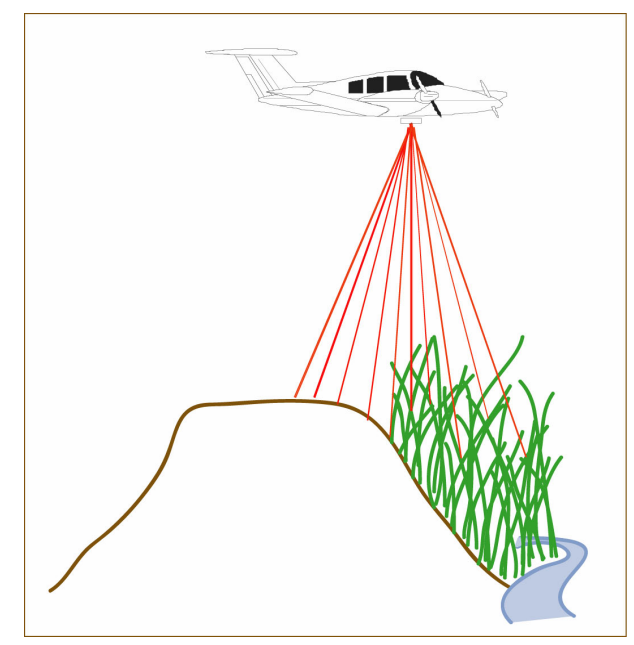

Figure 7. Schematic diagram depicting complications of lidar collection in dense bulrush located along levee banks.

A third challenge in interpreting lidar data is partially dry salt ponds. We have determined that under typical water conditions the lidar will return a narrow swath of high intensity returns or no return at all. However, these salt ponds are a unique environment and it is uncertain how lidar would reflect upon puddles of highly saline (which may appear white or red in color) water. It is possible that the particulate matter (salt, algae, etc.) floating at the surface of such ponds would return a reading that could be misinterpreted as bare earth. In the case of these partially dry salt 
ponds we encourage the end user to look at the ponds in detail before making any assumptions regarding this data.

\section{Available Data}

To make this enormous data set manageable for various end users, all of the deliverables (except hill-shaded images) are partitioned into both $1 \times 1 \mathrm{~km}$ and $2 \times 2 \mathrm{~km}$ tiles with 25 -meters of overlap between adjacent tiles (Table 4). The bare earth and full feature (all return) point data are available as ASCII comma delimited text files. TerraPoint also generated a bare earth grid of last returns at $1 \mathrm{~m}$ resolution, in ASCII format. The gridded bare earth data is also available at $1 \mathrm{~m}$ and $25 \mathrm{~m}$ resolution in an ArcInfo ASCII format for easy import into a GIS. Contours generated at a 50 $\mathrm{cm}$ nominal contour interval are available in AutoCAD (DWG) format. One-meter resolution hillshaded images of both the bare earth and full feature data sets are available GeoTIFF format. In addition to the elevation data, digital video imagery was collected at 2 frames per second during all flight missions. The geo-referenced video files are in AVI format with accompanying *.GPS files designed for viewing with Trident 3D Vision software.

Table 4. Table of data available from the 2004 South Bay lidar survey.

\begin{tabular}{|l|l|l|}
\hline \multicolumn{2}{|c|}{ Available Data } & \multicolumn{2}{c|}{ File Format } & Data Partitions \\
\hline Full Feature Points & ASCII text & $1 \mathrm{~km} \mathrm{\&} 2 \mathrm{~km}$ tiles \\
\hline Bare Earth Points & ASCII text & $1 \mathrm{~km} \& 2 \mathrm{~km}$ tiles \\
\hline $1 \mathrm{~m}$ Bare Earth Grids & ASCII text & $1 \mathrm{~km} \mathrm{\&} 2 \mathrm{~km}$ tiles \\
\hline $1 \mathrm{~m}$ Bare Earth Grids & ArcInfo ASCII text & $2 \mathrm{~km}$ tiles \\
\hline 25 m Bare Earth Grids & ArcInfo ASCII text & $2 \mathrm{~km}$ tiles \\
\hline Full Feature Hill-Shaded Image & GeoTIFF & 3 large regions \\
\hline Bare Earth Hill-Shaded Image & GeoTIFF & 3 large regions \\
\hline Contours (50cm interval) & AutoCAD DWG & $1 \mathrm{~km} \& 2 \mathrm{~km}$ tiles \\
\hline Digital Video Imagery & AVI & $\begin{array}{l}\text { collected at 2 frames per second } \\
\text { (sorted by Julian day and flight number) }\end{array}$ \\
\hline
\end{tabular}

The San Francisco Estuary Institute is responsible for maintaining and distributing this data. Contact Eric Zhang (ericz@sfei.org or 510-746-7361) to obtain the data.

\section{Sample Maps and Imagery}

This exceptional topographic data set of the South Bay provides an unprecedented view of the region. In this section we will present a large overview map highlighting the subtle relief of the terrain surrounding the bay, the location of the salt ponds slated for restoration, and provide context of the bay within the larger geologic setting (Fig. 8). This map is followed up by some close-up perspective views of Newark Slough, Coyote Creek, and the Palo Alto regions (Figs. 9, 10, 11, respectively). The close-up shaded-relief images accentuate the great detail with which the lidar captures the subtle morphologic features found in the marsh, tidal flats, as well as man-made structures. The perspective views are followed by a sequence of high resolution aerial photographs of Alviso, Bair Island, and the Shoreline Amphitheater displayed adjacent to the shaded-relief image of that particular area as captured through the lidar (Figs. 12, 13, 14, respectively). These phenomenal images provide an excellent context for viewing and evaluating the hill-shaded images. 


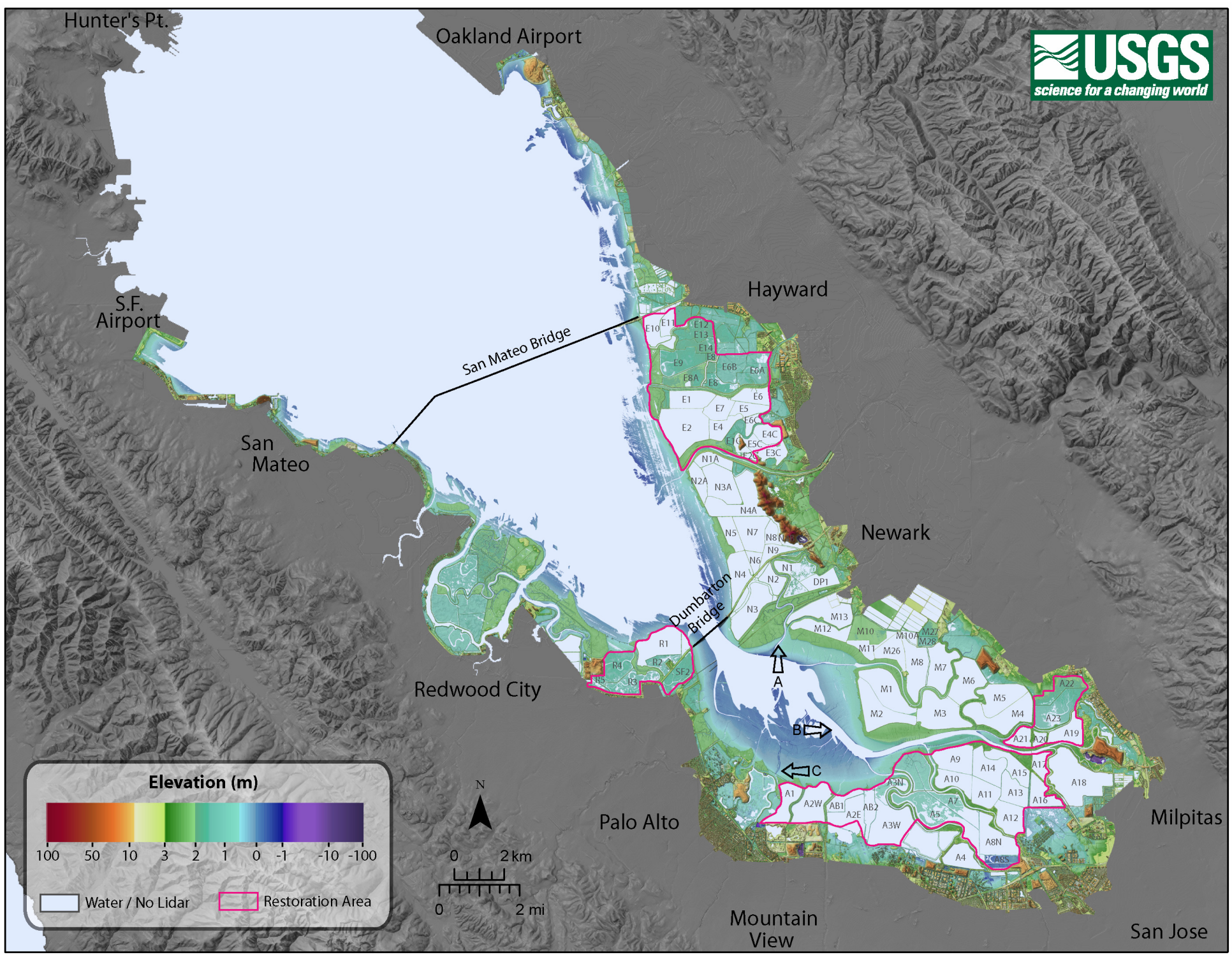

Figure 8. DEM of the South San Francisco Bay area. Full-feaure lidar data gridded at $2 \mathrm{~m}$ resolution and colored by elevation (over-water returns removed). The lidar is overlying a USGS $30 \mathrm{~m}$ gray-shaded DEM of the surrounding areas (Graham and Pike, 1997). Ponds are labeled as reference points. Arrows within the bay south of the Dumbarton Bridge indicate the orientation and location of the following perspective views (A - Figure 9, B - Figure 10, and C - Figure11). 


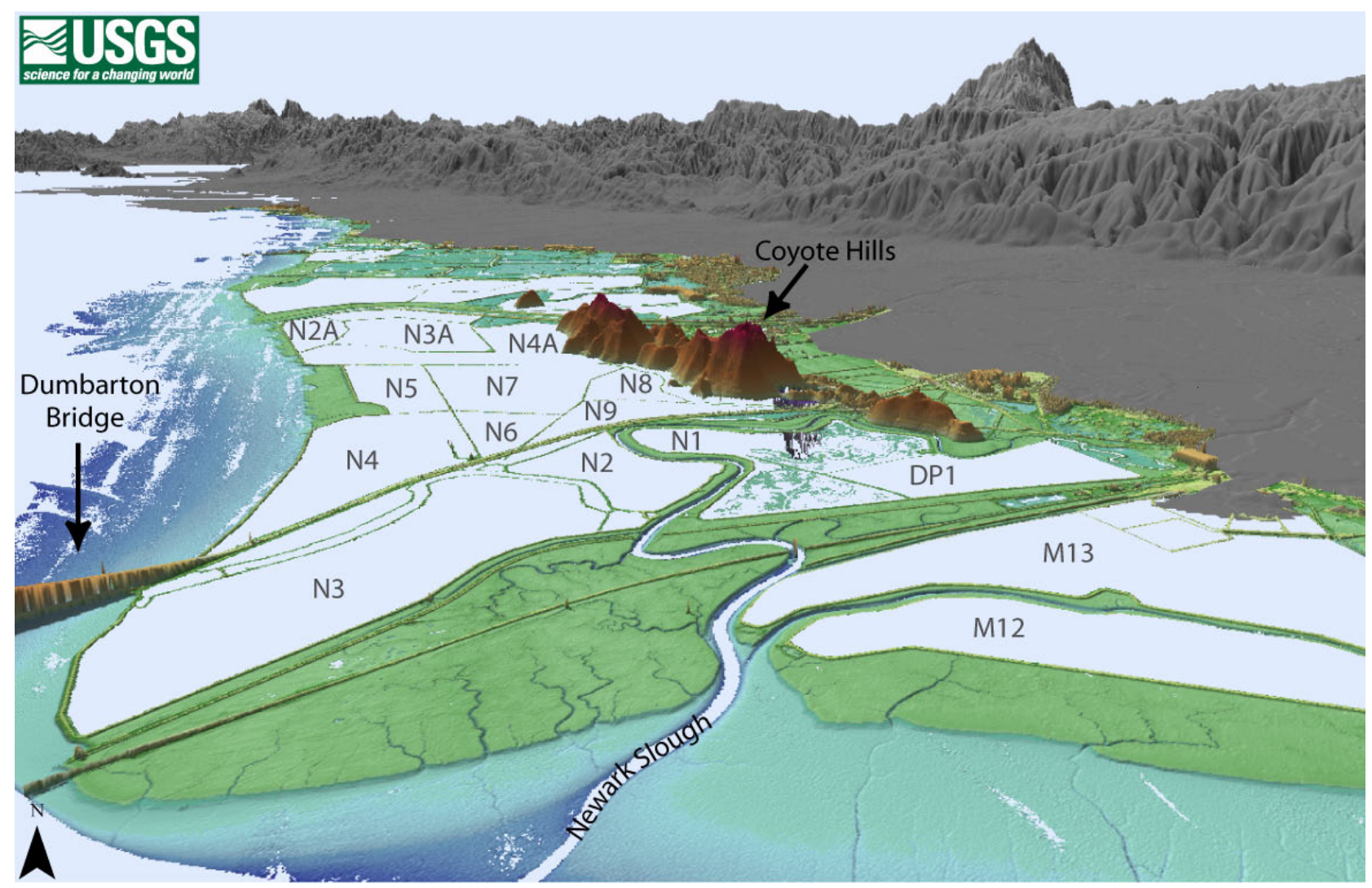

Figure 9. Shaded relief map of full feature lidar colored by elevation. Perspective view is looking north towards Newark Slough and Coyote Hills. The distance across the bottom of the image is approximately $4 \mathrm{~km}$ with a vertical exaggeration of $5 \mathrm{x}$. 


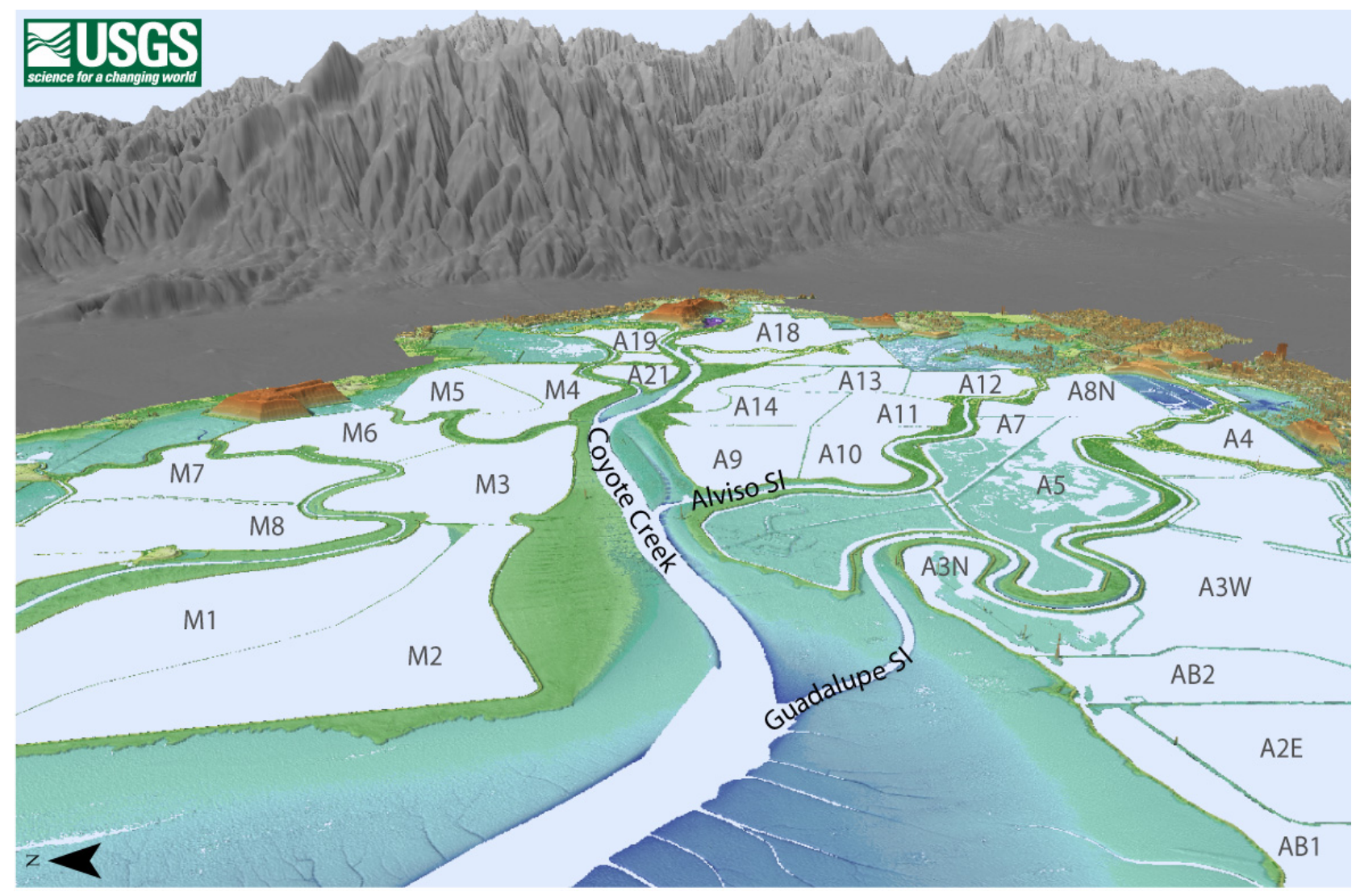

Figure 10. Shaded relief map of full feature lidar colored by elevation. Perspective view is looking east towards Coyote Creek. The distance across the bottom of the image is approximately $4.5 \mathrm{~km}$ with a vertical exaggeration of $5 \mathrm{x}$. 


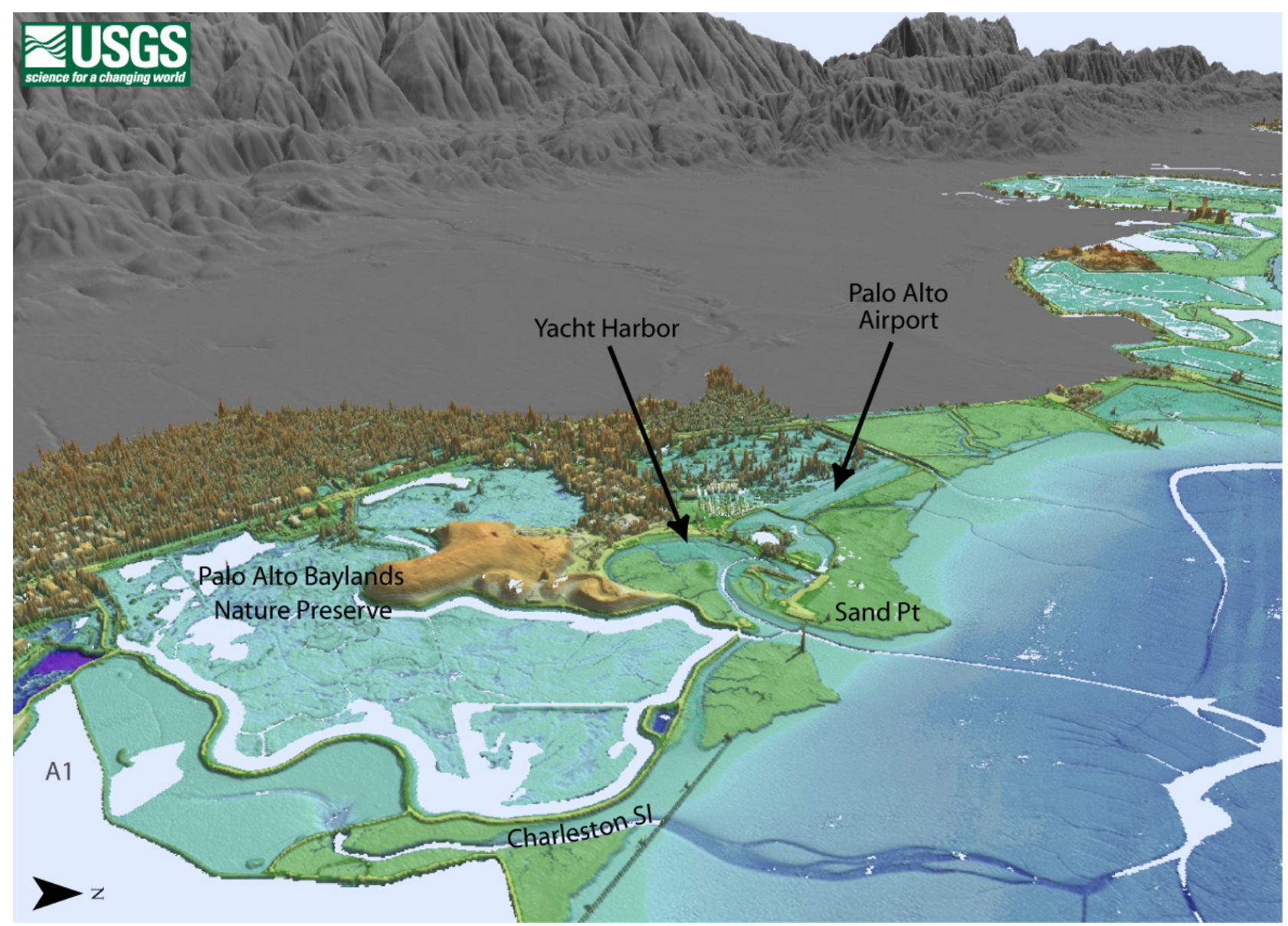

Figure 11. Shaded relief map of full feature lidar colored by elevation. Perspective view is looking west towards Palo Alto. The distance across the bottom of the image is approximately $3.5 \mathrm{~km}$ with a vertical exaggeration of $5 \mathrm{x}$. 

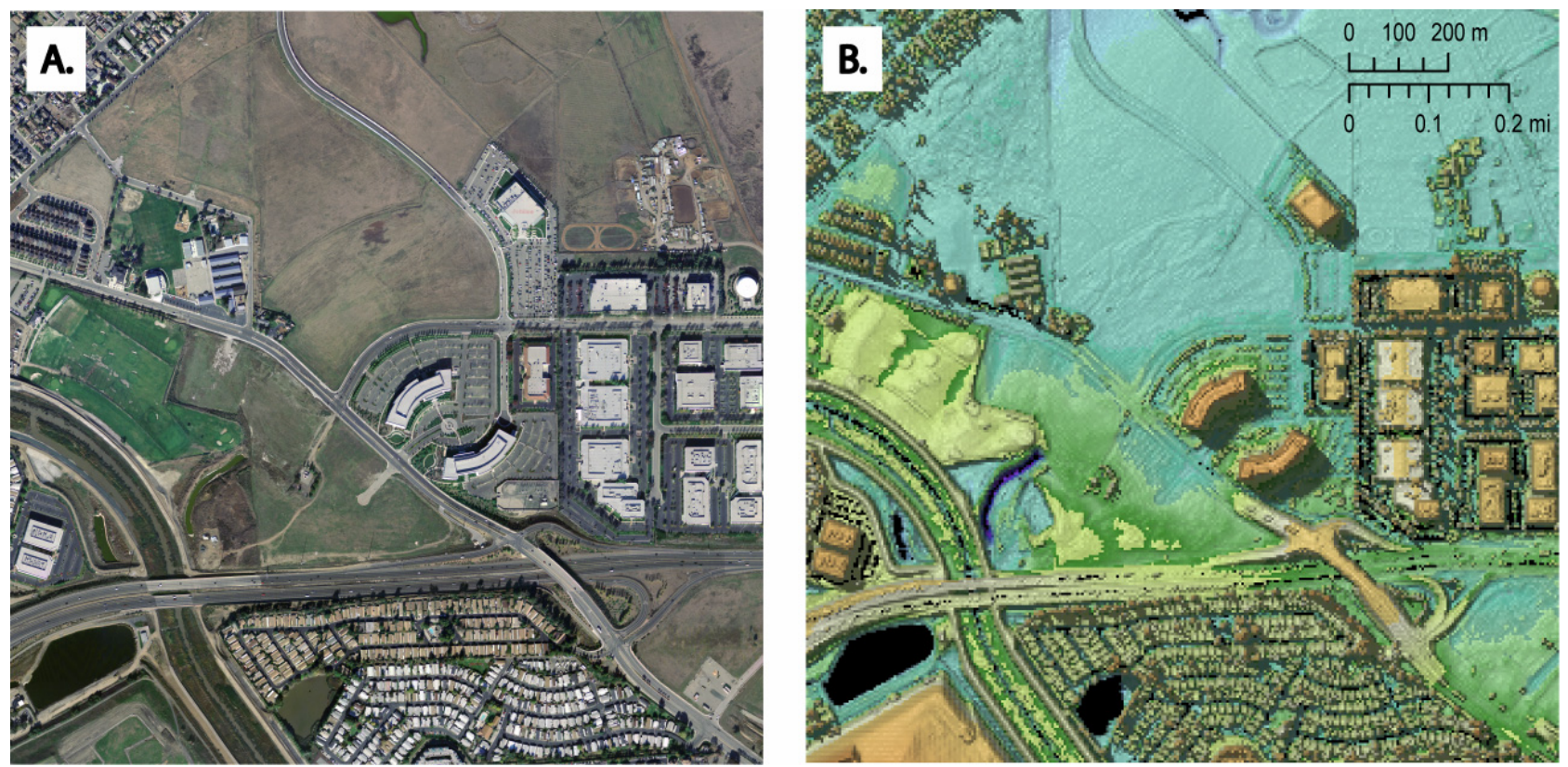

Figure 12. (A) National Geospatial Intelligence Agency (NGA) imagery of intersection of Highway 237 and North $1^{\text {st }}$ Avenue in Alviso. (B) Full feature hill-shaded image of the same location.
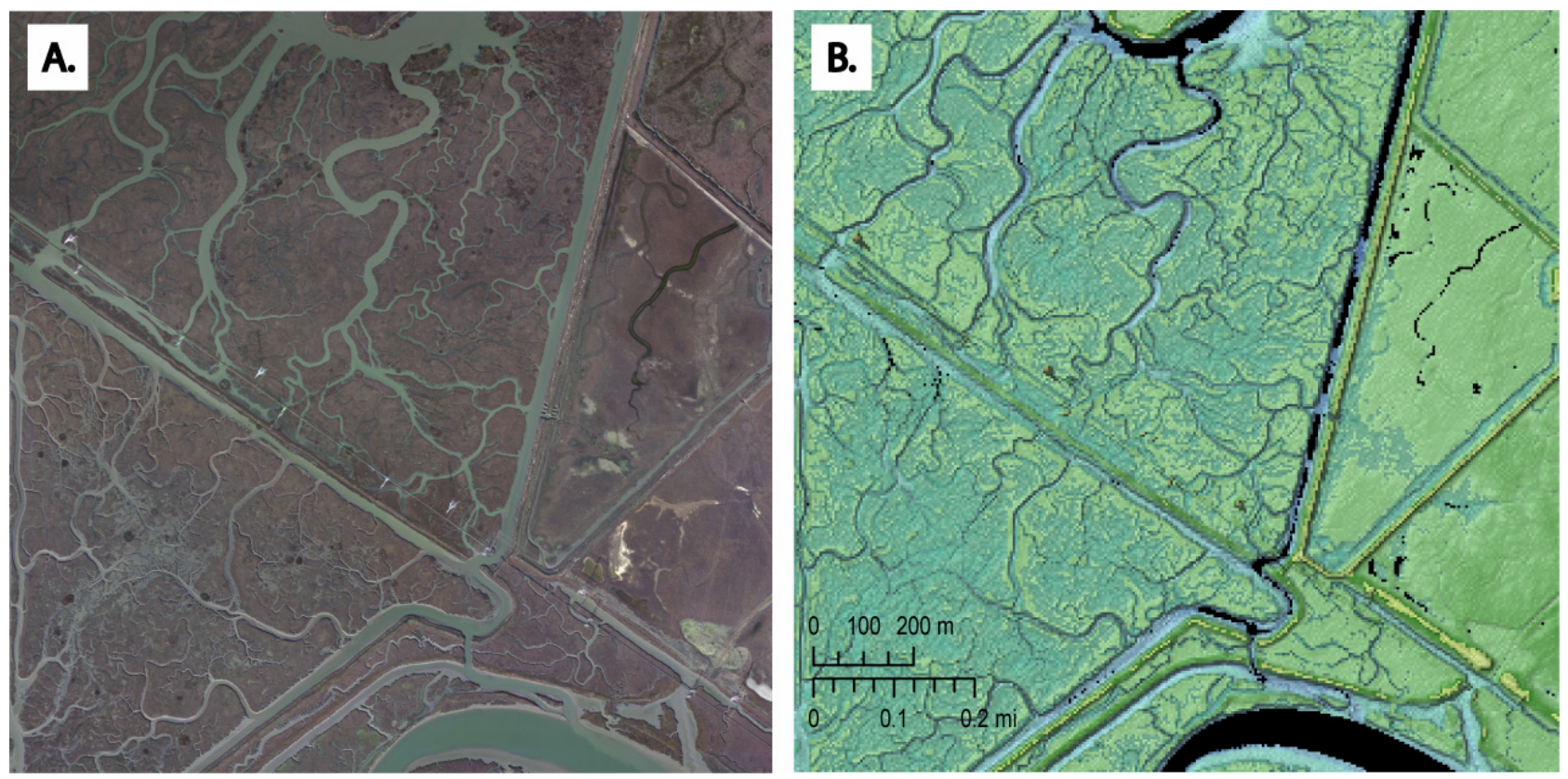

Figure 13. (A) NGA imagery of marsh and channels in Bair Island. (B) Full feature hillshaded image of the same location. 

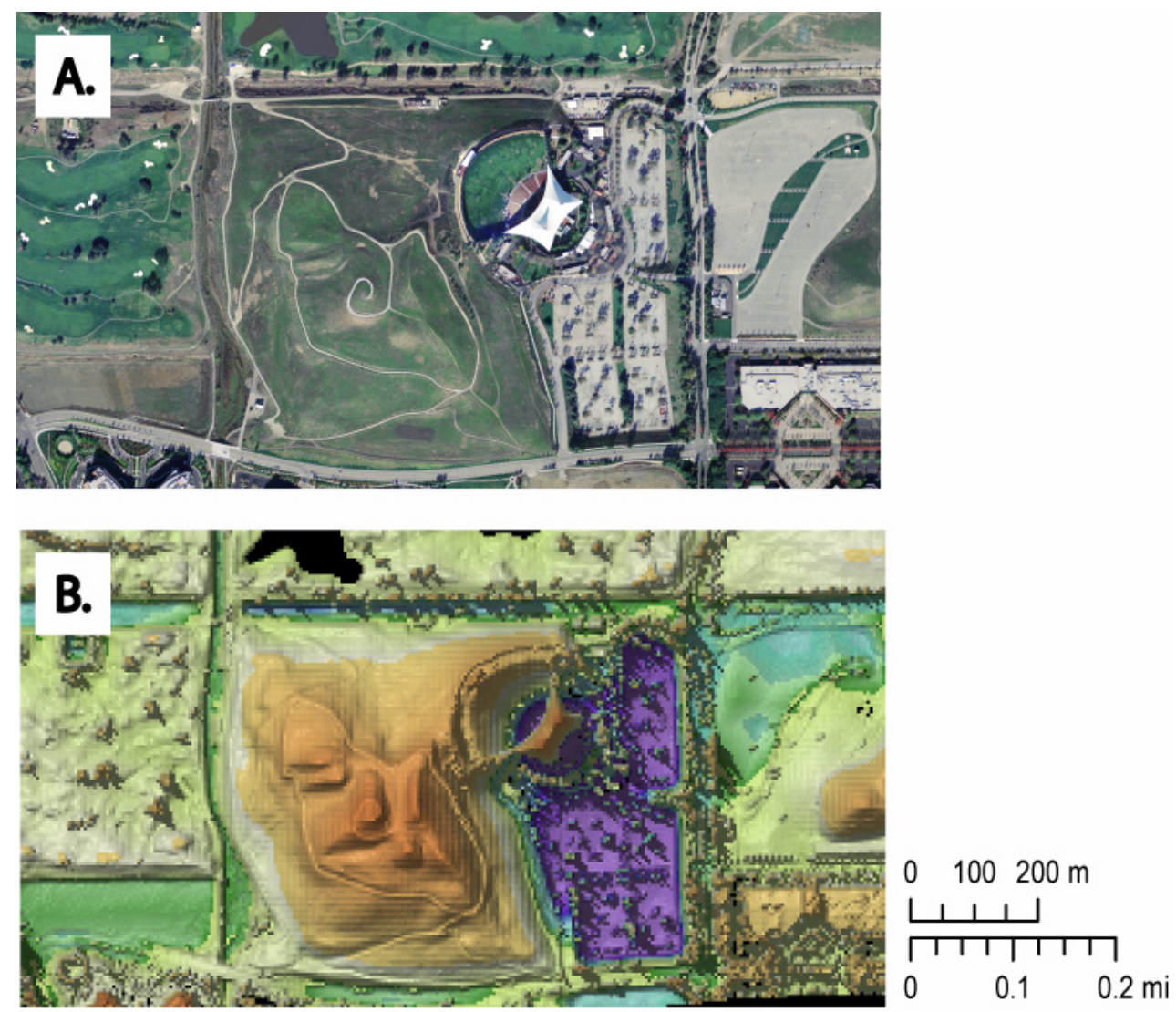

Figure 14. (A) NGA imagery of the Shoreline Amphitheater (and surrounding area) in Mountain View. (B) Full feature hill-shaded image of the same location.

\section{Future Work}

The collection of topographic lidar of South Bay is one component of a very comprehensive long term planning process which seeks to best understand the biological, physical, and social implications of marsh restoration. This topographic survey will soon be merged with recently collected bathymetric data of the bay and salt ponds to create a continuous DEM of the bay and surrounding areas that will be used as the basis for numerous models and scientific studies. In addition to providing a baseline for evaluating effectiveness of restoration efforts, the combined data set will be used to model processes and formulate approaches that will improve the success of restoration.

\section{Acknowledgments}

The authors would like to thank Ralph Haugerud (USGS) for his immense assistance in analyzing the lidar accuracy and suggestions on processing methods to improve the data quality. Thanks to Pete Darnell, Gerry Hatcher, and Joshua Logan (all of the USGS) for contributing their GIS and lidar expertise. Tim Hayes, City of San Jose, provided the IKONOS satellite imagery. The National Geospatial-Intelligence Agency and the USGS supplied the high-resolution aerial photographs. The City of San Jose, Alamada County Public Works Agency, and Philip Williams \& Associates provided elevation data used for preliminary accuracy analyses. Nicole Athearn, (USGS) and John Krause (CA Department of Fish and Game) collected vegetation measurements 
for ground-truthing. Clyde Morris, (U.S. Fish \& Wildlife Service), provided access to ponds and marsh for lidar ground-truthing. Lastly, we would like to acknowledge the staff at TerraPoint and Mosaic Mapping (especially Claude Vickers, Simon Newby, and Alan Dodson) for their role in completing this project.

Funding for the 2004 South Bay lidar survey was provided by the California State Coastal Conservancy (CCC). Data analysis was supported by the CCC, USGS Coastal and Marine Geology Program, and the USGS San Francisco Bay Priority Ecosystem Program.

\section{References Cited}

Foxgrover, A.C., Higgins, S.A., Ingraca, M.K., Jaffe, B.E., and Smith, R.E., 2004, Deposition, erosion, and bathymetric change in South San Francisco Bay: 1858-1983: U.S. Geological Survey Open-File Report 2004-1192, 25 p. [URL: http://pubs.usgs.gov/of/2004/1192]

Graham, S.E. and Pike, R.J, 1997, San Francisco Bay Region Landslide Folio Part B - Shaded Relief Map of the San Francisco Bay Region, California: U.S. Geological Survey Open-File Report 97-745 B, [URL: http://geopubs.wr.usgs.gov/open-file/of97-745]

Mosaic Mapping Systems Inc., 2001, A White paper on LIDAR mapping. 16 p. [URL: http://www.mosaicmapping.com/library/LidarWhitePaper.pdf]

Nichols, F.H., Cloern, J.E., Luoma, S.N., and Peterson, D.H., 1986, The modification of an estuary. Science, 231: 567-573.

Puget Sound Lidar Consortium Web Site, 2005, [URL: http://duff.geology.washington.edu/data/raster/lidar/DATA.htm]

\section{Contact Information}

For general USGS South Bay project information: For information regarding this report:

Bruce E. Jaffe, Project Chief

Email: bjaffe@usgs.gov Amy C. Foxgrover Email: afoxgrover@usgs.gov

For details on the South Bay Salt Pond Restoration Project visit: http://www.southbayrestoration.org/ 


\section{Appendix}




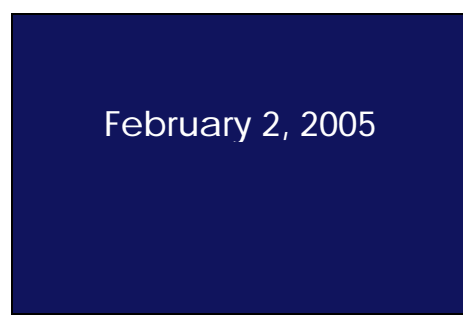

Project Report

\section{USGS- South Bay Restoration Project}

Contract \#2206-H

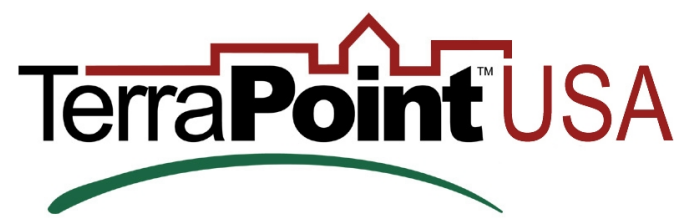

Report Presented to:

Amy Hutzel

Califomia Coastal Conservancy

1330 Broad way, 11th Floor,

Oakland, CA 94612

Bruce J affe

US Geological Survey Pa cific Science Center

400 Natural Bridges Drive

Santa Cruz, CA 95060 


\section{Project Overview}

\section{Field Crew:}

The Terrapoint field crew consisted of Roger Shreenan and Al Greatrex, who altemated as field project managers and Bamy Kaiser. The Aspen Helicopters Incomorated aircraft crew consisted of Kevin Kintz, Diana Feddersohn and Richard E. Saenz (pilots).

\section{Post Processing Crew:}

Roger Shreenan completed the processing of GPS data. Kresimir Kusevic, Alan Dodson, Roger Shreenan and Claude Vickers camed out data validation and boresight corrections. Vegetation removal and final product generation were completed the Ottawa processing team: Alan Dodson, Andrew Magnan, Krista Helman, Bruce Adey, Shaun Perry, Josh Beaton and Claude Vickers. Claude Vickers and Alan Dodson coordinated the Ottawa processing.

\section{Size of Project}

The South Bay restoration project covered approximately 334 square kilometers.

\section{Location:}

The project consisted and the mud flats and associated salt ponds of San Francisco Bay and surround ing 100-yearflood plain.

\section{Project Type:}

The purpose of this project is to provide a high quality DEM for drainage mapping and salt pond restoration for the USGS.

\section{Approximate Duration of Project}

The field data collection took place from May 5 to May 21, 2004. The control network and check point surveys were established from April 30 to May 20, 2004.

Boresight correction, vegetation removal and product generation took place from J une 3 to October 27, 2004.

\section{Number of Fights:}

Twenty-five flights were required to cover the project area with approximately one hundred thirty six flight lines. 


\section{Coordinate System(s) Used:}

All horizontal coordinate data was collected and referenced to NAD83 and NAVD88 as Universal Transverse Mercator Zone 10. GEOID03 grid \#5 for CONUS (24-42N, 230-249E) was applied to the vertical component of all deliverables.

\section{Survey Measurement Units Used/ Delivered:}

All surveys were conducted and products delivered in the metric system.

\section{Processing Software Used:}

The following software was used to reduce the GPS kinematic data, compute the 3-D laser points, classify and edit laser points, produce shaded relief images and transform the ellipsoidal heights to Orthometric:

- ArcView

- Flykin

- Microstation

- Terrascan

- TerraModeler

- TerraModel

- Terra point Proprietary LDAR processing softwa re

\section{Capsule Review of Ground Control Survey(s) and Adjustment(s)}

Terrapoint's field crew acquired and adjusted the ground control survey information. Terrapoint collected all of their LDAR data referenced to points BASE1, BASE2, BASE3 and BASE4. Plea se see the base coordinates and associated control in table 1 below. Kinematic GPS profiles and static GPS check points were acquired as discrete $x, y, z$ check points were collected as part of the ground truthing activities. A plot of these check points and control are located in Map A.

\begin{tabular}{|c|c|c|c|c|c|c|c|}
\hline \multicolumn{8}{|c|}{ Table 1: Control and Base Coordinate } \\
\hline NAME & \multicolumn{3}{|c|}{ Latitude } & \multicolumn{3}{|c|}{ Longitude } & $\begin{array}{c}\text { Orthometric } \\
\text { Elevations (Geoid03) }\end{array}$ \\
\hline ah7470 & 37 & 30 & 28.76286 & -122 & 12 & 39.08903 & 3.521 \\
\hline ai7653 & 37 & 43 & 11.04196 & -122 & 7 & 9.20686 & 149.986 \\
\hline BASE1 & 37 & 34 & 7.35898 & -122 & 6 & 16.12822 & 3.18 \\
\hline BASE2 & 37 & 31 & 8.79511 & -122 & 3 & 23.68627 & 10.62 \\
\hline BASE3 & 37 & 30 & 26.18105 & -122 & 14 & 42.72399 & 3.468 \\
\hline BASE4 & 37 & 39 & 48.1243 & -122 & 7 & 23.05579 & 9.272 \\
\hline HS2851 & 37 & 26 & 10.03157 & -122 & 54 & 24.8923 & 4.805 \\
\hline HT0565 & 37 & 35 & 28.63886 & -122 & 19 & 9.92157 & 13.999 \\
\hline SF01 & 37 & 25 & 32.53794 & -122 & 4 & 30.56896 & 18.616 \\
\hline $\begin{array}{l}\text { South Bay } \\
\text { Date: Feb } \\
\text { Revision } 1\end{array}$ & & & & 3 & & $\begin{array}{l}5216 \text { G ro } \\
\text { he Wood } \\
\text { hone: (2 } \\
\text { =ax: (218) }\end{array}$ & $\begin{array}{l}\text { gans Park Drive } \\
\text { lands, TX } 77380 \\
\text { 218) } 364-4080 \\
\text { 296- } 0869\end{array}$ \\
\hline
\end{tabular}




\section{Health and Safety}

Following Terrapoint's safety procedures, the field crew conducted a safety meeting upon a mival at the project site. 


\section{Equipment Used}

\section{Aircraft Type:}

A Partenavia P68 twin-engine aircraft (N300LF) was used for this project. The a ircraft was based out of Oxnard, Califomia. The Partenavia P-68 has a maximum flight range of a pproximately $1740 \mathrm{~km}$, and was typic a lly flying at an altitude of 245 meters AGL (above ground level) for the duration of the survey.

\section{Sensors Used:}

The Airbome LDAR survey was conducted using Terrapoint's ALMIS (Airbome Laser Mapping Imaging System), flying at an optimum height of 245 meters AG L at 100 knots. The system consists of a 60-d egree full angle Riegl laser, a Novatel GPS receiver and a Honeywell IMU unit. The nominal flight line spacing was 99 meters, providing overlap of $51 \%$ between flight lines.

\section{GPSType(s):}

Two Trimble 4000ssi dual frequency GPS receivers were used on the ground to support the a irbome operations on this project.

\section{Accuracy}

The following list itemizes the accuracy atta inable over the project area, as a function of terrain type and vegetation cover. Note that the accuracy quoted is the accuracy of the attainable DEM, once it is processed and edited to this stage. All data accuracies quoted relate to post processed GPS/IMU/LiDAR solutions.

Accuracy is as follows, quoted at the $95 \%$ c onfidence level ( 2 sigma),

1. Absolute Vertical Accuracy:

+/-10-15 centimeters on Hard Surfaces (roads and buildings)

+/-15-25 centimeters on Soft/Vegetated Surfaces (flat to rolling terrain)

+/-25-40 centimeters on Soft/Vegetated Surfaces (hilly terrain)

2. Absolute Horizontal Accuracy:

+/- 20 - 60 centimeters on all but extremely hilly terra in. 
To verify that the accuracy criteria were being achieved, the kinematic and static checkpoints were compared with a triangulated surface generated from the bald earth LDAR points. The statistical comparisons can be found in Appendix A for the kinematic points and Appendix B for the static points.

593 kinematic check points compared to the LDAR bald earth surface on paved surfaces found that the average emor was -1.9 centimeters and that $95 \%$ ( 2 sigma) of the checkpoints were within 13.2 centimeters of true values. An overview of the results from the kinematic GPS checkpoints follows in table 2 .

\begin{tabular}{|c|c|}
\hline \multicolumn{2}{|c|}{ Table 2: Kinematic Survey Results } \\
\hline Summary Statistics & Centimeters \\
\hline Sample Size & 593 pts. \\
\hline Average Error & -1.191 \\
\hline RMSE (1 Sigma) & 6.47 \\
\hline NSSDA (2 Sigma) & 13.21 \\
\hline Standard Deviation & 6.47 \\
\hline Error Range & -30.0 to +12.0 \\
\hline
\end{tabular}

165 Static check points compared to the LDAR bald earth surface on soft surfaces with varying vegetation cover found that the average error was 3.6 centimeters and that $95 \%$ ( 2 sigma) of the check points were within 28 centimeters of true values. An overview of the results from the kinematic G PS chec kpoints follows in table 3.

\begin{tabular}{|c|c|}
\hline \multicolumn{2}{|c|}{ Table 3: Static Survey Results } \\
\hline Summary Statistics & Centimeters \\
\hline Sample Size & 145 pts. \\
\hline Average Error & 3.19 \\
\hline RMSE (1 Sigma) & 13.37 \\
\hline NSSDA (2 Sigma) & 26.21 \\
\hline Standard Deviation & 13.03 \\
\hline Error Range & -39.0 to +53.0 \\
\hline
\end{tabular}




\section{Quality Control}

Quality control of the data was ongoing throughout the process. Following data acquisition, preliminary GPS processing was conducted in the field to ensure completeness and integrity.

The GPS and inertial data were processed in tandem to achieve the best positional result. Once the position and attitude of the aircraft were known at each epoch (1-second intervals), then these data were integrated with the laser ranges to provide a position for each data point on the ground. The data were then processed using TerraPoint's proprietary laser processing software suite to produce coordinates.

Each flight involved setting up two base stations to collect data. Utilizing two base stations ensures GPS data collection in the event that the main base station fails. For all flights the GPS data were of high quality. This minimized the absolute error for the a ircraft position.

The primary quality control tool for the laser ranges is the percentage of retums that are received back at the laser after it has emitted a signal. The acceptable range for retums, typically between $90 \%$ and $95 \%$ was met for this project. Lower percentages are nomal over water and other poor reflectivity surfaces such as the dark, wet surfaces typical of the project area's mud flats. 


\section{Point Generation}

The points are generated as Terrascan binary Format using Terrapoint's proprietary Laser Postprocessor Softwa re. This software combines the Raw Laser file and GPS/IMU information to generate a point cloud for each ind ividual flight.

All the point cloud files encompassing the project area were then divided into 2 kilometer by 2-kilometer tiles. The referencing system of these tiles is based upon the project boundary minimum and maximums. This process is camied out in Terrascan. The tile index graphics are represented in Map B.

The bald earth is subsequently extracted from the raw LDAR points using Terrascan in a Microstation environment. The automated vegetation removal process takes place by building an iterative surface model. This surface model is generated using three ma in parameters: Building size, Iteration angle and Iteration distance.

The initial model is based upon low points selected by a roaming window and are assumed to be ground points. The size of this roaming window is determined by the building size parameter. These low points are triangulated and the remaining points are evaluated and subsequently added to the model if they meet the Iteration angle and distance constraints (fig. 1). This process is repeated until no additional points are added within an iteration.

There is also a maximum terrain angle constraint that determines the maximum terrain angle allowed within the model.

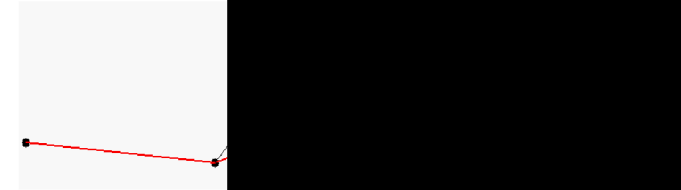

Figure 1: Terrascan iteration methodology.

(Image Source: Terrascan User's Guide, www.terrasolid.fi) 


\section{Quality Control}

Once the data setup has taken place the manual quality control of the surface occurs. This process consists of visually exa mining the LiDAR points within Terrascan and correcting errors that occurred during the automated process. These corrections include verifying that all non ground elements, such as vegetation and buildings are removed from the ground model and that all small terrain undulations such as road beds, dykes, rock cutsand hill topsare present within the model.

This process is done with the help of hillshades, contours, profiles and crosssections. To correct misclassifications, a full suite of Terrascan and custom in-house data tools are used. 


\section{Deliverables}

Below is a list of the deliverables for this project:

All LDAR Data Products were delivered on DVD-ROM. Three copies were provided. All products other than hill-shade data were provided in $1 \mathrm{k}$ and $2 \mathrm{k}$ tiles with a 25 -meter buffer. Hill-shades were delivered in three large areas.

Full Feature or All Retum Point Data

Data delivered in ASCII, comma delimited files with one record per retum containing data columns as defined in Table 4. The records are ordered sequentially according to Easting with no duplicate records. The individual retums are classified into the following categonies: ground or water, above ground (low), above ground (high), building and NADIR as defined in Table 5. This ASCIl product was generated using an in house custom utility. The process involved extracting a Terrascan Binary file packed with the scan angle and the extra precision required for the for a unique time stamp.

Bare Earth Point Data

Data delivered in ASC II, comma delimited files with one record per retum containing data columns as defined in Table 4. The records are ordered sequentially according to Easting with no duplicate records. This product is a subset of the full feature or all retum point data product containing only code 3 , ground points, as described in table 5 below. This ASCII product was generated using an in house custom utility. The process involved extracting a Terrascan Binary file packed with the scan angle and the extra precision required for the for a unique time stamp. 
Bare Earth and Full Feature Hill-Shade Image

Data delivered in GeoTIFF format with a TFW file. The image resolution is $1 \mathrm{~m}$. This product was generated in Arc View.

Gridded Bare Earth Point Data

Bare earth Digital Elevation Model (DEM) using last retum, with vegetation and building elevations removed. The data was gridded at $1 \mathrm{~m}$ postings, and delivered in ASCll format. This product was generated in Terrascan.

Contour Data

Data is delivered at $50 \mathrm{~cm}$ nominal contour interval, $2.5 \mathrm{~m}$ labeled index contours in AutoCAD format. This product was generated using a combination of TerraModeler and Mic rostation.

\begin{tabular}{|l|l|l|}
\hline \multicolumn{2}{|c|}{ Table 4: Individual laser retum (point cloud) data product specifications } \\
\hline Spec ific ation & \multicolumn{1}{|c|}{ Desc niption } & \multicolumn{1}{c|}{ Notes } \\
\hline $\begin{array}{l}\text { Data Field 1: } \\
\text { Time }\end{array}$ & GPStime & $\begin{array}{l}\text { Reported to nearest } \\
\text { mic rosecond }\end{array}$ \\
\hline $\begin{array}{l}\text { Data Field 2: } \\
\text { x,y location }\end{array}$ & $\begin{array}{l}\text { Geographic location of } \\
\text { retum }\end{array}$ & NAD83-92, to nea rest 0.01m \\
\hline $\begin{array}{l}\text { Data Field 3: } \\
\text { Elevation }\end{array}$ & Elevation of retum & NAVD-88, to nea rest 0.01m \\
\hline $\begin{array}{l}\text { Data Field 4: } \\
\text { Retum classific ation }\end{array}$ & $\begin{array}{l}\text { Retum classific a tion of this } \\
\text { retum }\end{array}$ & First or last retum \\
\hline $\begin{array}{l}\text { Data Field 5: } \\
\text { Off Nadir Angle }\end{array}$ & $\begin{array}{l}\text { Angle between na dir and } \\
\text { transmitted pulse }\end{array}$ & $\begin{array}{l}\text { Reported to nearest } 0.01 \\
\text { degrees }\end{array}$ \\
\hline $\begin{array}{l}\text { Data Field 6: } \\
\text { Retum Intensity }\end{array}$ & Intensity of retum & According to Table 4 \\
\hline $\begin{array}{l}\text { Data Field 7: } \\
\text { Classification Code }\end{array}$ & Classific a tion of retum & \\
\hline
\end{tabular}




\begin{tabular}{|c|c|c|}
\hline \multicolumn{3}{|c|}{ Table 5: Retum Classific ation System } \\
\hline Code & Description & Notes \\
\hline 3 & Ground orwater & -Bare Earth surface \\
\hline 10 & Above Ground - Low* & $\begin{array}{l}\text {-Located } 0-1.5 \mathrm{~m} \text { above } \\
\text { ground }\end{array}$ \\
\hline 5 & Above Ground - High * & $\begin{array}{l}\text {-Non-ground points, } 1.51 \mathrm{~m} \\
\text { up to } 60 \mathrm{~m} \text { above ground }\end{array}$ \\
\hline 7 & Build ings* & $\begin{array}{l}\text {-Manually extracted LiDAR } \\
\text { hits correspond ing to } \\
\text { build ings from codes } 10 \text { and } \\
5\end{array}$ \\
\hline 13 & Strong retum at na dir & $\begin{array}{l}\text {-Retums having intensity } \\
\text { values greater than or } \\
\text { equal to } 40 \text { at nadir. } \\
\text {-Can correspond to any } \\
\text { features from the above } \\
\text { feature codes }\end{array}$ \\
\hline
\end{tabular}

NOTE: * Codes 10 and 5 capture all above ground features not deemed to be building - i.e.

vegetation and other man made structures

Please note that all products, other than the hillshade products were delivered in 2 kilometer tiles (Map B) and 1 kilometer tiles (Map C). 


\section{Problems, Resolutions and Conclusions}

\section{Boresight}

Our laser encountered some technical diffic ulties during acquisition. The laser manufacturer, Riegl, was unable to pin point the problem on the bench due to the small magnitude of the error. Riegl anticipated this result due to the limits of testing within a lab setting. As a precaution to eliminate any possible source of error, the laser angle encoder unit and the bearings were replaced. As an additional precaution, an extra screw was added during the inspection to improve the mounting of encoder mechanism. The unit belt was eliminated as the source of the problem. As a result of this malfunction, the boresight values for each flight had to be thoroughly reviewed. This manual process took approximately three weeks to resolve for the appropriate boresight corrections. The majority of the flights required a single roll correction of 0.097 degrees while others required an adjustment of 0.068 or 0.142 degrees. Certa in flights required two-roll corrections.

Unfortunately, this boresight problem caused by equipment malfunction was only discovered after initially delivering the project - this was principally due to a shortcoming in our QC methodology that did not reveal mechanical problems such as those encountered with our scanning laser. It should be noted that the laser deployed for this project had previously operated without error on approximately 200 missions. We therefore consider the problems encountered with the South Bay project to be an outlier. Nevertheless, our processing flow has now been modified to identify such outliers by performing more quality control checks on the data prior to entering production. These include: profiles, full feature hillshades, GPS checks and distance grids. The distance grids are quite beneficial as they visually display relative elevation emor between flightlines. Please note that we attempted to perform distance grids on all the tiles, but were successful on only 127 of 145 tiles due to lack of overlap in open water or tiles containing a great deal of flightlines causing the application to crash. Close attention was paid to these tiles in particular during the second round of production as to ensure the quality was good. The distance images were captured as screengrabs from the application and are located on the accompanying disk.

The late discovery of this problem proved to be special challenge, as the processing team had spent the majority of the initial filtering run extracting the buildings from the point cloud. To deliver this project in a rapid manner, we opted to ma inta in the building classific ations as to minimize 
the amount of reprocessing. Therefore we could not reprocess the point cloud with the boresight compensation values. An additional problem ensued; two GPS week rollovers occurred during acquisition. Due to software limitations we are unable to store GPS week, only GPS time, therefore, there is a strong likelihood of having multiple identical GPS times within the dataset. This situation leads to the possibility of associating the LDAR data to the wrong trajectory and applying an incorrect roll compensation factor based upon aircraft position and required correction. To overcome these obstacles we developed a new procedure using existing software and custom applications. Once applied, these corrections were verified with the aforementioned distance grids. This issue is being addressed in future projects by allowing the LDAR operator to tag flight lines with an attribute during a cquisition.

As a result of applying the roll compensation the overall quality of the dataset increased significantly allowing the project to meet the set accuracy guidelines. Upon the discovery of this problem by the USGS a few selected distance grids were generated. These grids indicated an a verage error of 30 centimeters while a few area sindic ated emors of 45-50 centimeters. Once the boresight corrections were applied, all but a few areas are now within the range of $+/-15$ centimeters. A few a reas remain as outliers in the 15 to $30 \mathrm{~cm}$ range.

A benefit of the correction was the elimination of "false vegetation". The error was more evident in flat open areas of the mud flats. The error manifested itself to look like isolated areas of low scrub. Once corrected these were reduced significantly to meet specification or eliminated all together. Vegetation removal also proved to be tricky as quite often the bulrush directly adjoining dikes masked themselves as extensions to the dikes. Pickle weed and other forms of low vegetation shorter than $20 \mathrm{~cm}$ also tended blend very well into the mudflats. Particular attention had to be paid to these areas and the assistance of the USGS proved to be a valuable asset in disceming valid ground from vegetation.

\section{Building Extraction}

As mentioned above, one of the obstacles encountered was the high concentration of buildings for extraction. The lack of a reliable automated extraction tool for buildings caused a great impediment to delivering the project within the original time frame. Constant development is undertaken by the manufacturer of Terrascan to streamline the difficult process of building extraction. 


\section{Storage Format}

Our standard point storage format, Terrascan Binary, also proved to be a hindrance to completing this project due to the inability to store the required scan angle and time stamp to the microsecond. We are investigating using LAS binary as our standard storage in the future.

\section{High Tide Versus Low Tide}

One of the acquisition constraints set for this project was that certa in areas were to be acquired at low tide level. Although these guidelines were followed, Terrapoint's ALMIS system acquires data at all times when flying and does not have flight line logging abilities. Therefore on many occasions transit lines were flown at high tide over a reas requining low tide coverage. This proved to be only a minor issue in processing as the majority of the high tide lines were classified as code 10 (not ground or water). Some points were not removed in the automated filtering process and were classified as code 10 or eliminated during the manual quality control process.

\section{Conclusion}

In conclusion, all parties have leamed a great from this project. New measures are being put forth at Terrapoint to allow us in the future to deliver a better product in a shorter time frame. 


\section{Appendix A. Kinematic GPS Statistic al Comparisons}

All tests done with maximum triangle length of 1.5 meters and maximum slope of 60 degrees

\section{Section 1 of 1 (Hard Surface)}

\begin{tabular}{|c|c|c|c|c|c|c|c|}
\hline Point Number & Location Description & Easting & Northing & Known Z & Laser Z & $\mathrm{Dz}$ & $(\mathrm{Dz})^{2}$ \\
\hline 310 & Tiles $48,49 \& 50$ & 579086.32 & 4158336.57 & 3.03 & 3.06 & 0.03 & 0.0009 \\
\hline 311 & Tiles 48, $49 \& 50$ & 579086.36 & 4158336.58 & 3.03 & 3.06 & 0.03 & 0.0009 \\
\hline 312 & Tiles $48,49 \& 50$ & 579086.65 & 4158336.62 & 3.02 & 3.09 & 0.07 & 0.0049 \\
\hline 313 & Tiles 48, $49 \& 50$ & 579087.10 & 4158336.68 & 3.02 & 3.09 & 0.07 & 0.0049 \\
\hline 321 & Tiles 48, $49 \& 50$ & 579112.68 & 4158341.72 & 3.15 & 3.16 & 0.01 & 0.0001 \\
\hline 326 & Tiles $48,49 \& 50$ & 579144.58 & 4158354.23 & 3.27 & 3.33 & 0.06 & 0.0036 \\
\hline 327 & Tiles $48,49 \& 50$ & 579151.52 & 4158357.77 & 3.19 & 3.20 & 0.01 & 0.0001 \\
\hline 328 & Tiles 48, $49 \& 50$ & 579158.69 & 4158361.32 & 3.11 & 3.12 & 0.01 & 0.0001 \\
\hline 330 & Tiles $48,49 \& 50$ & 579173.87 & 4158367.92 & 2.93 & 2.92 & -0.01 & 0.0001 \\
\hline 331 & Tiles $48,49 \& 50$ & 579182.02 & 4158370.81 & 2.85 & 2.81 & -0.04 & 0.0016 \\
\hline 334 & Tiles $48,49 \& 50$ & 579208.14 & 4158378.87 & 2.70 & 2.73 & 0.03 & 0.0009 \\
\hline 337 & Tiles $48,49 \& 50$ & 579235.37 & 4158386.82 & 2.72 & 2.81 & 0.09 & 0.0081 \\
\hline 338 & Tiles $48,49 \& 50$ & 579244.59 & 4158389.54 & 2.70 & 2.77 & 0.07 & 0.0049 \\
\hline 342 & Tiles 48, $49 \& 50$ & 579282.06 & 4158400.78 & 2.60 & 2.67 & 0.07 & 0.0049 \\
\hline 354 & Tiles $48,49 \& 50$ & 579394.72 & 4158434.12 & 2.71 & 2.68 & -0.03 & 0.0009 \\
\hline 355 & Tiles $48,49 \& 50$ & 579404.21 & 4158436.95 & 2.71 & 2.72 & 0.01 & 0.0001 \\
\hline 359 & Tiles $48,49 \& 50$ & 579441.75 & 4158448.58 & 2.59 & 2.59 & 0.00 & 0.0000 \\
\hline 366 & Tiles $48,49 \& 50$ & 579509.45 & 4158467.52 & 2.49 & 2.51 & 0.02 & 0.0004 \\
\hline 368 & Tiles $48,49 \& 50$ & 579530.12 & 4158473.55 & 2.59 & 2.55 & -0.04 & 0.0016 \\
\hline 369 & Tiles $48,49 \& 50$ & 579540.62 & 4158476.76 & 2.56 & 2.57 & 0.01 & 0.0001 \\
\hline 371 & Tiles 48, $49 \& 50$ & 579561.77 & 4158482.98 & 2.60 & 2.62 & 0.02 & 0.0004 \\
\hline 373 & Tiles $48,49 \& 50$ & 579583.16 & 4158489.31 & 2.61 & 2.60 & \begin{tabular}{|l|}
-0.01 \\
\end{tabular} & 0.0001 \\
\hline 379 & Tiles $48,49 \& 50$ & 579649.81 & 4158509.54 & 2.55 & 2.56 & 0.01 & 0.0001 \\
\hline 389 & Tiles 48, $49 \& 50$ & 579762.61 & 4158544.33 & 2.50 & 2.48 & $\mid-0.02$ & 0.0004 \\
\hline 390 & Tiles 48, $49 \& 50$ & 579773.68 & 4158547.71 & 2.59 & 2.58 & $|-0.01|$ & 0.0001 \\
\hline 396 & Tiles 48, 49 \& 50 & 579837.31 & 4158567.52 & 2.63 & 2.56 & \begin{tabular}{|l|}
-0.07 \\
\end{tabular} & 0.0049 \\
\hline 401 & Tiles 48, $49 \& 50$ & 579887.67 & 4158582.87 & 2.65 & 2.61 & -0.04 & 0.0016 \\
\hline 402 & Tiles $48,49 \& 50$ & 579897.43 & 4158585.76 & 2.66 & 2.62 & -0.04 & 0.0016 \\
\hline 404 & Tiles $48,49 \& 50$ & 579916.77 & 4158591.56 & 2.61 & 2.58 & -0.03 & 0.0009 \\
\hline 406 & Tiles 48, $49 \& 50$ & 579936.28 & 4158597.48 & 2.56 & 2.61 & 0.05 & 0.0025 \\
\hline 407 & Tiles 48, $49 \& 50$ & 579946.18 & 4158600.48 & 2.52 & 2.57 & 0.05 & 0.0025 \\
\hline 413 & Tiles $48,49 \& 50$ & 580005.23 & 4158618.70 & 2.69 & 2.65 & -0.04 & 0.0016 \\
\hline 414 & Tiles $48,49 \& 50$ & 580015.22 & 4158621.79 & 2.69 & 2.70 & 0.01 & 0.0001 \\
\hline 415 & Tiles $48,49 \& 50$ & 580025.19 & 4158624.93 & 2.67 & 2.60 & $\mid-0.07$ & 0.0049 \\
\hline 416 & Tiles 48, $49 \& 50$ & 580035.13 & 4158628.08 & 2.67 & 2.61 & $\mid-0.06$ & 0.0036 \\
\hline
\end{tabular}

South Bay Restoration Final Report Date: February 2, 2005

Revision 1.2
16 


\begin{tabular}{|c|c|c|c|c|c|c|c|}
\hline 417 & Tiles 48, $49 \& 50$ & 580045.06 & 4158631.24 & 2.70 & 2.69 & $|-0.01|$ & 0.0001 \\
\hline 418 & Tiles $48,49 \& 50$ & 580054.97 & 4158634.55 & 2.77 & 2.78 & 0.01 & 0.0001 \\
\hline 419 & Tiles $48,49 \& 50$ & 580064.91 & 4158638.02 & 2.78 & 2.80 & 0.02 & 0.0004 \\
\hline 440 & Tiles 48, $49 \& 50$ & 580290.63 & 4158708.50 & 2.82 & 2.78 & -0.04 & 0.0016 \\
\hline 441 & Tiles $48,49 \& 50$ & 580301.66 & 4158711.77 & 2.80 & 2.77 & -0.03 & 0.0009 \\
\hline 442 & Tiles $48,49 \& 50$ & 580312.68 & 4158715.03 & 2.85 & 2.85 & 0.00 & 0.0000 \\
\hline 443 & Tiles $48,49 \& 50$ & 580323.68 & 4158718.31 & 2.90 & 2.92 & 0.02 & 0.0004 \\
\hline 446 & Tiles 48, $49 \& 50$ & 580356.77 & 4158728.62 & 3.00 & 2.97 & -0.03 & 0.0009 \\
\hline 447 & Tiles $48,49 \& 50$ & 580367.74 & 4158732.45 & 3.08 & 3.05 & -0.03 & 0.0009 \\
\hline 448 & Tiles $48,49 \& 50$ & 580378.55 & 4158736.75 & 3.08 & 3.08 & 0.00 & 0.0000 \\
\hline 452 & Tiles $48,49 \& 50$ & 580419.34 & 4158758.23 & 3.25 & 3.29 & 0.04 & 0.0016 \\
\hline 453 & Tiles $48,49 \& 50$ & 580429.36 & 4158763.97 & 3.25 & 3.28 & 0.03 & 0.0009 \\
\hline 456 & Tiles 48, $49 \& 50$ & 580459.30 & 4158781.66 & 3.18 & 3.22 & 0.04 & 0.0016 \\
\hline 460 & Tiles $48,49 \& 50$ & 580499.22 & 4158804.20 & 3.19 & 3.26 & 0.07 & 0.0049 \\
\hline 461 & Tiles $48,49 \& 50$ & 580509.14 & 4158809.88 & 3.21 & 3.30 & 0.09 & 0.0081 \\
\hline 462 & Tiles $48,49 \& 50$ & 580518.95 & 4158815.57 & 3.29 & 3.33 & 0.04 & 0.0016 \\
\hline 463 & Tiles $48,49 \& 50$ & 580528.75 & 4158821.28 & 3.25 & 3.29 & 0.04 & 0.0016 \\
\hline 464 & Tiles 48, $49 \& 50$ & 580538.55 & 4158827.08 & 3.20 & 3.28 & 0.08 & 0.0064 \\
\hline 465 & Tiles $48,49 \& 50$ & 580548.35 & 4158832.96 & 3.19 & 3.27 & 0.08 & 0.0064 \\
\hline 466 & Tiles $48,49 \& 50$ & 580558.21 & 4158838.79 & 3.19 & 3.19 & 0.00 & 0.0000 \\
\hline 467 & Tiles $48,49 \& 50$ & 580568.12 & 4158844.64 & 3.20 & 3.24 & 0.04 & 0.0016 \\
\hline 468 & Tiles 48, $49 \& 50$ & 580578.13 & 4158850.46 & 3.17 & 3.24 & 0.07 & 0.0049 \\
\hline 469 & Tiles $48,49 \& 50$ & 580588.16 & 4158856.31 & 3.13 & 3.21 & 0.08 & 0.0064 \\
\hline 470 & Tiles 48, $49 \& 50$ & 580598.24 & 4158862.16 & 3.13 & 3.19 & 0.06 & 0.0036 \\
\hline 471 & Tiles 48, $49 \& 50$ & 580608.31 & 4158868.06 & 3.13 & 3.18 & 0.05 & 0.0025 \\
\hline 472 & Tiles $48,49 \& 50$ & 580618.29 & 4158873.93 & 3.11 & 3.12 & 0.01 & 0.0001 \\
\hline 477 & Tiles $48,49 \& 50$ & 580664.65 & 4158900.71 & 3.02 & 2.94 & -0.08 & 0.0064 \\
\hline 481 & Tiles $48,49 \& 50$ & 580690.58 & 4158912.06 & 3.03 & 3.03 & 0.00 & 0.0000 \\
\hline 482 & Tiles $48,49 \& 50$ & 580695.85 & 4158911.27 & 3.03 & 2.99 & -0.04 & 0.0016 \\
\hline 483 & Tiles 48, $49 \& 50$ & 580700.88 & 4158909.28 & 2.94 & 2.86 & -0.08 & 0.0064 \\
\hline 487 & Tiles 48, $49 \& 50$ & 580721.74 & 4158896.51 & 3.41 & 3.36 & -0.05 & 0.0025 \\
\hline 489 & Tiles $48,49 \& 50$ & 580729.58 & 4158884.50 & 3.69 & 3.56 & -0.13 & 0.0169 \\
\hline 494 & Tiles $48,49 \& 50$ & 580747.37 & 4158842.88 & 3.70 & 3.57 & -0.13 & 0.0169 \\
\hline 495 & Tiles $48,49 \& 50$ & 580751.10 & 4158834.15 & 3.70 & 3.63 & -0.07 & 0.0049 \\
\hline 497 & Tiles $48,49 \& 50$ & 580758.61 & 4158816.64 & 3.71 & 3.72 & 0.01 & 0.0001 \\
\hline 499 & Tiles $48,49 \& 50$ & 580766.28 & 4158798.84 & 3.70 & 3.63 & -0.07 & 0.0049 \\
\hline 500 & Tiles $48,49 \& 50$ & 580770.28 & 4158789.76 & 3.73 & 3.65 & -0.08 & 0.0064 \\
\hline 524 & Tiles $48,49 \& 50$ & 580868.43 & 4158565.91 & 3.35 & 3.16 & -0.19 & 0.0361 \\
\hline 526 & Tiles $48,49 \& 50$ & 580876.19 & 4158548.31 & 3.37 & 3.26 & -0.11 & 0.0121 \\
\hline 528 & Tiles 48, $49 \& 50$ & 580883.20 & 4158530.75 & 3.39 & 3.21 & -0.18 & 0.0324 \\
\hline 534 & Tiles 48, $49 \& 50$ & 580905.35 & 4158479.68 & 3.44 & 3.32 & -0.12 & 0.0144 \\
\hline 536 & Tiles $48,49 \& 50$ & 580909.87 & 4158463.00 & 3.47 & 3.23 & -0.24 & 0.0576 \\
\hline 540 & Tiles $48,49 \& 50$ & 580907.38 & 4158430.29 & 3.56 & 3.39 & -0.17 & 0.0289 \\
\hline 544 & Tiles 48, $49 \& 50$ & 580898.70 & 4158397.36 & 3.29 & 3.24 & -0.05 & 0.0025 \\
\hline 547 & Tiles 48, $49 \& 50$ & 580888.96 & 4158372.87 & 3.48 & 3.37 & -0.11 & 0.0121 \\
\hline 548 & Tiles 48, $49 \& 50$ & 580885.75 & 4158364.63 & 3.53 & 3.40 & -0.13 & 0.0169 \\
\hline 562 & Tiles 48, $49 \& 50$ & 580836.94 & 4158256.09 & 3.60 & 3.66 & 0.06 & 0.0036 \\
\hline 565 & Tiles $48,49 \& 50$ & 580819.61 & 4158240.15 & 3.68 & 3.73 & 0.05 & 0.0025 \\
\hline
\end{tabular}

South Bay Restoration Final Report Date: February 2, 2005

Revision 1.2 


\begin{tabular}{|c|c|c|c|c|c|c|c|}
\hline 566 & Tiles 48, $49 \& 50$ & 580813.13 & 4158235.17 & 3.61 & 3.64 & $\mid 0.03$ & 0.0009 \\
\hline 567 & Tiles $48,49 \& 50$ & 580806.56 & 4158230.45 & 3.55 & 3.59 & 0.04 & 0.0016 \\
\hline 568 & Tiles $48,49 \& 50$ & 580800.15 & 4158225.89 & 3.51 & 3.56 & 0.05 & 0.0025 \\
\hline 578 & Tiles 48, $49 \& 50$ & 580740.18 & 4158179.08 & 3.43 & 3.42 & -0.01 & 0.0001 \\
\hline 579 & Tiles $48,49 \& 50$ & 580733.94 & 4158173.64 & 3.39 & 3.44 & 0.05 & 0.0025 \\
\hline 580 & Tiles $48,49 \& 50$ & 580727.76 & 4158167.71 & 3.37 & 3.36 & -0.01 & 0.0001 \\
\hline 582 & Tiles $48,49 \& 50$ & 580715.82 & 4158154.25 & 3.40 & 3.43 & 0.03 & 0.0009 \\
\hline 583 & Tiles 48, $49 \& 50$ & 580709.80 & 4158146.92 & 3.43 & 3.44 & 0.01 & 0.0001 \\
\hline 586 & Tiles $48,49 \& 50$ & 580690.61 & 4158123.18 & 3.36 & 3.39 & 0.03 & 0.0009 \\
\hline 590 & Tiles $48,49 \& 50$ & 580663.76 & 4158089.33 & 3.38 & 3.42 & 0.04 & 0.0016 \\
\hline 591 & Tiles $48,49 \& 50$ & 580657.00 & 4158080.81 & 3.40 & 3.42 & 0.02 & 0.0004 \\
\hline 592 & Tiles $48,49 \& 50$ & 580650.22 & 4158072.20 & 3.35 & 3.37 & 0.02 & 0.0004 \\
\hline 593 & Tiles 48, $49 \& 50$ & 580643.28 & 4158063.62 & 3.32 & 3.38 & 0.06 & 0.0036 \\
\hline 597 & Tiles $48,49 \& 50$ & 580614.49 & 4158030.01 & 3.18 & 3.23 & 0.05 & 0.0025 \\
\hline 598 & Tiles $48,49 \& 50$ & 580607.11 & 4158021.76 & 3.16 & 3.17 & 0.01 & 0.0001 \\
\hline 599 & Tiles $48,49 \& 50$ & 580599.78 & 4158013.40 & 3.13 & 3.21 & 0.08 & 0.0064 \\
\hline 600 & Tiles $48,49 \& 50$ & 580592.56 & 4158005.04 & 3.14 & 3.08 & -0.06 & 0.0036 \\
\hline 601 & Tiles 48, $49 \& 50$ & 580585.56 & 4157996.70 & 3.08 & 3.07 & -0.01 & 0.0001 \\
\hline 602 & Tiles $48,49 \& 50$ & 580578.72 & 4157988.51 & 3.03 & 3.10 & 0.07 & 0.0049 \\
\hline 607 & Tiles $48,49 \& 50$ & 580545.71 & 4157950.23 & 2.81 & 2.83 & 0.02 & 0.0004 \\
\hline 609 & Tiles $48,49 \& 50$ & 580532.72 & 4157936.84 & 2.81 & 2.83 & 0.02 & 0.0004 \\
\hline 611 & Tiles $48,49 \& 50$ & 580519.57 & 4157924.63 & 2.80 & 2.80 & 0.00 & 0.0000 \\
\hline 612 & Tiles $48,49 \& 50$ & 580512.51 & 4157919.04 & 2.84 & 2.85 & 0.01 & 0.0001 \\
\hline 613 & Tiles 48, $49 \& 50$ & 580505.19 & 4157913.95 & 2.90 & 2.95 & 0.05 & 0.0025 \\
\hline 614 & Tiles $48,49 \& 50$ & 580497.74 & 4157909.71 & 2.96 & 2.99 & 0.03 & 0.0009 \\
\hline 615 & Tiles 48, 49 \& 50 & 580490.46 & 4157906.40 & 3.03 & 3.05 & 0.02 & 0.0004 \\
\hline 616 & Tiles $48,49 \& 50$ & 580483.45 & 4157903.91 & 3.06 & 3.03 & -0.03 & 0.0009 \\
\hline 619 & Tiles $48,49 \& 50$ & 580466.84 & 4157899.48 & 3.02 & 3.03 & 0.01 & 0.0001 \\
\hline 624 & Tiles 48, 49 \& 50 & 580448.32 & 4157898.88 & 2.95 & 3.01 & 0.06 & 0.0036 \\
\hline 625 & Tiles 48, $49 \& 50$ & 580444.45 & 4157899.60 & 2.95 & 3.01 & 0.06 & 0.0036 \\
\hline 627 & Tiles 48, $49 \& 50$ & 580438.04 & 4157901.71 & 2.97 & 3.02 & 0.05 & 0.0025 \\
\hline 628 & Tiles $48,49 \& 50$ & 580435.65 & 4157902.84 & 2.98 & 3.00 & 0.02 & 0.0004 \\
\hline 629 & Tiles $48,49 \& 50$ & 580433.91 & 4157903.87 & 3.00 & 3.02 & 0.02 & 0.0004 \\
\hline 630 & Tiles $48,49 \& 50$ & 580432.96 & 4157904.46 & 3.00 & 3.01 & 0.01 & 0.0001 \\
\hline 631 & Tiles 48, $49 \& 50$ & 580432.60 & 4157904.67 & 3.00 & 3.02 & 0.02 & 0.0004 \\
\hline 632 & Tiles 48, $49 \& 50$ & 580432.59 & 4157904.68 & 3.00 & 3.02 & 0.02 & 0.0004 \\
\hline 633 & Tiles $48,49 \& 50$ & 580432.90 & 4157904.49 & 3.00 & 3.01 & 0.01 & 0.0001 \\
\hline 634 & Tiles $48,49 \& 50$ & 580433.65 & 4157904.04 & 3.00 & 3.00 & 0.00 & 0.0000 \\
\hline 636 & Tiles $48,49 \& 50$ & 580436.12 & 4157902.49 & 2.99 & 3.00 & 0.01 & 0.0001 \\
\hline 637 & Tiles 48, $49 \& 50$ & 580437.78 & 4157901.41 & 2.98 & 3.02 & 0.04 & 0.0016 \\
\hline 639 & Tiles $48,49 \& 50$ & 580441.40 & 4157899.40 & 2.97 & 3.03 & 0.06 & 0.0036 \\
\hline 641 & Tiles $48,49 \& 50$ & 580444.50 & 4157898.16 & 2.98 & 3.04 & 0.06 & 0.0036 \\
\hline 642 & Tiles $48,49 \& 50$ & 580446.27 & 4157897.65 & 2.98 & 3.01 & 0.03 & 0.0009 \\
\hline 643 & Tiles 48, $49 \& 50$ & 580447.76 & 4157897.27 & 2.98 & 2.98 & 0.00 & 0.0000 \\
\hline 644 & Tiles 48, $49 \& 50$ & 580449.03 & 4157896.97 & 2.98 & 2.92 & -0.06 & 0.0036 \\
\hline 645 & Tiles 48, $49 \& 50$ & 580450.54 & 4157896.55 & 2.95 & 3.00 & 0.05 & 0.0025 \\
\hline 646 & Tiles 48, $49 \& 50$ & 580452.02 & 4157895.99 & 2.88 & 2.98 & 0.10 & 0.0100 \\
\hline 664 & Tiles 48, $49 \& 50$ & 580465.43 & 4157899.70 & 3.04 & 3.06 & 0.02 & 0.0004 \\
\hline
\end{tabular}

South Bay Restoration Final Report Date: February 2, 2005

Revision 1.2
18

25216 Grogans Park Drive The Woodlands, TX 77380 Phone: (218) $364-4080$ Fax: (218) 296- 0869 


\begin{tabular}{|c|c|c|c|c|c|c|c|}
\hline 666 & Tiles 48, $49 \& 50$ & 580475.52 & 4157901.45 & 3.04 & 3.03 & $|-0.01|$ & 0.0001 \\
\hline 668 & Tiles $48,49 \& 50$ & 580487.23 & 4157905.15 & 3.06 & 3.07 & 0.01 & 0.0001 \\
\hline 670 & Tiles $48,49 \& 50$ & 580500.60 & 4157911.30 & 2.94 & 2.99 & 0.05 & 0.0025 \\
\hline 671 & Tiles 48, $49 \& 50$ & 580507.43 & 4157915.40 & 2.88 & 2.91 & 0.03 & 0.0009 \\
\hline 672 & Tiles $48,49 \& 50$ & 580514.17 & 4157920.18 & 2.83 & 2.85 & 0.02 & 0.0004 \\
\hline 674 & Tiles $48,49 \& 50$ & 580527.12 & \begin{tabular}{|l|}
4157931.41 \\
\end{tabular} & 2.80 & 2.78 & -0.02 & 0.0004 \\
\hline 675 & Tiles $48,49 \& 50$ & 580533.44 & 4157937.61 & 2.81 & 2.83 & 0.02 & 0.0004 \\
\hline 677 & Tiles 48, $49 \& 50$ & 580545.99 & 4157950.45 & 2.82 & 2.83 & 0.01 & 0.0001 \\
\hline 684 & Tiles $48,49 \& 50$ & 580586.16 & 4157997.26 & 3.09 & 3.08 & -0.01 & 0.0001 \\
\hline 685 & Tiles $48,49 \& 50$ & 580591.96 & 4158004.20 & 3.13 & 3.14 & 0.01 & 0.0001 \\
\hline 686 & Tiles $48,49 \& 50$ & 580597.93 & 4158011.12 & 3.12 & 3.17 & 0.05 & 0.0025 \\
\hline 687 & Tiles $48,49 \& 50$ & 580604.00 & 4158018.03 & 3.13 & 3.13 & 0.00 & 0.0000 \\
\hline 688 & Tiles 48, $49 \& 50$ & 580610.12 & 4158024.99 & 3.17 & 3.20 & 0.03 & 0.0009 \\
\hline 689 & Tiles $48,49 \& 50$ & 580616.29 & 4158032.01 & 3.19 & 3.25 & 0.06 & 0.0036 \\
\hline 693 & Tiles $48,49 \& 50$ & 580641.18 & 4158060.70 & 3.30 & 3.27 & -0.03 & 0.0009 \\
\hline 694 & Tiles $48,49 \& 50$ & 580647.27 & 4158068.21 & 3.33 & 3.35 & 0.02 & 0.0004 \\
\hline 695 & Tiles $48,49 \& 50$ & 580653.34 & 4158075.79 & 3.38 & 3.41 & 0.03 & 0.0009 \\
\hline 696 & Tiles $48,49 \& 50$ & 580659.44 & 4158083.41 & 3.39 & 3.40 & 0.01 & 0.0001 \\
\hline 697 & Tiles $48,49 \& 50$ & 580665.46 & 4158091.02 & 3.39 & 3.38 & -0.01 & 0.0001 \\
\hline 701 & Tiles $48,49 \& 50$ & 580689.14 & 4158121.00 & 3.34 & 3.36 & 0.02 & 0.0004 \\
\hline 702 & Tiles $48,49 \& 50$ & 580695.03 & 4158128.32 & 3.37 & 3.41 & 0.04 & 0.0016 \\
\hline 704 & Tiles $48,49 \& 50$ & 580706.65 & 4158142.92 & 3.42 & 3.41 & -0.01 & 0.0001 \\
\hline 705 & Tiles $48,49 \& 50$ & 580712.61 & 4158150.14 & 3.43 & 3.49 & 0.06 & 0.0036 \\
\hline 706 & Tiles 48, $49 \& 50$ & 580718.77 & 4158157.23 & 3.38 & 3.43 & 0.05 & 0.0025 \\
\hline 707 & Tiles $48,49 \& 50$ & 580725.08 & 4158164.17 & 3.36 & 3.41 & 0.05 & 0.0025 \\
\hline 709 & Tiles $48,49 \& 50$ & 580738.19 & 4158177.12 & 3.41 & 3.44 & 0.03 & 0.0009 \\
\hline 710 & Tiles $48,49 \& 50$ & 580745.02 & 4158182.95 & 3.48 & 3.56 & 0.08 & 0.0064 \\
\hline 720 & Tiles $48,49 \& 50$ & 580803.12 & 4158227.88 & 3.52 & 3.48 & -0.04 & 0.0016 \\
\hline 721 & Tiles $48,49 \& 50$ & 580808.74 & 4158232.05 & 3.56 & 3.61 & 0.05 & 0.0025 \\
\hline 722 & Tiles $48,49 \& 50$ & 580814.39 & 4158236.14 & 3.64 & 3.65 & 0.01 & 0.0001 \\
\hline 725 & Tiles 48, $49 \& 50$ & 580830.98 & 4158249.56 & 3.65 & 3.69 & 0.04 & 0.0016 \\
\hline 734 & Tiles $48,49 \& 50$ & 580866.45 & 4158313.47 & 3.59 & 3.61 & 0.02 & 0.0004 \\
\hline 740 & Tiles $48,49 \& 50$ & 580886.72 & 4158366.03 & 3.52 & 3.51 & -0.01 & 0.0001 \\
\hline 741 & Tiles $48,49 \& 50$ & 580890.11 & 4158374.76 & 3.46 & 3.36 & -0.10 & 0.0100 \\
\hline 745 & Tiles 48, $49 \& 50$ & 580902.86 & 4158409.25 & 3.40 & 3.18 & -0.22 & 0.0484 \\
\hline 751 & Tiles $48,49 \& 50$ & 580910.02 & 4158463.03 & 3.48 & 3.24 & -0.24 & 0.0576 \\
\hline 753 & Tiles $48,49 \& 50$ & 580905.41 & 4158479.97 & 3.44 & 3.31 & -0.13 & 0.0169 \\
\hline 755 & Tiles $48,49 \& 50$ & 580898.10 & 4158496.05 & 3.48 & 3.41 & -0.07 & 0.0049 \\
\hline 763 & Tiles $48,49 \& 50$ & 580869.21 & 4158564.49 & 3.36 & 3.12 & -0.24 & 0.0576 \\
\hline 764 & Tiles 48, $49 \& 50$ & 580865.27 & 4158573.37 & 3.38 & 3.15 & -0.23 & 0.0529 \\
\hline 766 & Tiles $48,49 \& 50$ & 580857.05 & 4158591.21 & 3.44 & 3.29 & -0.15 & 0.0225 \\
\hline 768 & Tiles $48,49 \& 50$ & 580848.94 & 4158609.33 & 3.46 & 3.35 & -0.11 & 0.0121 \\
\hline 773 & Tiles $48,49 \& 50$ & 580828.81 & 4158655.29 & 3.26 & 3.18 & -0.08 & 0.0064 \\
\hline 780 & Tiles 48, $49 \& 50$ & 580801.25 & 4158718.51 & 3.62 & 3.32 & -0.30 & 0.0900 \\
\hline 789 & Tiles 48, $49 \& 50$ & 580767.73 & 4158796.02 & 3.71 & 3.65 & -0.06 & 0.0036 \\
\hline 791 & Tiles 48, $49 \& 50$ & 580760.32 & 4158813.09 & 3.72 & 3.66 & -0.06 & 0.0036 \\
\hline 798 & Tiles 48, $49 \& 50$ & 580735.43 & 4158872.07 & 3.78 & 3.69 & -0.09 & 0.0081 \\
\hline 802 & Tiles $48,49 \& 50$ & 580721.35 & 4158897.00 & 3.39 & 3.36 & -0.03 & 0.0009 \\
\hline
\end{tabular}

South Bay Restoration Final Report Date: February 2, 2005

Revision 1.2
19 


\begin{tabular}{|c|c|c|c|c|c|c|c|}
\hline 804 & Tiles $48,49 \& 50$ & 580710.29 & 4158905.01 & 2.93 & 2.87 & $\mid-0.06$ & 0.0036 \\
\hline 806 & Tiles $48,49 \& 50$ & 580698.00 & 4158910.77 & 3.01 & 2.92 & -0.09 & 0.0081 \\
\hline 807 & Tiles $48,49 \& 50$ & 580691.55 & 4158911.37 & 3.02 & 3.00 & -0.02 & 0.0004 \\
\hline 811 & Tiles 48, $49 \& 50$ & 580665.07 & 4158900.98 & 3.02 & 2.98 & -0.04 & 0.0016 \\
\hline 817 & Tiles $48,49 \& 50$ & 580613.06 & 4158871.40 & 3.11 & 3.18 & 0.07 & 0.0049 \\
\hline 818 & Tiles $48,49 \& 50$ & 580603.26 & 4158865.64 & 3.12 & 3.16 & 0.04 & 0.0016 \\
\hline 819 & Tiles $48,49 \& 50$ & 580593.18 & 4158859.74 & 3.12 & 3.16 & 0.04 & 0.0016 \\
\hline 820 & Tiles 48, $49 \& 50$ & 580582.87 & 4158853.79 & 3.13 & 3.17 & 0.04 & 0.0016 \\
\hline 821 & Tiles $48,49 \& 50$ & 580572.36 & 4158847.76 & 3.16 & 3.19 & 0.03 & 0.0009 \\
\hline 822 & Tiles $48,49 \& 50$ & 580561.81 & 4158841.53 & 3.19 & 3.17 & -0.02 & 0.0004 \\
\hline 823 & Tiles $48,49 \& 50$ & 580551.23 & 4158835.25 & 3.17 & 3.21 & 0.04 & 0.0016 \\
\hline 824 & Tiles $48,49 \& 50$ & 580540.60 & 4158828.93 & 3.19 & 3.23 & 0.04 & 0.0016 \\
\hline 825 & Tiles 48, $49 \& 50$ & 580529.92 & 4158822.63 & 3.22 & 3.22 & 0.00 & 0.0000 \\
\hline 827 & Tiles $48,49 \& 50$ & 580508.52 & 4158810.11 & 3.20 & 3.26 & 0.06 & 0.0036 \\
\hline 833 & Tiles $48,49 \& 50$ & 580446.21 & 4158774.12 & 3.16 & 3.19 & 0.03 & 0.0009 \\
\hline 835 & Tiles $48,49 \& 50$ & 580426.09 & 4158762.58 & 3.25 & 3.25 & 0.00 & 0.0000 \\
\hline 838 & Tiles $48,49 \& 50$ & 580396.65 & 4158746.40 & 3.14 & 3.17 & 0.03 & 0.0009 \\
\hline 840 & Tiles $48,49 \& 50$ & 580376.98 & 4158736.97 & 3.03 & 3.03 & 0.00 & 0.0000 \\
\hline 841 & Tiles $48,49 \& 50$ & 580366.86 & 4158732.87 & 3.04 & 3.05 & 0.01 & 0.0001 \\
\hline 842 & Tiles $48,49 \& 50$ & 580356.51 & 4158729.11 & 2.97 & 2.95 & -0.02 & 0.0004 \\
\hline 844 & Tiles $48,49 \& 50$ & 580335.30 & 4158722.30 & 2.88 & 2.86 & -0.02 & 0.0004 \\
\hline 846 & Tiles $48,49 \& 50$ & 580313.75 & 4158715.77 & 2.85 & 2.85 & 0.00 & 0.0000 \\
\hline 848 & Tiles $48,49 \& 50$ & 580291.95 & 4158709.21 & 2.79 & 2.83 & 0.04 & 0.0016 \\
\hline 869 & Tiles 48, $49 \& 50$ & 580063.77 & 4158637.91 & 2.77 & 2.74 & -0.03 & 0.0009 \\
\hline 870 & Tiles 48, $49 \& 50$ & 580053.16 & 4158634.28 & 2.75 & 2.72 & -0.03 & 0.0009 \\
\hline 871 & Tiles 48, 49 \& 50 & 580042.47 & 4158630.77 & 2.67 & 2.63 & $\mid-0.04$ & 0.0016 \\
\hline 872 & Tiles $48,49 \& 50$ & 580031.75 & 4158627.36 & 2.66 & 2.61 & -0.05 & 0.0025 \\
\hline 873 & Tiles $48,49 \& 50$ & 580021.15 & 4158624.07 & 2.67 & 2.71 & 0.04 & 0.0016 \\
\hline 875 & Tiles $48,49 \& 50$ & 580000.55 & 4158617.85 & 2.69 & 2.66 & -0.03 & 0.0009 \\
\hline 882 & Tiles 48, $49 \& 50$ & 579929.45 & 4158596.00 & 2.57 & 2.49 & -0.08 & 0.0064 \\
\hline 884 & Tiles 48, $49 \& 50$ & 579908.60 & 4158589.43 & 2.66 & 2.70 & 0.04 & 0.0016 \\
\hline 885 & Tiles $48,49 \& 50$ & 579897.92 & 4158586.12 & 2.67 & 2.67 & 0.00 & 0.0000 \\
\hline 886 & Tiles $48,49 \& 50$ & 579887.05 & 4158582.91 & 2.65 & 2.63 & -0.02 & 0.0004 \\
\hline 888 & Tiles $48,49 \& 50$ & 579865.30 & 4158576.37 & 2.62 & 2.62 & 0.00 & 0.0000 \\
\hline 892 & Tiles 48, $49 \& 50$ & 579822.94 & 4158563.13 & 2.67 & 2.62 & -0.05 & 0.0025 \\
\hline 896 & Tiles 48, $49 \& 50$ & 579782.34 & 4158550.68 & 2.63 & 2.67 & 0.04 & 0.0016 \\
\hline 897 & Tiles $48,49 \& 50$ & 579772.05 & 4158547.54 & 2.58 & 2.58 & 0.00 & 0.0000 \\
\hline 898 & Tiles $48,49 \& 50$ & 579761.56 & 4158544.41 & 2.49 & 2.46 & -0.03 & 0.0009 \\
\hline 899 & Tiles $48,49 \& 50$ & 579750.96 & 4158541.30 & 2.42 & 2.40 & -0.02 & 0.0004 \\
\hline 916 & Tiles $48,49 \& 50$ & 579561.44 & 4158483.53 & 2.59 & 2.56 & -0.03 & 0.0009 \\
\hline 917 & Tiles $48,49 \& 50$ & 579550.29 & 4158480.15 & 2.57 & 2.61 & 0.04 & 0.0016 \\
\hline 919 & Tiles $48,49 \& 50$ & 579528.13 & 4158473.52 & 2.59 & 2.60 & 0.01 & 0.0001 \\
\hline 931 & Tiles $48,49 \& 50$ & 579398.56 & 4158435.68 & 2.70 & 2.73 & 0.03 & 0.0009 \\
\hline 932 & Tiles 48, $49 \& 50$ & 579387.49 & 4158432.28 & 2.73 & 2.73 & 0.00 & 0.0000 \\
\hline 946 & Tiles 48, $49 \& 50$ & 579234.94 & 4158387.03 & 2.71 & 2.81 & 0.10 & 0.0100 \\
\hline 947 & Tiles 48, $49 \& 50$ & 579224.67 & 4158384.10 & 2.72 & 2.77 & 0.05 & 0.0025 \\
\hline 948 & Tiles 48, $49 \& 50$ & 579214.59 & 4158381.04 & 2.71 & 2.77 & 0.06 & 0.0036 \\
\hline 949 & Tiles $48,49 \& 50$ & 579204.57 & 4158377.92 & 2.69 & 2.73 & 0.04 & 0.0016 \\
\hline
\end{tabular}

South Bay Restoration Final Report Date: February 2, 2005

Revision 1.2 


\begin{tabular}{|c|c|c|c|c|c|c|c|}
\hline 950 & Tiles 48, $49 \& 50$ & 579194.53 & 4158374.93 & 2.73 & 2.82 & $\mid 0.09$ & 0.0081 \\
\hline 952 & Tiles $48,49 \& 50$ & 579174.89 & 4158368.21 & 2.91 & 2.94 & 0.03 & 0.0009 \\
\hline 954 & Tiles $48,49 \& 50$ & 579156.19 & 4158359.89 & 3.12 & 3.12 & 0.00 & 0.0000 \\
\hline 955 & Tiles $48,49 \& 50$ & 579147.07 & 4158355.50 & 3.25 & 3.29 & 0.04 & 0.0016 \\
\hline 956 & Tiles $48,49 \& 50$ & 579137.95 & 4158351.14 & 3.26 & 3.27 & 0.01 & 0.0001 \\
\hline 966 & Tiles $48,49 \& 50$ & 579043.47 & 4158328.67 & 2.84 & 2.85 & 0.01 & 0.0001 \\
\hline 971 & Tiles $48,49 \& 50$ & 579000.81 & 4158313.90 & 2.95 & 2.99 & 0.04 & 0.0016 \\
\hline 973 & Tiles $48,49 \& 50$ & 578984.83 & 4158309.31 & 3.19 & 3.13 & -0.06 & 0.0036 \\
\hline 974 & Tiles $48,49 \& 50$ & 578977.41 & 4158307.20 & 3.36 & 3.36 & 0.00 & 0.0000 \\
\hline 977 & Tiles 48, $49 \& 50$ & 578963.69 & 4158302.72 & 3.91 & 3.92 & 0.01 & 0.0001 \\
\hline 989 & Tiles $48,49 \& 50$ & 578908.21 & 4158306.90 & 5.35 & 5.32 & \begin{tabular}{|l|}
-0.03 \\
\end{tabular} & 0.0009 \\
\hline 990 & Tiles $48,49 \& 50$ & 578899.61 & 4158310.13 & 5.35 & 5.27 & -0.08 & 0.0064 \\
\hline 992 & Tiles $48,49 \& 50$ & 578881.03 & 4158317.04 & 5.30 & 5.20 & -0.10 & 0.0100 \\
\hline 1008 & Tiles $48,49 \& 50$ & 578721.50 & 4158376.94 & 5.49 & 5.46 & -0.03 & 0.0009 \\
\hline 1011 & Tiles $48,49 \& 50$ & 578689.95 & 4158388.41 & 5.25 & 5.30 & 0.05 & 0.0025 \\
\hline 1024 & Tiles $48,49 \& 50$ & 578547.49 & 4158441.20 & 4.75 & 4.70 & -0.05 & 0.0025 \\
\hline 1029 & Tiles $48,49 \& 50$ & 578491.88 & 4158462.02 & 4.86 & 4.88 & 0.02 & 0.0004 \\
\hline 1030 & Tiles $48,49 \& 50$ & 578480.73 & 4158466.44 & 4.93 & 4.88 & -0.05 & 0.0025 \\
\hline 1031 & Tiles $48,49 \& 50$ & 578469.63 & 4158470.93 & 4.98 & 4.96 & -0.02 & 0.0004 \\
\hline 1037 & Tiles $48,49 \& 50$ & 578401.36 & 4158502.50 & 4.86 & 4.69 & \begin{tabular}{|l|}
-0.17 \\
\end{tabular} & 0.0289 \\
\hline 1039 & Tiles $48,49 \& 50$ & 578378.00 & 4158513.61 & 4.93 & 4.80 & -0.13 & 0.0169 \\
\hline 1044 & Tiles $48,49 \& 50$ & 578318.99 & 4158541.85 & 4.66 & 4.66 & 0.00 & 0.0000 \\
\hline 1051 & Tiles $48,49 \& 50$ & 578234.77 & 4158581.99 & 4.64 & 4.61 & -0.03 & 0.0009 \\
\hline 1056 & Tiles 48, $49 \& 50$ & 578177.20 & 4158609.45 & 4.58 & 4.59 & 0.01 & 0.0001 \\
\hline 1057 & Tiles 48, $49 \& 50$ & 578165.89 & 4158614.94 & 4.41 & 4.37 & $\mid-0.04$ & 0.0016 \\
\hline 1062 & Tiles $48,49 \& 50$ & 578109.67 & 4158641.66 & 4.58 & 4.44 & -0.14 & 0.0196 \\
\hline 1064 & Tiles 48, 49 \& 50 & 578087.03 & 4158651.97 & 4.85 & 4.85 & 0.00 & 0.0000 \\
\hline 1066 & Tiles 48, $49 \& 50$ & 578063.64 & 4158661.90 & 4.69 & 4.55 & $\mid-0.14$ & 0.0196 \\
\hline 1078 & Tiles 48, $49 \& 50$ & 577925.11 & 4158706.06 & 4.29 & 4.19 & $\mid-0.10$ & 0.0100 \\
\hline 1082 & Tiles 48, $49 \& 50$ & 577878.97 & 4158715.50 & 4.21 & 4.16 & -0.05 & 0.0025 \\
\hline 1085 & Tiles $48,49 \& 50$ & 577844.43 & 4158721.12 & 4.30 & 4.14 & -0.16 & 0.0256 \\
\hline 1172 & Tiles $48,49 \& 50$ & 577000.78 & 4158355.47 & 3.90 & 3.62 & -0.28 & 0.0784 \\
\hline 1193 & Tiles $48,49 \& 50$ & 576891.01 & 4158184.94 & 3.62 & 3.54 & \begin{tabular}{|l|}
-0.08 \\
\end{tabular} & 0.0064 \\
\hline 1299 & Tiles 48, $49 \& 50$ & 576892.05 & 4158185.96 & 3.60 & 3.49 & $\mid-0.11$ & 0.0121 \\
\hline 1303 & Tiles $48,49 \& 50$ & 576914.31 & 4158221.23 & 3.67 & 3.51 & -0.16 & 0.0256 \\
\hline 1363 & Tiles $48,49 \& 50$ & 577310.03 & 4158626.08 & 4.09 & 4.10 & 0.01 & 0.0001 \\
\hline 1372 & Tiles $48,49 \& 50$ & 577393.41 & 4158665.07 & 4.22 & 4.22 & 0.00 & 0.0000 \\
\hline 1375 & Tiles 48, $49 \& 50$ & 577423.42 & 4158676.35 & 4.25 & 4.27 & 0.02 & 0.0004 \\
\hline 1412 & Tiles 48, $49 \& 50$ & 577800.39 & 4158725.88 & 4.31 & 4.28 & $\mid-0.03$ & 0.0009 \\
\hline 1417 & Tiles 48, $49 \& 50$ & 577851.65 & 4158720.07 & 4.39 & 4.37 & -0.02 & 0.0004 \\
\hline 1418 & Tiles 48, $49 \& 50$ & 577861.84 & 4158718.42 & 4.33 & 4.07 & -0.26 & 0.0676 \\
\hline 1420 & Tiles 48, $49 \& 50$ & 577882.71 & 4158714.81 & 4.24 & 4.23 & $\mid-0.01$ & 0.0001 \\
\hline 1424 & Tiles 48, $49 \& 50$ & 577924.55 & 4158705.96 & 4.27 & 4.10 & -0.17 & 0.0289 \\
\hline 1427 & Tiles 48, $49 \& 50$ & 577953.82 & 4158698.65 & 4.42 & 4.43 & 0.01 & 0.0001 \\
\hline 1435 & Tiles $48,49 \& 50$ & 578033.07 & 4158673.28 & 4.56 & 4.58 & 0.02 & 0.0004 \\
\hline 1437 & Tiles $48,49 \& 50$ & 578053.87 & 4158665.31 & 4.60 & 4.48 & -0.12 & 0.0144 \\
\hline 1443 & Tiles $48,49 \& 50$ & 578115.10 & 4158638.65 & 4.54 & 4.34 & -0.20 & 0.0400 \\
\hline 1444 & Tiles $48,49 \& 50$ & 578125.11 & 4158633.84 & 4.45 & 4.34 & $\mid-0.11$ & 0.0121 \\
\hline
\end{tabular}

South Bay Restoration Final Report Date: February 2, 2005

Revision 1.2 


\begin{tabular}{|c|c|c|c|c|c|c|c|}
\hline 1448 & Tiles 48, $49 \& 50$ & 578164.79 & 4158615.43 & 4.39 & 4.33 & $\mid-0.06$ & 0.0036 \\
\hline 1451 & Tiles $48,49 \& 50$ & 578194.31 & 4158601.11 & 4.62 & 4.52 & -0.10 & 0.0100 \\
\hline 1452 & Tiles $48,49 \& 50$ & 578204.24 & 4158596.45 & 4.66 & 4.48 & -0.18 & 0.0324 \\
\hline 1453 & Tiles 48, $49 \& 50$ & 578214.13 & 4158591.61 & 4.71 & 4.66 & -0.05 & 0.0025 \\
\hline 1455 & Tiles $48,49 \& 50$ & 578234.34 & 4158582.02 & 4.64 & 4.63 & -0.01 & 0.0001 \\
\hline 1457 & Tiles $48,49 \& 50$ & 578254.66 & 4158572.44 & 4.59 & 4.51 & -0.08 & 0.0064 \\
\hline 1458 & Tiles $48,49 \& 50$ & 578264.80 & 4158567.66 & 4.62 & 4.49 & -0.13 & 0.0169 \\
\hline 1469 & Tiles 48, $49 \& 50$ & 578370.39 & 4158516.91 & 4.96 & 4.92 & -0.04 & 0.0016 \\
\hline 1471 & Tiles $48,49 \& 50$ & 578389.41 & 4158507.91 & 4.89 & 4.80 & -0.09 & 0.0081 \\
\hline 1474 & Tiles $48,49 \& 50$ & 578419.38 & 4158493.44 & 4.94 & 4.90 & -0.04 & 0.0016 \\
\hline 1480 & Tiles $48,49 \& 50$ & 578480.81 & 4158466.27 & 4.92 & 4.90 & -0.02 & 0.0004 \\
\hline 1481 & Tiles $48,49 \& 50$ & 578491.14 & 4158462.15 & 4.86 & 4.86 & 0.00 & 0.0000 \\
\hline 1482 & Tiles 48, $49 \& 50$ & 578501.51 & 4158458.21 & 4.90 & 4.85 & -0.05 & 0.0025 \\
\hline 1484 & Tiles $48,49 \& 50$ & 578522.21 & 4158450.43 & 4.83 & 4.88 & 0.05 & 0.0025 \\
\hline 1486 & Tiles $48,49 \& 50$ & 578542.85 & 4158442.78 & 4.70 & 4.68 & -0.02 & 0.0004 \\
\hline 1500 & Tiles $48,49 \& 50$ & 578680.79 & 4158391.30 & 5.22 & 5.16 & -0.06 & 0.0036 \\
\hline 1501 & Tiles $48,49 \& 50$ & 578689.83 & 4158387.96 & 5.25 & 5.27 & 0.02 & 0.0004 \\
\hline 1503 & Tiles $48,49 \& 50$ & 578707.18 & 4158381.57 & 5.44 & 5.40 & -0.04 & 0.0016 \\
\hline 1512 & Tiles $48,49 \& 50$ & 578779.26 & 4158354.22 & 5.19 & 5.19 & 0.00 & 0.0000 \\
\hline 1522 & Tiles $48,49 \& 50$ & 578859.65 & 4158324.85 & 5.16 & 5.15 & -0.01 & 0.0001 \\
\hline 1524 & Tiles $48,49 \& 50$ & 578876.91 & 4158318.60 & 5.26 & 5.28 & 0.02 & 0.0004 \\
\hline 1528 & Tiles $48,49 \& 50$ & 578911.21 & 4158305.91 & 5.36 & 5.30 & -0.06 & 0.0036 \\
\hline 1530 & Tiles $48,49 \& 50$ & 578925.60 & 4158300.28 & 5.38 & 5.38 & 0.00 & 0.0000 \\
\hline 1534 & Tiles 48, $49 \& 50$ & 578947.66 & 4158297.57 & 4.78 & 4.71 & -0.07 & 0.0049 \\
\hline 1536 & Tiles $48,49 \& 50$ & 578957.21 & 4158300.27 & 4.20 & 4.18 & -0.02 & 0.0004 \\
\hline 1538 & Tiles $48,49 \& 50$ & 578963.49 & 4158302.39 & 3.96 & 3.94 & -0.02 & 0.0004 \\
\hline 1542 & Tiles 48, $49 \& 50$ & 578976.26 & 4158306.79 & 3.37 & 3.40 & 0.03 & 0.0009 \\
\hline 1546 & Tiles $48,49 \& 50$ & 578999.09 & 4158313.94 & 2.97 & 2.96 & -0.01 & 0.0001 \\
\hline 1548 & Tiles $48,49 \& 50$ & 579013.19 & 4158318.52 & 2.93 & 2.95 & 0.02 & 0.0004 \\
\hline 1552 & Tiles $48,49 \& 50$ & 579041.10 & 4158328.25 & 2.85 & 2.85 & 0.00 & 0.0000 \\
\hline 1553 & Tiles 48, $49 \& 50$ & 579047.97 & 4158330.28 & 2.83 & 2.95 & 0.12 & 0.0144 \\
\hline 1560 & Tiles $48,49 \& 50$ & 579082.94 & 4158336.62 & 3.02 & 3.08 & 0.06 & 0.0036 \\
\hline 2443 & Tiles $79,80 \& 81$ & 583035.95 & 4152883.72 & 8.30 & 8.18 & -0.12 & 0.0144 \\
\hline 2446 & Tiles $79,80 \& 81$ & 583006.39 & 4152880.28 & 8.09 & 8.04 & -0.05 & 0.0025 \\
\hline 2447 & Tiles $79,80 \& 81$ & 582996.56 & 4152878.23 & 7.87 & 7.79 & -0.08 & 0.0064 \\
\hline 2449 & Tiles $79,80 \& 81$ & 582977.31 & 4152872.41 & 7.40 & 7.36 & -0.04 & 0.0016 \\
\hline 2451 & Tiles $79,80 \& 81$ & 582958.66 & 4152865.48 & 7.09 & 7.02 & -0.07 & 0.0049 \\
\hline 2452 & Tiles $79,80 \& 81$ & 582949.54 & 4152861.85 & 6.86 & 6.77 & -0.09 & 0.0081 \\
\hline 2453 & Tiles $79,80 \& 81$ & 582940.44 & 4152858.39 & 6.64 & 6.53 & -0.11 & 0.0121 \\
\hline 2456 & Tiles $79,80 \& 81$ & 582913.68 & 4152848.64 & 6.17 & 6.07 & -0.10 & 0.0100 \\
\hline 2458 & Tiles $79,80 \& 81$ & 582895.97 & 4152842.35 & 5.64 & 5.57 & -0.07 & 0.0049 \\
\hline 2459 & Tiles $79,80 \& 81$ & 582887.11 & 4152839.19 & 5.51 & 5.41 & -0.10 & 0.0100 \\
\hline 2463 & Tiles $79,80 \& 81$ & 582852.50 & 4152826.13 & 5.19 & 5.01 & -0.18 & 0.0324 \\
\hline 2465 & Tiles $79,80 \& 81$ & 582835.46 & 4152819.36 & 5.30 & 5.18 & -0.12 & 0.0144 \\
\hline 2466 & Tiles $79,80 \& 81$ & 582826.92 & 4152815.98 & 5.35 & 5.31 & -0.04 & 0.0016 \\
\hline 2467 & Tiles $79,80 \& 81$ & 582818.32 & 4152812.45 & 5.34 & 5.34 & 0.00 & 0.0000 \\
\hline 2469 & Tiles $79,80 \& 81$ & 582801.15 & 4152804.98 & 5.27 & 5.25 & -0.02 & 0.0004 \\
\hline 2470 & Tiles $79,80 \& 81$ & 582792.58 & 4152801.11 & 5.26 & 5.25 & -0.01 & 0.0001 \\
\hline
\end{tabular}

South Bay Restoration Final Report Date: February 2, 2005

Revision 1.2
22

25216 Grogans Park Drive The Woodlands, TX 77380 Phone: (218) $364-4080$ Fax: (218) 296- 0869 


\begin{tabular}{|c|c|c|c|c|c|c|c|}
\hline 2471 & Tiles $79,80 \& 81$ & 582783.90 & 4152797.14 & 5.38 & 5.33 & $|-0.05|$ & 0.0025 \\
\hline 2473 & Tiles $79,80 \& 81$ & 582766.24 & 4152789.25 & 5.67 & 5.64 & -0.03 & 0.0009 \\
\hline 2474 & Tiles $79,80 \& 81$ & 582757.15 & 4152785.33 & 5.61 & 5.51 & -0.10 & 0.0100 \\
\hline 2475 & Tiles $79,80 \& 81$ & 582748.01 & 4152781.33 & 5.53 & 5.41 & -0.12 & 0.0144 \\
\hline 2484 & Tiles $79,80 \& 81$ & 582665.21 & 4152746.56 & 5.27 & 5.09 & -0.18 & 0.0324 \\
\hline 2485 & Tiles $79,80 \& 81$ & 582656.39 & 4152742.91 & 5.37 & 5.15 & -0.22 & 0.0484 \\
\hline 2486 & Tiles $79,80 \& 81$ & 582647.79 & 4152739.29 & 5.32 & 5.25 & -0.07 & 0.0049 \\
\hline 2487 & Tiles $79,80 \& 81$ & 582639.29 & 4152735.73 & 5.29 & 5.26 & -0.03 & 0.0009 \\
\hline 2488 & Tiles $79,80 \& 81$ & 582630.96 & 4152732.08 & 5.29 & 5.08 & -0.21 & 0.0441 \\
\hline 2489 & Tiles $79,80 \& 81$ & 582622.78 & 4152728.19 & 5.38 & 5.26 & -0.12 & 0.0144 \\
\hline 2490 & Tiles $79,80 \& 81$ & 582614.62 & 4152724.36 & 5.33 & 5.34 & 0.01 & 0.0001 \\
\hline 2492 & Tiles $79,80 \& 81$ & 582597.81 & 4152716.83 & 5.11 & 4.96 & -0.15 & 0.0225 \\
\hline 2495 & Tiles $79,80 \& 81$ & 582571.52 & 4152705.70 & 5.03 & 4.92 & -0.11 & 0.0121 \\
\hline 2508 & Tiles $79,80 \& 81$ & 582459.53 & 4152659.78 & 3.79 & 3.81 & 0.02 & 0.0004 \\
\hline 2509 & Tiles $79,80 \& 81$ & 582451.41 & 4152657.35 & 3.62 & 3.59 & -0.03 & 0.0009 \\
\hline 2510 & Tiles $79,80 \& 81$ & 582443.36 & 4152654.78 & 3.56 & 3.54 & -0.02 & 0.0004 \\
\hline 2511 & Tiles $79,80 \& 81$ & 582435.33 & 4152651.97 & 3.53 & 3.48 & -0.05 & 0.0025 \\
\hline 2512 & Tiles $79,80 \& 81$ & 582427.15 & 4152648.96 & 3.48 & 3.49 & 0.01 & 0.0001 \\
\hline 2514 & Tiles $79,80 \& 81$ & 582410.73 & 4152642.41 & 3.38 & 3.31 & -0.07 & 0.0049 \\
\hline 2515 & Tiles $79,80 \& 81$ & 582402.57 & 4152638.96 & 3.42 & 3.36 & -0.06 & 0.0036 \\
\hline 2516 & Tiles $79,80 \& 81$ & 582394.42 & 4152635.44 & 3.43 & 3.42 & -0.01 & 0.0001 \\
\hline 2517 & Tiles $79,80 \& 81$ & 582386.33 & 4152631.89 & 3.47 & 3.43 & -0.04 & 0.0016 \\
\hline 2518 & Tiles $79,80 \& 81$ & 582378.32 & 4152628.33 & 3.53 & 3.49 & -0.04 & 0.0016 \\
\hline 2521 & Tiles $79,80 \& 81$ & 582354.58 & 4152617.35 & 3.62 & 3.68 & 0.06 & 0.0036 \\
\hline 2525 & Tiles $79,80 \& 81$ & 582323.17 & 4152603.84 & 4.11 & 4.18 & 0.07 & 0.0049 \\
\hline 2526 & Tiles 79, 80 \& 81 & 582315.47 & 4152600.41 & 4.08 & 3.96 & $\mid-0.12$ & 0.0144 \\
\hline 2527 & Tiles 79,80 \& 81 & 582307.81 & 4152596.89 & 3.95 & 3.94 & $\mid-0.01$ & 0.0001 \\
\hline 2528 & Tiles $79,80 \& 81$ & 582300.01 & 4152593.47 & 3.87 & 3.90 & 0.03 & 0.0009 \\
\hline 2531 & Tiles 79, 80 \& 81 & 582276.39 & 4152583.72 & 3.75 & 3.73 & $\mid-0.02$ & 0.0004 \\
\hline 2533 & Tiles $79,80 \& 81$ & 582260.56 & 4152576.99 & 3.64 & 3.64 & 0.00 & 0.0000 \\
\hline 2534 & Tiles 79, $80 \& 81$ & 582252.66 & 4152573.65 & 3.63 & 3.54 & -0.09 & 0.0081 \\
\hline 2535 & Tiles $79,80 \& 81$ & 582244.93 & 4152570.23 & 3.59 & 3.58 & -0.01 & 0.0001 \\
\hline 2536 & Tiles $79,80 \& 81$ & 582237.32 & 4152566.81 & 3.60 & 3.58 & -0.02 & 0.0004 \\
\hline 2537 & Tiles $79,80 \& 81$ & 582229.70 & 4152563.45 & 3.59 & 3.67 & 0.08 & 0.0064 \\
\hline 2538 & Tiles $79,80 \& 81$ & 582221.93 & 4152560.14 & 3.50 & 3.41 & -0.09 & 0.0081 \\
\hline 2539 & Tiles $79,80 \& 81$ & 582214.07 & 4152556.78 & 3.44 & 3.39 & -0.05 & 0.0025 \\
\hline 2540 & Tiles $79,80 \& 81$ & 582206.15 & 4152553.38 & 3.44 & 3.50 & 0.06 & 0.0036 \\
\hline 2541 & Tiles $79,80 \& 81$ & 582198.08 & 4152549.87 & 3.50 & 3.44 & -0.06 & 0.0036 \\
\hline 2544 & Tiles $79,80 \& 81$ & 582174.14 & 4152538.98 & 3.72 & 3.66 & -0.06 & 0.0036 \\
\hline 2548 & Tiles $79,80 \& 81$ & 582141.81 & 4152525.23 & 3.75 & 3.72 & -0.03 & 0.0009 \\
\hline 2549 & Tiles $79,80 \& 81$ & 582133.84 & 4152521.69 & 3.79 & 3.68 & -0.11 & 0.0121 \\
\hline 2550 & Tiles $79,80 \& 81$ & 582125.79 & 4152518.29 & 3.79 & 3.77 & -0.02 & 0.0004 \\
\hline 2552 & Tiles $79,80 \& 81$ & 582109.59 & 4152511.19 & 3.64 & 3.62 & -0.02 & 0.0004 \\
\hline 2554 & Tiles $79,80 \& 81$ & 582093.53 & 4152504.01 & 3.65 & 3.63 & -0.02 & 0.0004 \\
\hline 2555 & Tiles $79,80 \& 81$ & 582085.51 & 4152500.41 & 3.62 & 3.52 & -0.10 & 0.0100 \\
\hline 2558 & Tiles $79,80 \& 81$ & 582060.78 & 4152489.37 & 3.79 & 3.77 & $\mid-0.02$ & 0.0004 \\
\hline 2559 & Tiles $79,80 \& 81$ & 582052.31 & 4152485.68 & 3.83 & 3.80 & -0.03 & 0.0009 \\
\hline 2560 & Tiles $79,80 \& 81$ & 582043.68 & 4152482.05 & 3.81 & 3.81 & 0.00 & 0.0000 \\
\hline
\end{tabular}

South Bay Restoration Final Report Date: February 2, 2005

Revision 1.2 


\begin{tabular}{|c|c|c|c|c|c|c|c|}
\hline 2561 & Tiles $79,80 \& 81$ & 582034.93 & 4152478.31 & 3.79 & 3.77 & $\mid-0.02$ & 0.0004 \\
\hline 2562 & Tiles 79, $80 \& 81$ & 582026.04 & 4152474.57 & 3.82 & 3.82 & 0.00 & 0.0000 \\
\hline 2565 & Tiles $79,80 \& 81$ & 581999.46 & 4152463.27 & 3.90 & 3.88 & -0.02 & 0.0004 \\
\hline 2567 & Tiles $79,80 \& 81$ & 581982.21 & 4152455.49 & 3.87 & 3.85 & -0.02 & 0.0004 \\
\hline 2570 & Tiles $79,80 \& 81$ & 581956.15 & 4152443.96 & 3.93 & 3.84 & -0.09 & 0.0081 \\
\hline 2573 & Tiles $79,80 \& 81$ & 581929.12 & 4152432.25 & 3.66 & 3.64 & -0.02 & 0.0004 \\
\hline 2574 & Tiles $79,80 \& 81$ & 581919.95 & 4152428.30 & 3.67 & 3.70 & 0.03 & 0.0009 \\
\hline 2575 & Tiles $79,80 \& 81$ & 581910.82 & 4152424.17 & 3.72 & 3.74 & 0.02 & 0.0004 \\
\hline 2576 & Tiles $79,80 \& 81$ & 581901.78 & 4152420.03 & 3.78 & 3.79 & 0.01 & 0.0001 \\
\hline 2580 & Tiles $79,80 \& 81$ & 581865.78 & 4152403.38 & 3.58 & 3.63 & 0.05 & 0.0025 \\
\hline 2581 & Tiles $79,80 \& 81$ & 581856.53 & 4152399.39 & 3.69 & 3.72 & 0.03 & 0.0009 \\
\hline 2585 & Tiles $79,80 \& 81$ & 581820.29 & 4152383.03 & 3.72 & 3.67 & -0.05 & 0.0025 \\
\hline 2588 & Tiles $79,80 \& 81$ & 581791.99 & 4152369.40 & 3.62 & 3.58 & -0.04 & 0.0016 \\
\hline 2589 & Tiles $79,80 \& 81$ & 581782.40 & 4152364.76 & 3.57 & 3.60 & 0.03 & 0.0009 \\
\hline 2590 & Tiles $79,80 \& 81$ & 581772.95 & 4152359.90 & 3.60 & 3.61 & 0.01 & 0.0001 \\
\hline 2593 & Tiles $79,80 \& 81$ & 581744.51 & 4152344.61 & 3.67 & 3.67 & 0.00 & 0.0000 \\
\hline 2594 & Tiles $79,80 \& 81$ & 581735.08 & 4152339.43 & 3.66 & 3.69 & 0.03 & 0.0009 \\
\hline 2595 & Tiles $79,80 \& 81$ & 581725.73 & 4152334.30 & 3.71 & 3.72 & 0.01 & 0.0001 \\
\hline 2596 & Tiles $79,80 \& 81$ & 581716.61 & 4152329.01 & 3.72 & 3.73 & 0.01 & 0.0001 \\
\hline 2597 & Tiles $79,80 \& 81$ & 581707.50 & 4152323.65 & 3.72 & 3.77 & 0.05 & 0.0025 \\
\hline 2598 & Tiles $79,80 \& 81$ & 581698.24 & 4152318.32 & 3.76 & 3.79 & 0.03 & 0.0009 \\
\hline 2599 & Tiles $79,80 \& 81$ & 581688.79 & 4152313.04 & 3.77 & 3.80 & 0.03 & 0.0009 \\
\hline 2601 & Tiles $79,80 \& 81$ & 581669.58 & 4152302.70 & 3.78 & 3.90 & 0.12 & 0.0144 \\
\hline 2606 & Tiles $79,80 \& 81$ & 581622.38 & 4152277.64 & 3.59 & 3.68 & 0.09 & 0.0081 \\
\hline 2610 & Tiles $79,80 \& 81$ & 581584.83 & 4152257.82 & 3.32 & 3.31 & -0.01 & 0.0001 \\
\hline 2611 & Tiles $79,80 \& 81$ & 581575.74 & 4152252.44 & 3.37 & 3.45 & 0.08 & 0.0064 \\
\hline 2686 & Tiles $79,80 \& 81$ & 581610.14 & 4152271.28 & 3.49 & 3.54 & 0.05 & 0.0025 \\
\hline 2690 & Tiles $79,80 \& 81$ & 581640.16 & 4152287.03 & 3.71 & 3.73 & 0.02 & 0.0004 \\
\hline 2694 & Tiles $79,80 \& 81$ & 581670.74 & 4152303.20 & 3.78 & 3.87 & 0.09 & 0.0081 \\
\hline 2697 & Tiles $79,80 \& 81$ & 581694.12 & 4152316.00 & 3.77 & 3.81 & 0.04 & 0.0016 \\
\hline 2698 & Tiles $79,80 \& 81$ & 581702.00 & 4152320.44 & 3.73 & 3.79 & 0.06 & 0.0036 \\
\hline 2699 & Tiles $79,80 \& 81$ & 581709.91 & 4152325.00 & 3.71 & 3.77 & 0.06 & 0.0036 \\
\hline 2700 & Tiles $79,80 \& 81$ & 581717.85 & 4152329.56 & 3.71 & 3.68 & -0.03 & 0.0009 \\
\hline 2701 & Tiles $79,80 \& 81$ & 581725.88 & 4152334.13 & 3.70 & 3.73 & 0.03 & 0.0009 \\
\hline 2702 & Tiles 79,80 \& 81 & 581734.06 & 4152338.75 & 3.67 & 3.75 & 0.08 & 0.0064 \\
\hline 2705 & Tiles $79,80 \& 81$ & 581759.49 & 4152352.62 & 3.60 & 3.58 & -0.02 & 0.0004 \\
\hline 2707 & Tiles $79,80 \& 81$ & 581776.82 & 4152361.75 & 3.59 & 3.58 & -0.01 & 0.0001 \\
\hline 2708 & Tiles $79,80 \& 81$ & 581785.65 & 4152366.18 & 3.57 & 3.63 & 0.06 & 0.0036 \\
\hline 2709 & Tiles $79,80 \& 81$ & 581794.55 & 4152370.56 & 3.64 & 3.60 & -0.04 & 0.0016 \\
\hline 2710 & Tiles $79,80 \& 81$ & 581803.48 & 4152374.92 & 3.68 & 3.73 & 0.05 & 0.0025 \\
\hline 2712 & Tiles $79,80 \& 81$ & 581821.53 & 4152383.52 & 3.72 & 3.73 & 0.01 & 0.0001 \\
\hline 2717 & Tiles $79,80 \& 81$ & 581866.66 & 4152403.94 & 3.57 & 3.58 & 0.01 & 0.0001 \\
\hline 2718 & Tiles $79,80 \& 81$ & 581875.56 & 4152407.85 & 3.54 & 3.54 & 0.00 & 0.0000 \\
\hline 2721 & Tiles $79,80 \& 81$ & 581901.93 & 4152420.02 & 3.79 & 3.79 & 0.00 & 0.0000 \\
\hline 2722 & Tiles 79,80 \& 81 & 581910.85 & 4152424.15 & 3.72 & 3.74 & 0.02 & 0.0004 \\
\hline 2723 & Tiles $79,80 \& 81$ & 581919.77 & 4152428.23 & 3.67 & 3.69 & 0.02 & 0.0004 \\
\hline 2724 & Tiles $79,80 \& 81$ & 581928.74 & 4152432.17 & 3.65 & 3.63 & -0.02 & 0.0004 \\
\hline 2730 & Tiles $79,80 \& 81$ & 581982.28 & 4152455.48 & 3.88 & 3.86 & $\mid-0.02$ & 0.0004 \\
\hline
\end{tabular}

South Bay Restoration Final Report Date: February 2, 2005

Revision 1.2 


\begin{tabular}{|c|c|c|c|c|c|c|c|}
\hline 2732 & Tiles $79,80 \& 81$ & 582000.18 & 4152463.46 & 3.90 & 3.82 & -0.08 & 0.0064 \\
\hline 2733 & Tiles 79, $80 \& 81$ & 582009.07 & 4152467.33 & 3.89 & 3.87 & -0.02 & 0.0004 \\
\hline 2735 & Tiles $79,80 \& 81$ & 582026.93 & 4152474.97 & 3.81 & 3.84 & 0.03 & 0.0009 \\
\hline 2737 & Tiles $79,80 \& 81$ & 582045.01 & 4152482.59 & 3.80 & 3.78 & -0.02 & 0.0004 \\
\hline 2739 & Tiles $79,80 \& 81$ & 582063.38 & 4152490.60 & 3.77 & 3.83 & 0.06 & 0.0036 \\
\hline 2740 & Tiles $79,80 \& 81$ & 582072.48 & 4152494.60 & 3.67 & 3.72 & 0.05 & 0.0025 \\
\hline 2741 & Tiles $79,80 \& 81$ & 582081.53 & 4152498.62 & 3.61 & 3.61 & 0.00 & 0.0000 \\
\hline 2742 & Tiles $79,80 \& 81$ & 582090.47 & 4152502.66 & 3.64 & 3.65 & 0.01 & 0.0001 \\
\hline 2744 & Tiles $79,80 \& 81$ & 582108.27 & 4152510.52 & 3.62 & 3.60 & -0.02 & 0.0004 \\
\hline 2745 & Tiles $79,80 \& 81$ & 582117.03 & 4152514.44 & 3.69 & 3.73 & 0.04 & 0.0016 \\
\hline 2746 & Tiles $79,80 \& 81$ & 582125.67 & 4152518.22 & 3.78 & 3.79 & 0.01 & 0.0001 \\
\hline 2747 & Tiles $79,80 \& 81$ & 582134.25 & 4152521.90 & 3.78 & 3.74 & $\mid-0.04$ & 0.0016 \\
\hline 2749 & Tiles $79,80 \& 81$ & 582151.34 & 4152529.16 & 3.73 & 3.75 & 0.02 & 0.0004 \\
\hline 2750 & Tiles $79,80 \& 81$ & 582159.83 & 4152532.74 & 3.75 & 3.79 & 0.04 & 0.0016 \\
\hline 2752 & Tiles $79,80 \& 81$ & 582176.65 & 4152540.09 & 3.70 & 3.73 & 0.03 & 0.0009 \\
\hline 2754 & Tiles $79,80 \& 81$ & 582193.37 & 4152547.50 & 3.58 & 3.56 & -0.02 & 0.0004 \\
\hline 2755 & Tiles $79,80 \& 81$ & 582201.58 & 4152551.28 & 3.47 & 3.49 & 0.02 & 0.0004 \\
\hline 2756 & Tiles $79,80 \& 81$ & 582209.77 & 4152554.95 & 3.41 & 3.47 & 0.06 & 0.0036 \\
\hline 2758 & Tiles $79,80 \& 81$ & 582225.95 & 4152561.96 & 3.53 & 3.52 & -0.01 & 0.0001 \\
\hline 2759 & Tiles $79,80 \& 81$ & 582233.96 & 4152565.30 & 3.60 & 3.62 & 0.02 & 0.0004 \\
\hline 2760 & Tiles $79,80 \& 81$ & 582241.97 & 4152568.75 & 3.60 & 3.61 & 0.01 & 0.0001 \\
\hline 2761 & Tiles $79,80 \& 81$ & 582249.86 & 4152572.34 & 3.60 & 3.59 & -0.01 & 0.0001 \\
\hline 2762 & Tiles $79,80 \& 81$ & 582257.67 & 4152575.74 & 3.64 & 3.63 & -0.01 & 0.0001 \\
\hline 2763 & Tiles $79,80 \& 81$ & 582265.35 & 4152578.96 & 3.69 & 3.72 & 0.03 & 0.0009 \\
\hline 2764 & Tiles $79,80 \& 81$ & 582272.87 & 4152582.15 & 3.71 & 3.71 & 0.00 & 0.0000 \\
\hline 2766 & Tiles $79,80 \& 81$ & 582287.46 & 4152588.23 & 3.86 & 3.89 & 0.03 & 0.0009 \\
\hline 2768 & Tiles $79,80 \& 81$ & 582301.50 & 4152594.04 & 3.87 & 3.90 & 0.03 & 0.0009 \\
\hline 2769 & Tiles $79,80 \& 81$ & 582308.37 & 4152596.99 & 3.96 & 3.94 & -0.02 & 0.0004 \\
\hline 2770 & Tiles $79,80 \& 81$ & 582315.07 & 4152600.04 & 4.07 & 4.10 & 0.03 & 0.0009 \\
\hline 2771 & Tiles $79,80 \& 81$ & 582321.78 & 4152603.04 & 4.14 & 4.18 & 0.04 & 0.0016 \\
\hline 2772 & Tiles $79,80 \& 81$ & 582328.56 & 4152606.06 & 4.07 & 4.11 & 0.04 & 0.0016 \\
\hline 2776 & Tiles $79,80 \& 81$ & 582358.13 & 4152618.96 & 3.58 & 3.67 & 0.09 & 0.0081 \\
\hline 2779 & Tiles $79,80 \& 81$ & 582382.05 & 4152630.17 & 3.48 & 3.43 & -0.05 & 0.0025 \\
\hline 2780 & Tiles $79,80 \& 81$ & 582390.37 & 4152633.91 & 3.42 & 3.42 & 0.00 & 0.0000 \\
\hline 2781 & Tiles 79,80 \& 81 & 582398.73 & 4152637.43 & 3.41 & 3.42 & 0.01 & 0.0001 \\
\hline 2782 & Tiles $79,80 \& 81$ & 582407.10 & 4152640.86 & 3.39 & 3.38 & -0.01 & 0.0001 \\
\hline 2784 & Tiles $79,80 \& 81$ & 582423.76 & 4152647.53 & 3.46 & 3.43 & -0.03 & 0.0009 \\
\hline 2785 & Tiles $79,80 \& 81$ & 582431.88 & 4152650.67 & 3.50 & 3.48 & -0.02 & 0.0004 \\
\hline 2786 & Tiles $79,80 \& 81$ & 582439.98 & 4152653.52 & 3.55 & 3.51 & -0.04 & 0.0016 \\
\hline 2787 & Tiles $79,80 \& 81$ & 582448.07 & 4152656.13 & 3.60 & 3.64 & 0.04 & 0.0016 \\
\hline 2788 & Tiles $79,80 \& 81$ & 582456.09 & 4152658.62 & 3.70 & 3.65 & -0.05 & 0.0025 \\
\hline 2789 & Tiles $79,80 \& 81$ & 582463.91 & 4152661.14 & 4.01 & 3.99 & $\mid-0.02$ & 0.0004 \\
\hline 2808 & Tiles $79,80 \& 81$ & 582621.58 & 4152728.09 & 5.35 & 5.21 & -0.14 & 0.0196 \\
\hline 2809 & Tiles $79,80 \& 81$ & 582629.73 & 4152731.89 & 5.30 & 5.08 & -0.22 & 0.0484 \\
\hline 2810 & Tiles 79,80 \& 81 & 582637.96 & 4152735.57 & 5.29 & 5.17 & -0.12 & 0.0144 \\
\hline 2811 & Tiles $79,80 \& 81$ & 582646.24 & 4152739.08 & 5.30 & 5.25 & -0.05 & 0.0025 \\
\hline 2812 & Tiles $79,80 \& 81$ & 582654.51 & 4152742.56 & 5.36 & 5.16 & -0.20 & 0.0400 \\
\hline 2816 & Tiles $79,80 \& 81$ & 582688.06 & 4152756.42 & 5.37 & 5.21 & $\mid-0.16$ & 0.0256 \\
\hline
\end{tabular}

South Bay Restoration Final Report Date: February 2, 2005

Revision 1.2
25

25216 Grogans Park Drive The Woodlands, TX 77380 Phone: (218) $364-4080$ Fax: (218) 296- 0869 


\begin{tabular}{|c|c|c|c|c|c|c|c|}
\hline 2820 & Tiles $79,80 \& 81$ & 582723.49 & 4152770.75 & 5.21 & 5.18 & $\mid-0.03$ & 0.0009 \\
\hline 2821 & Tiles $79,80 \& 81$ & 582732.49 & 4152774.43 & 5.27 & 5.24 & -0.03 & 0.0009 \\
\hline 2822 & Tiles $79,80 \& 81$ & 582741.36 & 4152778.15 & 5.43 & 5.37 & -0.06 & 0.0036 \\
\hline 2823 & Tiles $79,80 \& 81$ & 582750.13 & 4152781.91 & 5.55 & 5.48 & -0.07 & 0.0049 \\
\hline 2824 & Tiles $79,80 \& 81$ & 582758.92 & 4152785.78 & 5.62 & 5.65 & 0.03 & 0.0009 \\
\hline 2827 & Tiles $79,80 \& 81$ & 582785.56 & 4152797.94 & 5.34 & 5.33 & -0.01 & 0.0001 \\
\hline 2828 & Tiles $79,80 \& 81$ & 582794.73 & 4152802.13 & 5.25 & 5.18 & -0.07 & 0.0049 \\
\hline 2832 & Tiles $79,80 \& 81$ & 582831.82 & 4152817.84 & 5.32 & 5.32 & 0.00 & 0.0000 \\
\hline 2838 & Tiles $79,80 \& 81$ & 582887.30 & 4152839.16 & 5.51 & 5.41 & -0.10 & 0.0100 \\
\hline 2839 & Tiles $79,80 \& 81$ & 582896.66 & 4152842.48 & 5.64 & 5.58 & -0.06 & 0.0036 \\
\hline 2841 & Tiles $79,80 \& 81$ & 582915.06 & 4152849.08 & 6.21 & 6.10 & -0.11 & 0.0121 \\
\hline 2845 & Tiles $79,80 \& 81$ & 582950.63 & 4152862.01 & 6.87 & 6.80 & -0.07 & 0.0049 \\
\hline 2846 & Tiles $79,80 \& 81$ & 582959.26 & 4152865.20 & 7.09 & 7.02 & -0.07 & 0.0049 \\
\hline 2852 & Tiles $79,80 \& 81$ & 583012.89 & 4152881.31 & 8.20 & 8.15 & -0.05 & 0.0025 \\
\hline 2854 & Tiles $79,80 \& 81$ & 583032.02 & 4152883.27 & 8.30 & 8.31 & 0.01 & 0.0001 \\
\hline 2858 & Tiles $79,80 \& 81$ & 583070.54 & 4152887.52 & 8.41 & 8.28 & -0.13 & 0.0169 \\
\hline 2914 & Tiles 79, 80 \& 81 & 583398.35 & 4152894.98 & 5.49 & 5.49 & 0.00 & 0.0000 \\
\hline 2915 & Tiles $79,80 \& 81$ & 583404.98 & 4152894.60 & 5.03 & 5.09 & 0.06 & 0.0036 \\
\hline 2917 & Tiles $79,80 \& 81$ & 583418.79 & 4152894.39 & 4.66 & 4.70 & 0.04 & 0.0016 \\
\hline 2919 & Tiles $79,80 \& 81$ & 583432.69 & 4152895.65 & 4.26 & 4.27 & 0.01 & 0.0001 \\
\hline 2922 & Tiles $79,80 \& 81$ & 583454.05 & 4152902.12 & 3.51 & 3.48 & -0.03 & 0.0009 \\
\hline 2925 & Tiles $79,80 \& 81$ & 583474.51 & 4152913.96 & 3.52 & 3.52 & 0.00 & 0.0000 \\
\hline 2926 & Tiles $79,80 \& 81$ & 583481.08 & 4152918.25 & 3.55 & 3.50 & -0.05 & 0.0025 \\
\hline 2928 & Tiles $79,80 \& 81$ & 583494.31 & 4152927.90 & 3.45 & 3.46 & 0.01 & 0.0001 \\
\hline 2933 & Tiles $79,80 \& 81$ & 583531.98 & 4152950.36 & 3.45 & 3.49 & 0.04 & 0.0016 \\
\hline 2936 & Tiles 79, 80 \& 81 & 583556.92 & 4152961.49 & 3.33 & 3.42 & 0.09 & 0.0081 \\
\hline 2939 & Tiles 79,80 \& 81 & 583581.65 & 4152974.85 & 3.26 & 3.28 & 0.02 & 0.0004 \\
\hline 2940 & Tiles $79,80 \& 81$ & 583589.45 & 4152979.71 & 3.27 & 3.22 & -0.05 & 0.0025 \\
\hline 2942 & Tiles 79, 80 \& 81 & 583604.53 & 4152989.39 & 3.23 & 3.25 & 0.02 & 0.0004 \\
\hline 2947 & Tiles $79,80 \& 81$ & 583637.35 & 4153011.59 & 3.08 & 3.09 & 0.01 & 0.0001 \\
\hline 2948 & Tiles 79, $80 \& 81$ & 583642.08 & 4153015.18 & 3.05 & 2.97 & -0.08 & 0.0064 \\
\hline 2949 & Tiles $79,80 \& 81$ & 583646.92 & 4153017.79 & 3.01 & 3.03 & 0.02 & 0.0004 \\
\hline 2958 & Tiles $79,80 \& 81$ & 583683.15 & 4152978.37 & 3.20 & 3.16 & -0.04 & 0.0016 \\
\hline 2959 & Tiles $79,80 \& 81$ & 583686.93 & 4152969.84 & 3.21 & 3.11 & -0.10 & 0.0100 \\
\hline 2960 & Tiles $79,80 \& 81$ & 583690.82 & 4152961.02 & 3.20 & 3.07 & -0.13 & 0.0169 \\
\hline 2961 & Tiles $79,80 \& 81$ & 583694.78 & 4152951.98 & 3.19 & 3.20 & 0.01 & 0.0001 \\
\hline 2962 & Tiles $79,80 \& 81$ & 583698.78 & 4152942.78 & 3.25 & 3.16 & -0.09 & 0.0081 \\
\hline 2963 & Tiles $79,80 \& 81$ & 583702.83 & 4152933.44 & 3.32 & 3.38 & 0.06 & 0.0036 \\
\hline 2964 & Tiles $79,80 \& 81$ & 583706.76 & 4152923.90 & 3.29 & 3.21 & -0.08 & 0.0064 \\
\hline 2971 & Tiles $79,80 \& 81$ & 583732.92 & 4152857.48 & 3.13 & 3.00 & -0.13 & 0.0169 \\
\hline 2977 & Tiles $79,80 \& 81$ & 583770.54 & 4152806.30 & 3.16 & 3.12 & -0.04 & 0.0016 \\
\hline 2981 & Tiles $79,80 \& 81$ & 583796.18 & 4152770.88 & 2.99 & 2.89 & -0.10 & 0.0100 \\
\hline 2982 & Tiles $79,80 \& 81$ & 583801.44 & 4152761.60 & 2.99 & 2.97 & -0.02 & 0.0004 \\
\hline 2983 & Tiles $79,80 \& 81$ & 583806.16 & 4152752.06 & 3.02 & 2.91 & -0.11 & 0.0121 \\
\hline 2984 & Tiles $79,80 \& 81$ & 583810.18 & 4152742.30 & 3.06 & 3.04 & -0.02 & 0.0004 \\
\hline 2986 & Tiles $79,80 \& 81$ & 583816.41 & 4152722.33 & 3.08 & 3.07 & -0.01 & 0.0001 \\
\hline 2987 & Tiles $79,80 \& 81$ & 583818.77 & 4152712.13 & 3.01 & 3.00 & -0.01 & 0.0001 \\
\hline 3122 & Tiles $79,80 \& 81$ & 583963.75 & 4152345.88 & 3.69 & 3.66 & -0.03 & 0.0009 \\
\hline
\end{tabular}

South Bay Restoration Final Report Date: February 2, 2005

Revision 1.2
26

25216 Grogans Park Drive The Woodlands, TX 77380 Phone: (218) $364-4080$ Fax: (218) 296- 0869 


\begin{tabular}{|c|c|c|c|c|c|c|c|}
\hline 3158 & Tiles $79,80 \& 81$ & 583846.40 & 4152594.10 & 3.02 & 2.93 & $\mid-0.09$ & 0.0081 \\
\hline 3163 & Tiles $79,80 \& 81$ & 583828.36 & 4152644.19 & 3.05 & 2.93 & -0.12 & 0.0144 \\
\hline 3164 & Tiles $79,80 \& 81$ & 583826.15 & 4152655.16 & 3.04 & 3.00 & -0.04 & 0.0016 \\
\hline 3167 & Tiles $79,80 \& 81$ & 583821.91 & 4152688.89 & 3.05 & 3.07 & 0.02 & 0.0004 \\
\hline 3169 & Tiles $79,80 \& 81$ & 583818.71 & 4152711.23 & 3.00 & 3.01 & 0.01 & 0.0001 \\
\hline 3170 & Tiles $79,80 \& 81$ & 583816.38 & 4152722.07 & 3.08 & 3.05 & -0.03 & 0.0009 \\
\hline 3173 & Tiles $79,80 \& 81$ & 583805.92 & 4152752.62 & 3.03 & 2.92 & -0.11 & 0.0121 \\
\hline 3174 & Tiles $79,80 \& 81$ & 583801.11 & 4152762.00 & 3.00 & 2.97 & -0.03 & 0.0009 \\
\hline 3175 & Tiles $79,80 \& 81$ & 583795.69 & 4152771.13 & 2.99 & 2.91 & -0.08 & 0.0064 \\
\hline 3185 & Tiles $79,80 \& 81$ & 583733.46 & 4152857.62 & 3.13 & 3.06 & -0.07 & 0.0049 \\
\hline 3186 & Tiles $79,80 \& 81$ & 583728.79 & 4152866.57 & 3.18 & 3.07 & -0.11 & 0.0121 \\
\hline 3191 & Tiles $79,80 \& 81$ & 583709.89 & 4152916.03 & 3.25 & 3.15 & -0.10 & 0.0100 \\
\hline 3192 & Tiles $79,80 \& 81$ & 583705.74 & 4152926.13 & 3.30 & 3.31 & 0.01 & 0.0001 \\
\hline 3193 & Tiles $79,80 \& 81$ & 583701.49 & 4152936.19 & 3.29 & 3.24 & -0.05 & 0.0025 \\
\hline 3198 & Tiles $79,80 \& 81$ & 583679.26 & 4152985.57 & 3.29 & 3.25 & -0.04 & 0.0016 \\
\hline 3201 & Tiles $79,80 \& 81$ & 583667.85 & 4153009.78 & 3.24 & 3.18 & -0.06 & 0.0036 \\
\hline 3205 & Tiles $79,80 \& 81$ & 583647.34 & 4153018.18 & 3.03 & 3.00 & -0.03 & 0.0009 \\
\hline 3206 & Tiles $79,80 \& 81$ & 583641.89 & 4153015.43 & 3.05 & 2.98 & -0.07 & 0.0049 \\
\hline 3207 & Tiles $79,80 \& 81$ & 583636.23 & 4153011.32 & 3.08 & 3.03 & -0.05 & 0.0025 \\
\hline 3208 & Tiles $79,80 \& 81$ & 583629.97 & 4153006.51 & 3.10 & 3.03 & -0.07 & 0.0049 \\
\hline 3209 & Tiles $79,80 \& 81$ & 583623.03 & 4153001.47 & 3.12 & 3.08 & -0.04 & 0.0016 \\
\hline 3214 & Tiles $79,80 \& 81$ & 583581.11 & 4152974.99 & 3.26 & 3.27 & 0.01 & 0.0001 \\
\hline 3217 & Tiles $79,80 \& 81$ & 583553.83 & 4152960.64 & 3.32 & 3.31 & -0.01 & 0.0001 \\
\hline 3219 & Tiles $79,80 \& 81$ & 583536.17 & 4152952.66 & 3.41 & 3.43 & 0.02 & 0.0004 \\
\hline 3223 & Tiles $79,80 \& 81$ & 583502.79 & 4152934.95 & 3.45 & 3.41 & -0.04 & 0.0016 \\
\hline 3225 & Tiles 79, 80 \& 81 & 583488.59 & 4152924.10 & 3.50 & 3.51 & 0.01 & 0.0001 \\
\hline 3226 & Tiles $79,80 \& 81$ & 583482.98 & 4152917.82 & 3.55 & 3.58 & 0.03 & 0.0009 \\
\hline 3228 & Tiles $79,80 \& 81$ & 583476.63 & 4152903.48 & 3.86 & 3.85 & -0.01 & 0.0001 \\
\hline 3229 & Tiles 79, 80 \& 81 & 583476.20 & 4152895.51 & 4.21 & 4.22 & 0.01 & 0.0001 \\
\hline 3230 & Tiles $79,80 \& 81$ & 583477.46 & 4152887.47 & 4.58 & 4.58 & 0.00 & 0.0000 \\
\hline 3231 & Tiles 79, $80 \& 81$ & 583480.52 & 4152879.44 & 4.96 & 4.89 & -0.07 & 0.0049 \\
\hline 3232 & Tiles $79,80 \& 81$ & 583484.84 & 4152871.48 & 5.27 & 5.18 & -0.09 & 0.0081 \\
\hline 3234 & Tiles $79,80 \& 81$ & 583493.74 & 4152855.77 & 5.81 & 5.86 & 0.05 & 0.0025 \\
\hline 3235 & Tiles $79,80 \& 81$ & 583497.77 & 4152847.87 & 6.06 & 6.07 & 0.01 & 0.0001 \\
\hline 3238 & Tiles $79,80 \& 81$ & 583508.76 & 4152825.73 & 5.61 & 5.59 & -0.02 & 0.0004 \\
\hline 3239 & Tiles $79,80 \& 81$ & 583512.54 & 4152818.76 & 5.03 & 5.06 & 0.03 & 0.0009 \\
\hline 3240 & Tiles $79,80 \& 81$ & 583516.32 & 4152811.59 & 4.68 & 4.65 & -0.03 & 0.0009 \\
\hline 3243 & Tiles $79,80 \& 81$ & 583522.41 & 4152791.37 & 5.98 & 5.89 & -0.09 & 0.0081 \\
\hline 3244 & Tiles $79,80 \& 81$ & 583521.81 & 4152785.12 & 6.58 & 6.54 & -0.04 & 0.0016 \\
\hline 3245 & Tiles $79,80 \& 81$ & 583519.83 & 4152779.34 & 7.00 & 7.04 & 0.04 & 0.0016 \\
\hline 3248 & Tiles $79,80 \& 81$ & 583510.26 & 4152766.66 & 7.37 & 7.35 & -0.02 & 0.0004 \\
\hline 3255 & Tiles $79,80 \& 81$ & 583498.78 & 4152760.92 & 7.08 & 7.06 & -0.02 & 0.0004 \\
\hline 3258 & Tiles $79,80 \& 81$ & 583496.20 & 4152763.16 & 7.05 & 6.98 & -0.07 & 0.0049 \\
\hline 3259 & Tiles $79,80 \& 81$ & 583495.70 & 4152764.70 & 7.01 & 6.96 & -0.05 & 0.0025 \\
\hline 3260 & Tiles $79,80 \& 81$ & 583495.78 & 4152766.25 & 6.95 & 6.90 & -0.05 & 0.0025 \\
\hline 3261 & Tiles $79,80 \& 81$ & 583496.38 & 4152767.68 & 6.90 & 6.89 & -0.01 & 0.0001 \\
\hline 3262 & Tiles $79,80 \& 81$ & 583497.31 & 4152768.81 & 6.92 & 6.85 & -0.07 & 0.0049 \\
\hline 3263 & Tiles $79,80 \& 81$ & 583498.59 & 4152769.60 & 6.95 & 6.91 & $\mid-0.04$ & 0.0016 \\
\hline
\end{tabular}

South Bay Restoration Final Report Date: February 2, 2005

Revision 1.2
27

25216 Grogans Park Drive The Woodlands, TX 77380 Phone: (218) $364-4080$ Fax: (218) 296- 0869 


\begin{tabular}{|c|c|c|c|c|c|c|c|}
\hline 3264 & Tiles $79,80 \& 81$ & 583500.06 & 4152769.84 & 7.02 & 6.99 & $\mid-0.03$ & 0.0009 \\
\hline 3265 & Tiles $79,80 \& 81$ & 583501.87 & 4152769.77 & 7.09 & 7.09 & 0.00 & 0.0000 \\
\hline 3266 & Tiles $79,80 \& 81$ & 583503.93 & 4152769.58 & 7.19 & 7.18 & -0.01 & 0.0001 \\
\hline 3267 & Tiles $79,80 \& 81$ & 583506.16 & 4152769.54 & 7.29 & 7.26 & -0.03 & 0.0009 \\
\hline 3268 & Tiles $79,80 \& 81$ & 583508.50 & 4152769.68 & 7.33 & 7.27 & -0.06 & 0.0036 \\
\hline 3269 & Tiles $79,80 \& 81$ & 583511.10 & 4152770.16 & 7.33 & 7.32 & -0.01 & 0.0001 \\
\hline 3271 & Tiles $79,80 \& 81$ & 583516.70 & 4152773.07 & 7.30 & 7.33 & 0.03 & 0.0009 \\
\hline 3274 & Tiles $79,80 \& 81$ & 583522.59 & 4152784.57 & 6.66 & 6.61 & -0.05 & 0.0025 \\
\hline 3276 & Tiles $79,80 \& 81$ & 583522.48 & 4152796.44 & 5.41 & 5.37 & -0.04 & 0.0016 \\
\hline 3278 & Tiles $79,80 \& 81$ & 583517.78 & 4152809.31 & 4.65 & 4.63 & $\mid-0.02$ & 0.0004 \\
\hline 3280 & Tiles $79,80 \& 81$ & 583511.58 & 4152820.77 & 5.17 & 5.17 & 0.00 & 0.0000 \\
\hline 3281 & Tiles $79,80 \& 81$ & 583508.64 & 4152825.95 & 5.63 & 5.60 & -0.03 & 0.0009 \\
\hline 3282 & Tiles 79,80 \& 81 & 583505.93 & 4152831.16 & 5.99 & 6.05 & 0.06 & 0.0036 \\
\hline 3284 & Tiles $79,80 \& 81$ & 583500.66 & 4152842.67 & 6.19 & 6.17 & -0.02 & 0.0004 \\
\hline 3285 & Tiles $79,80 \& 81$ & 583497.85 & 4152849.18 & 6.06 & 6.02 & -0.04 & 0.0016 \\
\hline 3286 & Tiles $79,80 \& 81$ & 583494.74 & 4152855.89 & 5.85 & 5.79 & -0.06 & 0.0036 \\
\hline 3287 & Tiles $79,80 \& 81$ & 583491.24 & 4152862.46 & 5.63 & 5.51 & -0.12 & 0.0144 \\
\hline 3288 & Tiles $79,80 \& 81$ & 583487.54 & 4152868.63 & 5.41 & 5.44 & 0.03 & 0.0009 \\
\hline 3289 & Tiles $79,80 \& 81$ & 583483.91 & 4152874.47 & 5.18 & 5.17 & -0.01 & 0.0001 \\
\hline 3290 & Tiles $79,80 \& 81$ & 583480.73 & 4152880.25 & 4.93 & 4.91 & -0.02 & 0.0004 \\
\hline 3291 & Tiles $79,80 \& 81$ & 583478.36 & 4152886.18 & 4.68 & 4.63 & -0.05 & 0.0025 \\
\hline 3292 & Tiles $79,80 \& 81$ & 583477.01 & 4152892.00 & 4.38 & 4.37 & -0.01 & 0.0001 \\
\hline 3293 & Tiles $79,80 \& 81$ & 583476.62 & 4152897.61 & 4.14 & 4.09 & -0.05 & 0.0025 \\
\hline 3294 & Tiles $79,80 \& 81$ & 583476.42 & 4152902.38 & 3.91 & 3.94 & 0.03 & 0.0009 \\
\hline 3296 & Tiles $79,80 \& 81$ & 583472.92 & 4152908.55 & 3.73 & 3.75 & 0.02 & 0.0004 \\
\hline 3297 & Tiles $79,80 \& 81$ & 583469.53 & 4152909.53 & 3.49 & 3.44 & -0.05 & 0.0025 \\
\hline 3298 & Tiles $79,80 \& 81$ & 583465.26 & 4152908.63 & 3.42 & 3.40 & -0.02 & 0.0004 \\
\hline 3299 & Tiles $79,80 \& 81$ & 583460.02 & 4152905.96 & 3.46 & 3.42 & -0.04 & 0.0016 \\
\hline 3300 & Tiles $79,80 \& 81$ & 583453.75 & 4152902.71 & 3.50 & 3.51 & 0.01 & 0.0001 \\
\hline 3303 & Tiles $79,80 \& 81$ & 583430.10 & 4152895.77 & 4.34 & 4.42 & 0.08 & 0.0064 \\
\hline
\end{tabular}

\begin{tabular}{|l|l|}
\hline \multicolumn{2}{|l|}{ Statistics (Meters) } \\
\hline Average Dz & -0.0191 \\
\hline Average $(\mathrm{Dz})^{2}$ & 0.0045 \\
\hline Sum of $(\mathrm{Dz})^{2}$ & 2.6936 \\
\hline Standard Deviation & 0.0647 \\
\hline RMSE & 0.0674 \\
\hline NSSDA & 0.1321 \\
\hline
\end{tabular}

South Bay Restoration Final Report Date: February 2, 2005

Revision 1.2 


\title{
Appendix B. Static GPS Statistic al Comparisons
}

\author{
Project 2206, South San Francisco Bay \\ GPS / LiDAR Comparisons
}

\section{Static GPS Checks}

Comparisons constrained to a maximum triangle length of 3 metres and maximum slope of 60 degrees

\section{Section 1 of 5}

\begin{tabular}{|r|r|r|r|r|r|r|c|}
\hline Point Number & Location Description & Easting & Northing & Known Z & Laser Z & Dz & $(\mathrm{Dz})^{2}$ \\
\hline 1 & Tile 88 & 574824 & 4150721 & 1.98 & 2.16 & 0.18 & 0.0324 \\
\hline 2 & Tile 88 & 574788.9 & 4150726 & 1.92 & 2.17 & 0.25 & 0.0625 \\
\hline 3 & Tile 88 & 574759.7 & 4150731 & 1.99 & 2.22 & 0.23 & 0.0529 \\
\hline 4 & Tile 88 & 574730.5 & 4150736 & 2.03 & 2.17 & 0.14 & 0.0196 \\
\hline 5 & Tile 88 & 574688.9 & 4150743 & 2.05 & 2.35 & 0.30 & 0.0900 \\
\hline 6 & Tile 88 & 574660.8 & 4150747 & 1.95 & 2.25 & 0.30 & 0.0900 \\
\hline 7 & Tile 88 & 574621.2 & 4150754 & 2.01 & 2.21 & 0.20 & 0.0400 \\
\hline 8 & Tile 88 & 574591.6 & 4150758 & 2 & 2.26 & 0.26 & 0.0676 \\
\hline 9 & Tile 88 & 574548.8 & 4150765 & 1.89 & 2 & 0.11 & 0.0121 \\
\hline 10 & Tile 88 & 574547.3 & 4150769 & 1.69 & 1.63 & -0.06 & 0.0036 \\
\hline 11 & Tile 88 & 574547.4 & 4150770 & 1.75 & 1.86 & 0.11 & 0.0121 \\
\hline 12 & Tile 88 & 574570.2 & 4150764 & 1.89 & 2.18 & 0.29 & 0.0841 \\
\hline 13 & Tile 88 & 574607.5 & 4150758 & 2.03 & 2.27 & 0.24 & 0.0576 \\
\hline 14 & Tile 88 & 574642.7 & 4150752 & 2.1 & 2.21 & 0.11 & 0.0121 \\
\hline 15 & Tile 88 & 574689.4 & 4150744 & 2.1 & 2.33 & 0.23 & 0.0529 \\
\hline 16 & Tile 88 & 574730.1 & 4150737 & 2.03 & 2.25 & 0.22 & 0.0484 \\
\hline 17 & Tile 88 & 574761.1 & 4150733 & 1.98 & 2.2 & 0.22 & 0.0484 \\
\hline 19 & Tile 88 & 574809.7 & 4150725 & 2.05 & 2.16 & 0.11 & 0.0121 \\
\hline 20 & Tile 88 & 574830.1 & 4150720 & 3.04 & 3.16 & 0.12 & 0.0144 \\
\hline 21 & Tile 88 & 574537.3 & 4150768 & 0.36 & 0.39 & 0.03 & 0.0009 \\
\hline 22 & Tile 88 & 574534 & 4150768 & 0.28 & 0.37 & 0.09 & 0.0081 \\
\hline 23 & Tile 88 & 574534 & 4150768 & 0.29 & 0.37 & 0.08 & 0.0064 \\
\hline 25 & Tile 88 & 574537.8 & 4150769 & 0.37 & 0.35 & -0.02 & 0.0004 \\
\hline 26 & Tile 88 & 574534.7 & 4150769 & 0.5 & 0.38 & -0.12 & 0.0144 \\
\hline & & & & & & \\
\hline
\end{tabular}

\begin{tabular}{|l|l|}
\hline \multicolumn{2}{|l|}{ Statistics (Metres) } \\
\hline Average Dz & 0.1508 \\
\hline Average $(\mathrm{Dz})^{2}$ & 0.0351 \\
\hline Sum of $(\mathrm{Dz})^{2}$ & 0.8430 \\
\hline Standard Deviation & 0.1136 \\
\hline RMSE & 0.1874 \\
\hline NSSDA & 0.3673 \\
\hline
\end{tabular}


Section 2 of 5

\begin{tabular}{|r|c|r|r|r|r|r|c|}
\hline \multicolumn{1}{|c|}{ Point Number } & Location Description & Easting & Northing & Known Z & Laser Z & Dz & $(\mathrm{Dz})^{2}$ \\
\hline 27 & Tiles 112 \& 123 & 580893.8 & 4145208 & 1.24 & 1.15 & -0.09 & 0.0081 \\
\hline 36 & Tiles 112 \& 123 & 580995.6 & 4145178 & 3.25 & 3.2 & -0.05 & 0.0025 \\
\hline 37 & Tiles 112 \& 123 & 580996.3 & 4145180 & 3.4 & 3.39 & -0.01 & 0.0001 \\
\hline 38 & Tiles 112 \& 123 & 580997.2 & 4145183 & 3.27 & 3.13 & -0.14 & 0.0196 \\
\hline 40 & Tiles 112 \& 123 & 581043.3 & 4145159 & 3.15 & 3.2 & 0.05 & 0.0025 \\
\hline 41 & Tiles 112 \& 123 & 581044.3 & 4145162 & 3.38 & 3.29 & -0.09 & 0.0081 \\
\hline 42 & Tiles 112 \& 123 & 581045.7 & 4145165 & 3.1 & 3.09 & -0.01 & 0.0001 \\
\hline 43 & Tiles 112 \& 123 & 580909 & 4145212 & 3.31 & 3.18 & -0.13 & 0.0169 \\
\hline 44 & Tiles 112 \& 123 & 580911.4 & 4145219 & 2.54 & 2.81 & 0.27 & 0.0729 \\
\hline 46 & Tiles 112 \& 123 & 580914.2 & 4145240 & 2.26 & 2.54 & 0.28 & 0.0784 \\
\hline 47 & Tiles 112 \& 123 & 580903.7 & 4145247 & 2.28 & 2.3 & 0.02 & 0.0004 \\
\hline 48 & Tiles 112 \& 123 & 580891.8 & 4145254 & 2.02 & 2.18 & 0.16 & 0.0256 \\
\hline 57 & Tiles 112 \& 123 & 580884.5 & 4145260 & 1.7 & 1.7 & 0.00 & 0.0000 \\
\hline 58 & Tiles 112 \& 123 & 580906 & 4145247 & 2.18 & 2.37 & 0.19 & 0.0361 \\
\hline
\end{tabular}

\begin{tabular}{|l|l|}
\hline \multicolumn{2}{|l|}{ Statistics (Metres) } \\
\hline Average Dz & 0.0321 \\
\hline Average $(\mathrm{Dz})^{2}$ & 0.0181 \\
\hline Sum of $(\mathrm{Dz})^{2}$ & 0.2713 \\
\hline Standard Deviation & 0.1406 \\
\hline RMSE & 0.1345 \\
\hline NSSDA & 0.2636 \\
\hline
\end{tabular}

\section{Section 3 of 5}

\begin{tabular}{|r|c|r|r|r|r|r|c|}
\hline \multicolumn{1}{|c|}{ Point Number } & Location Description & Easting & Northing & Known Z & Laser Z & Dz & $(\mathrm{Dz})^{2}$ \\
\hline 62 & Tile 129 & 592010.2 & 4144301 & 3.45 & 3.71 & 0.26 & 0.0676 \\
\hline 63 & Tile 129 & 592010.2 & 4144301 & 3.45 & 3.71 & 0.26 & 0.0676 \\
\hline 67 & Tile 129 & 591987.8 & 4144325 & 3.55 & 3.57 & 0.02 & 0.0004 \\
\hline 68 & Tile 129 & 591990 & 4144327 & 3.76 & 3.81 & 0.05 & 0.0025 \\
\hline 69 & Tile 129 & 591992.8 & 4144329 & 3.59 & 3.63 & 0.04 & 0.0016 \\
\hline 72 & Tile 129 & 591966 & 4144362 & 3.91 & 3.92 & 0.01 & 0.0001 \\
\hline 73 & Tile 129 & 591966.1 & 4144362 & 3.94 & 3.93 & -0.01 & 0.0001 \\
\hline 74 & Tile 129 & 591968.5 & 4144364 & 3.85 & 3.97 & 0.12 & 0.0144 \\
\hline 76 & Tile 129 & 591947.4 & 4144387 & 3.67 & 3.77 & 0.10 & 0.0100 \\
\hline 77 & Tile 129 & 591949.2 & 4144388 & 3.84 & 3.89 & 0.05 & 0.0025 \\
\hline 79 & Tile 129 & 591871.8 & 4144255 & 1.77 & 1.84 & 0.07 & 0.0049 \\
\hline 80 & Tile 129 & 591872.1 & 4144251 & 2.94 & 2.95 & 0.01 & 0.0001 \\
\hline 81 & Tile 129 & 591872 & 4144249 & 3.15 & 3.08 & -0.07 & 0.0049 \\
\hline 83 & Tile 129 & 591863.2 & 4144207 & 0.5 & 0.65 & 0.15 & 0.0225 \\
\hline 84 & Tile 129 & 591859.1 & 4144188 & 0.41 & 0.57 & 0.16 & 0.0256 \\
\hline 86 & Tile 129 & 591851.6 & 4144095 & 0.29 & 0.43 & 0.14 & 0.0196 \\
\hline 88 & Tile 129 & 591858.3 & 4144058 & 0.41 & 0.74 & 0.33 & 0.1089 \\
\hline
\end{tabular}

South Bay Restoration Final Report Date: February 2, 2005

Revision 1.2 


\begin{tabular}{|r|r|r|r|r|r|r|r|}
\hline 91 & Tile 129 & 591859.7 & 4144203 & 0.34 & 0.43 & 0.09 & 0.0081 \\
\hline 92 & Tile 129 & 591861 & 4144203 & 0.87 & 0.48 & -0.39 & 0.1521 \\
\hline 93 & Tile 129 & 591862.5 & 4144213 & 0.52 & 0.51 & -0.01 & 0.0001 \\
\hline
\end{tabular}

\begin{tabular}{|l|l|}
\hline \multicolumn{2}{|l|}{ Statistics (Metres) } \\
\hline Average Dz & 0.0690 \\
\hline Average $(\mathrm{Dz})^{2}$ & 0.0245 \\
\hline Sum of $(\mathrm{Dz})^{2}$ & 0.5136 \\
\hline Standard Deviation & 0.1484 \\
\hline RMSE & 0.1564 \\
\hline NSSDA & 0.3065 \\
\hline
\end{tabular}

\section{Section 4 of 5}

\begin{tabular}{|c|c|c|c|c|c|c|c|}
\hline Point Number & Location Description & Easting & Northing & Known Z & Laser Z & $\mathrm{Dz}$ & $(\mathrm{Dz})^{2}$ \\
\hline 94 & Tile 26 (South) & 575773.9 & 4162371 & 1.57 & 1.49 & -0.08 & 0.0064 \\
\hline 95 & Tile 26 (South) & 575764.9 & 4162371 & 2.19 & 2.12 & -0.07 & 0.0049 \\
\hline 96 & Tile 26 (South) & 575760.9 & 4162371 & 3.33 & 3.21 & -0.12 & 0.0144 \\
\hline 97 & Tile 26 (South) & 575758.3 & 4162371 & 3.54 & 3.44 & -0.10 & 0.0100 \\
\hline 98 & Tile 26 (South) & 575754.3 & 4162372 & 3.41 & 3.3 & -0.11 & 0.0121 \\
\hline 99 & Tile 26 (South) & 575750.1 & 4162373 & 2.51 & 2.36 & -0.15 & 0.0225 \\
\hline 100 & Tile 26 (South) & 575734.3 & 4162374 & 2.03 & 2.02 & -0.01 & 0.0001 \\
\hline 101 & Tile 26 (South) & 575718.3 & 4162375 & 2.04 & 2.11 & 0.07 & 0.0049 \\
\hline 102 & Tile 26 (South) & 575699.3 & 4162375 & 2.1 & 2.13 & 0.03 & 0.0009 \\
\hline 103 & Tile 26 (South) & 575680.5 & 4162372 & 1.73 & 2.26 & 0.53 & 0.2809 \\
\hline 104 & Tile 26 (South) & 575681.3 & 4162360 & 2.12 & 2.24 & 0.12 & 0.0144 \\
\hline 105 & Tile 26 (South) & 575694.8 & 4162358 & 2.09 & 1.96 & -0.13 & 0.0169 \\
\hline 106 & Tile 26 (South) & 575716.7 & 4162358 & 2.06 & 2.03 & -0.03 & 0.0009 \\
\hline 107 & Tile 26 (South) & 575735.7 & 4162357 & 2.06 & 2.02 & -0.04 & 0.0016 \\
\hline 108 & Tile 26 (South) & 575749.8 & 4162357 & 2.29 & 2.31 & 0.02 & 0.0004 \\
\hline 109 & Tile 26 (South) & 575754.4 & 4162358 & 3.09 & 3.04 & -0.05 & 0.0025 \\
\hline 110 & Tile 26 (South) & 575757.9 & 4162357 & 3.41 & 3.3 & -0.11 & 0.0121 \\
\hline 111 & Tile 26 (South) & 575761.7 & 4162357 & 3.18 & 3.1 & -0.08 & 0.0064 \\
\hline 112 & Tile 26 (South) & 575764.3 & 4162357 & 2.31 & 2.39 & 0.08 & 0.0064 \\
\hline 113 & Tile 26 (South) & 575773.3 & 4162356 & 1.53 & 1.52 & -0.01 & 0.0001 \\
\hline 115 & Tile 26 (South) & 575766.8 & 4162329 & 2.11 & 2.12 & 0.01 & 0.0001 \\
\hline 116 & Tile 26 (South) & 575763.1 & 4162328 & 3.39 & 3.27 & -0.12 & 0.0144 \\
\hline 117 & Tile 26 (South) & 575759.7 & 4162328 & 3.47 & 3.24 & -0.23 & 0.0529 \\
\hline 118 & Tile 26 (South) & 575756.1 & 4162328 & 3.33 & 3.18 & -0.15 & 0.0225 \\
\hline 119 & Tile 26 (South) & 575752.5 & 4162328 & 2.25 & 2.19 & -0.06 & 0.0036 \\
\hline 120 & Tile 26 (South) & 575733.5 & 4162328 & 2.01 & 2.07 & 0.06 & 0.0036 \\
\hline 121 & Tile 26 (South) & 575713 & 4162329 & 2.01 & 2.1 & 0.09 & 0.0081 \\
\hline 122 & Tile 26 (South) & 575685.7 & 4162330 & 2.07 & 1.99 & -0.08 & 0.0064 \\
\hline 123 & Tile 26 (South) & 575665.9 & 4162331 & 2.11 & 2.09 & -0.02 & 0.0004 \\
\hline 124 & Tile 26 (South) & 575657.2 & 4162304 & 2.08 & 2.14 & 0.06 & 0.0036 \\
\hline 125 & Tile 26 (South) & 575679.6 & 4162299 & 2.06 & 2.12 & 0.06 & 0.0036 \\
\hline 126 & Tile 26 (South) & 575707.3 & 4162297 & 2.08 & 2.08 & 0.00 & 0.0000 \\
\hline
\end{tabular}

South Bay Restoration Final Report Date: February 2, 2005 


\begin{tabular}{|c|c|c|c|c|c|c|c|}
\hline 127 & Tile 26 (South) & |575733.3 & 4162295 & 2.04 & 2.03 & -0.01 & 0.0001 \\
\hline 128 & Tile 26 (South) & 575753.9 & 4162295 & 2.16 & 2.13 & -0.03 & 0.0009 \\
\hline 129 & Tile 26 (South) & 575758.9 & 4162295 & 3.3 & 3.24 & -0.06 & 0.0036 \\
\hline 130 & Tile 26 (South) & 575761.4 & 4162295 & 3.41 & 3.29 & -0.12 & 0.0144 \\
\hline 131 & Tile 26 (South) & 575774.8 & 4162296 & 1.55 & 1.45 & -0.10 & 0.0100 \\
\hline 132 & Tile 26 (South) & 575775.6 & 4162274 & 1.5 & 1.36 & -0.14 & 0.0196 \\
\hline 133 & Tile 26 (South) & 575768.9 & 4162274 & 2.14 & 2.04 & -0.10 & 0.0100 \\
\hline 137 & Tile 26 (South) & 575754.9 & 4162274 & 2.15 & 2.3 & 0.15 & 0.0225 \\
\hline 138 & Tile 26 (South) & 575739.3 & 4162281 & 2.09 & 2.11 & 0.02 & 0.0004 \\
\hline 139 & Tile 26 (South) & 575709.9 & 4162293 & 2.07 & 2.13 & 0.06 & 0.0036 \\
\hline 140 & Tile 26 (South) & 575681.6 & 4162306 & 2.07 & 2.17 & 0.10 & 0.0100 \\
\hline 141 & Tile 26 (South) & 575657 & 4162315 & 2.09 & 2.14 & 0.05 & 0.0025 \\
\hline 142 & Tile 26 (South) & 575683 & 4162329 & 2.05 & 2.11 & 0.06 & 0.0036 \\
\hline 143 & Tile 26 (South) & 575710.8 & 4162344 & 2.07 & 2.02 & -0.05 & 0.0025 \\
\hline
\end{tabular}

\begin{tabular}{|l|l|}
\hline \multicolumn{2}{|l|}{ Statistics (Metres) } \\
\hline Average Dz & -0.0183 \\
\hline Average $(\mathrm{Dz})^{2}$ & 0.0087 \\
\hline Sum of $(\mathrm{Dz})^{2}$ & 0.2084 \\
\hline Standard Deviation & 0.0933 \\
\hline RMSE & 0.0932 \\
\hline NSSDA & 0.1826 \\
\hline
\end{tabular}

\section{Section 5 of 5}

\begin{tabular}{|r|r|r|r|r|r|r|c|}
\hline Point Number & Location Description & Easting & Northing & Known Z & Laser Z & \multicolumn{1}{c|}{$\mathrm{Dz}$} & $(\mathrm{Dz})^{2}$ \\
\hline 144 & Tile 26 (North) & 576507.6 & 4162903 & 1.83 & 1.72 & -0.11 & 0.0121 \\
\hline 145 & Tile 26 (North) & 576500.2 & 4162906 & 2.4 & 2.42 & 0.02 & 0.0004 \\
\hline 147 & Tile 26 (North) & 576489.8 & 4162910 & 3.52 & 3.54 & 0.02 & 0.0004 \\
\hline 148 & Tile 26 (North) & 576483.8 & 4162912 & 1.99 & 2 & 0.01 & 0.0001 \\
\hline 150 & Tile 26 (North) & 576489.4 & 4162930 & 1.95 & 2.01 & 0.06 & 0.0036 \\
\hline 151 & Tile 26 (North) & 576494.5 & 4162929 & 3.37 & 3.2 & -0.17 & 0.0289 \\
\hline 153 & Tile 26 (North) & 576500.6 & 4162926 & 3.32 & 3.25 & -0.07 & 0.0049 \\
\hline 154 & Tile 26 (North) & 576507 & 4162924 & 2.39 & 2.33 & -0.06 & 0.0036 \\
\hline 155 & Tile 26 (North) & 576514.5 & 4162924 & 1.96 & 1.71 & -0.25 & 0.0625 \\
\hline 157 & Tile 26 (North) & 576512.4 & 4162945 & 2.48 & 2.5 & 0.02 & 0.0004 \\
\hline 158 & Tile 26 (North) & 576505.8 & 4162948 & 3.41 & 3.36 & -0.05 & 0.0025 \\
\hline 160 & Tile 26 (North) & 576501 & 4162949 & 3.15 & 3.16 & 0.01 & 0.0001 \\
\hline 161 & Tile 26 (North) & 576496.8 & 4162952 & 2.03 & 2.17 & 0.14 & 0.0196 \\
\hline 162 & Tile 26 (North) & 576513.5 & 4162976 & 3.35 & 3.32 & -0.03 & 0.0009 \\
\hline 164 & Tile 26 (North) & 576468.6 & 4162905 & 1.97 & 2 & 0.03 & 0.0009 \\
\hline 165 & Tile 26 (North) & 576436.1 & 4162928 & 1.89 & 1.96 & 0.07 & 0.0049 \\
\hline 166 & Tile 26 (North) & 576441.7 & 4162942 & 1.89 & 2.01 & 0.12 & 0.0144 \\
\hline 168 & Tile 26 (North) & 576487.4 & 4162938 & 1.98 & 2.04 & 0.06 & 0.0036 \\
\hline 169 & Tile 26 (North) & 576475.5 & 4162945 & 1.9 & 1.95 & 0.05 & 0.0025 \\
\hline 170 & Tile 26 (North) & 576463.8 & 4162952 & 1.85 & 1.87 & 0.02 & 0.0004 \\
\hline 171 & Tile 26 (North) & 576448.4 & 4162959 & 1.83 & 1.96 & 0.13 & 0.0169 \\
\hline & & & & & & \\
\hline & & & &
\end{tabular}

South Bay Restoration Final Report Date: February 2, 2005

Revision 1.2 


\begin{tabular}{|c|c|c|c|c|c|c|c|}
\hline 172 & Tile 26 (North) & 576454.3 & 4162977 & 1.91 & 2 & 0.09 & 0.0081 \\
\hline 173 & Tile 26 (North) & 576464.8 & 4162970 & 1.85 & 1.75 & -0.10 & 0.0100 \\
\hline 174 & Tile 26 (North) & 576478.1 & 4162964 & 1.93 & 1.99 & 0.06 & 0.0036 \\
\hline 175 & Tile 26 (North) & 576494.3 & 4162958 & 1.99 & 2 & 0.01 & 0.0001 \\
\hline 176 & Tile 26 (North) & 576495.6 & 4162978 & 2 & 2.05 & 0.05 & 0.0025 \\
\hline 177 & Tile 26 (North) & 576480.6 & 4162986 & 1.93 & 1.94 & 0.01 & 0.0001 \\
\hline 178 & Tile 26 (North) & 576467.7 & 4162991 & 1.85 & 1.79 & -0.06 & 0.0036 \\
\hline 179 & Tile 26 (North) & 576457.8 & 4162994 & 1.87 & 1.97 & 0.10 & 0.0100 \\
\hline 180 & Tile 26 (North) & 576430.5 & 4162923 & 1.88 & 1.98 & 0.10 & 0.0100 \\
\hline 181 & Tile 26 (North) & 576419.1 & 4162931 & 3.32 & 3.23 & -0.09 & 0.0081 \\
\hline 182 & Tile 26 (North) & 576415.4 & 4162932 & 3.14 & 2.99 & -0.15 & 0.0225 \\
\hline 183 & Tile 26 (North) & 576424.3 & 4162950 & 3.23 & 3.34 & 0.11 & 0.0121 \\
\hline 184 & Tile 26 (North) & 576427.2 & 4162948 & 3.38 & 3.3 & -0.08 & 0.0064 \\
\hline 185 & Tile 26 (North) & 576431.1 & 4162946 & 3 & 2.96 & -0.04 & 0.0016 \\
\hline 186 & Tile 26 (North) & 576436 & 4162944 & 2.03 & 2.14 & 0.11 & 0.0121 \\
\hline 188 & Tile 26 (North) & 576435.3 & 4162931 & 1.85 & 1.87 & 0.02 & 0.0004 \\
\hline 189 & Tile 26 (North) & 576430.6 & 4162934 & 2.12 & 2.18 & 0.06 & 0.0036 \\
\hline 190 & Tile 26 (North) & 576426.9 & 4162936 & 3.04 & 2.92 & -0.12 & 0.0144 \\
\hline 191 & Tile 26 (North) & 576422.7 & 4162939 & 3.33 & 3.3 & -0.03 & 0.0009 \\
\hline 192 & Tile 26 (North) & 576418.5 & 4162940 & 3.14 & 3.04 & -0.10 & 0.0100 \\
\hline
\end{tabular}

\begin{tabular}{|l|l|}
\hline \multicolumn{2}{|l|}{ Statistics (Metres) } \\
\hline Average Dz & 0.0087 \\
\hline Average $(\mathrm{Dz})^{2}$ & 0.0068 \\
\hline Sum of $(\mathrm{Dz})^{2}$ & 0.1635 \\
\hline Standard Deviation & 0.0838 \\
\hline RMSE & 0.0825 \\
\hline NSSDA & 0.1618 \\
\hline
\end{tabular}


Map A: Control and GPS Check Points

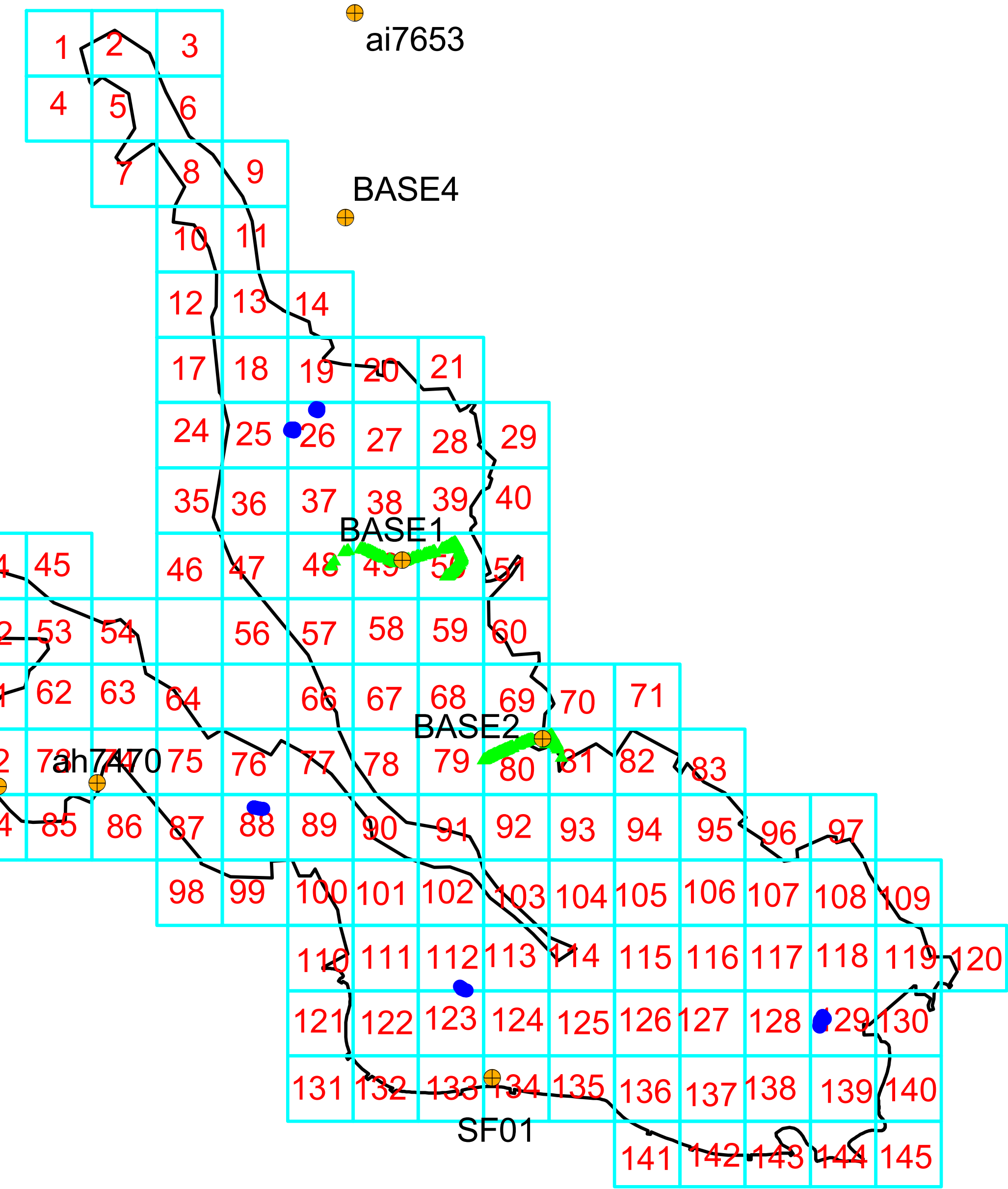


Map B: 2Km Project Tiles

with Boundary Overlayed

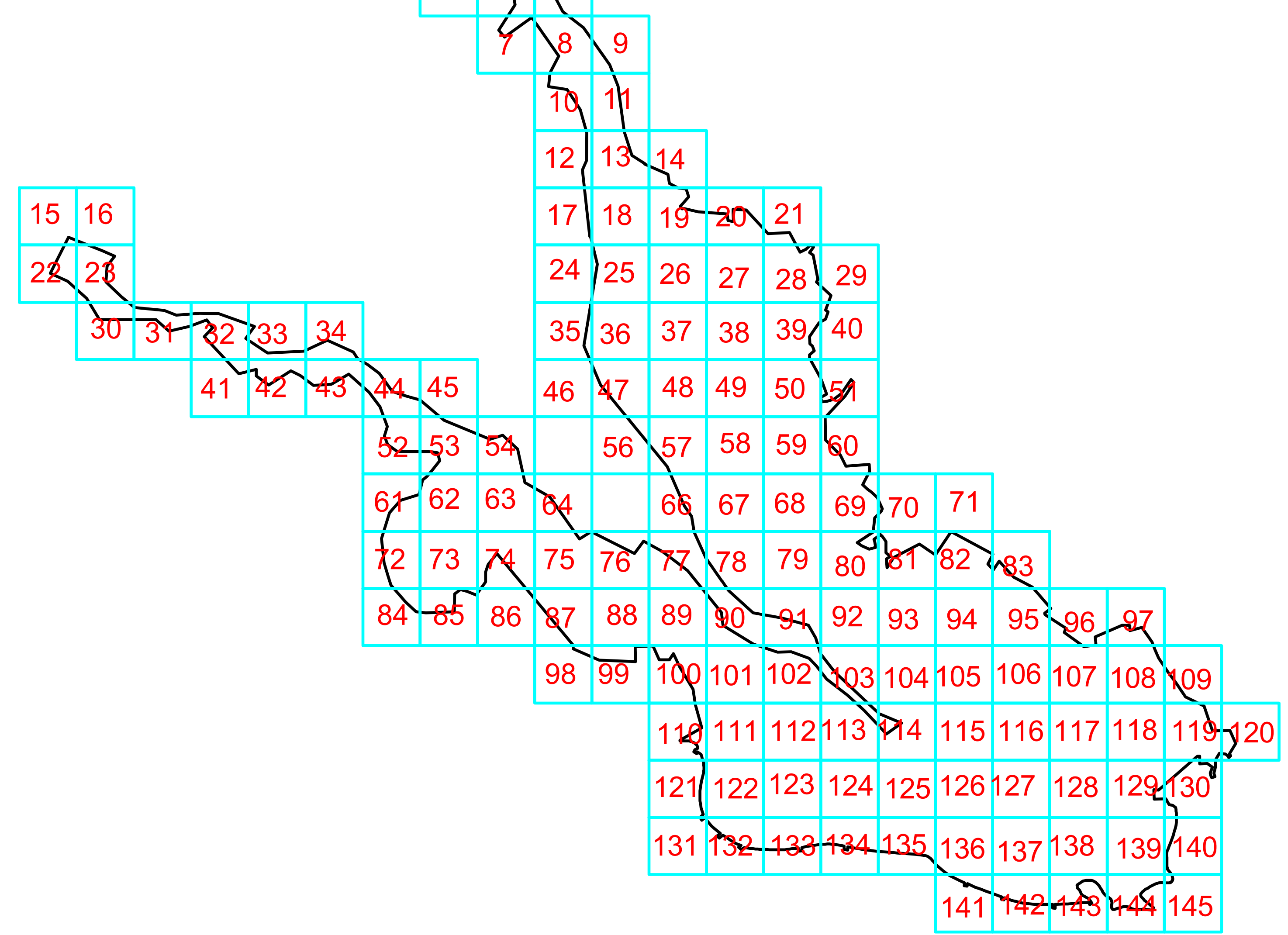


Map C: $1 \mathrm{Km}$ Project Tiles

with Boundary Overlayed

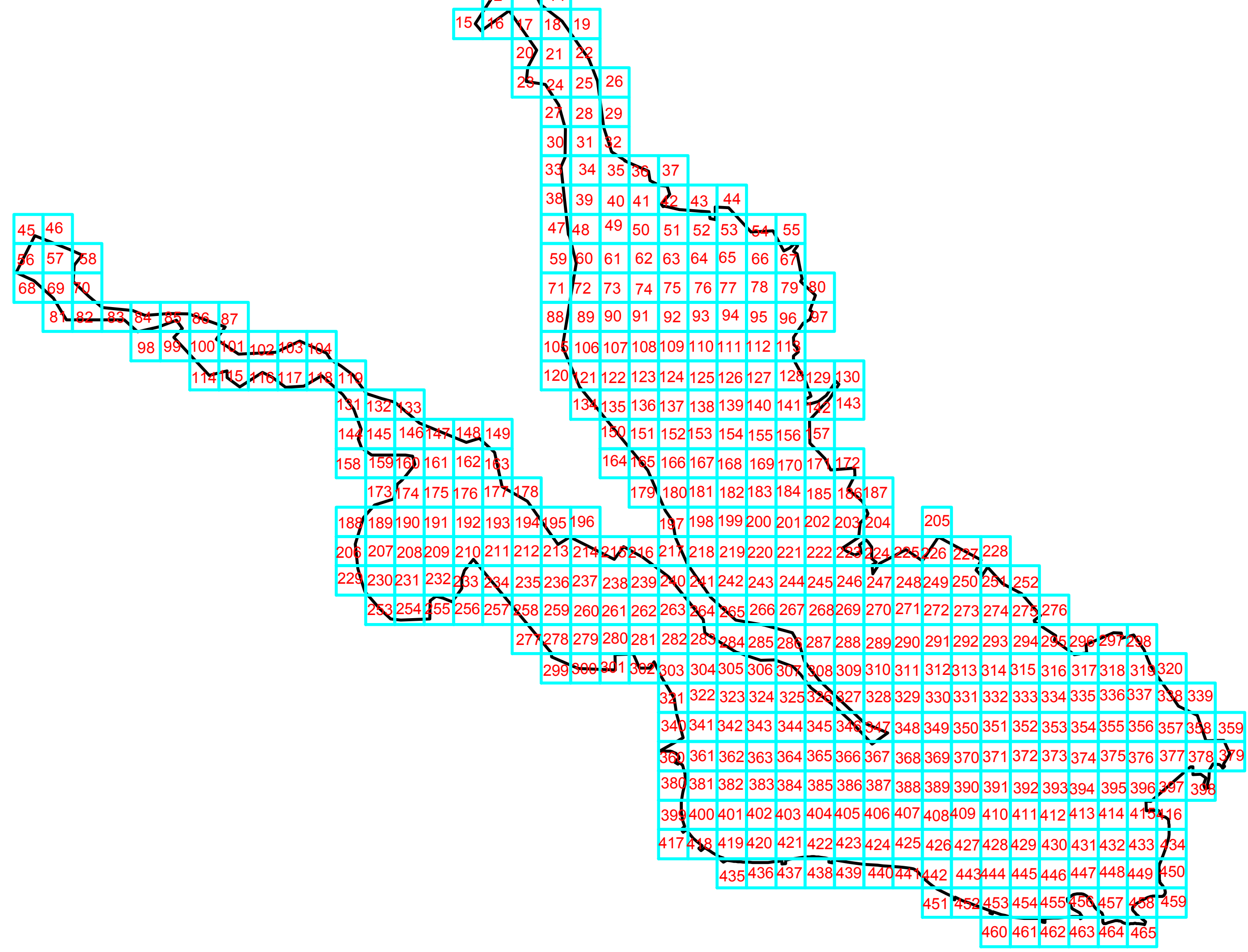

